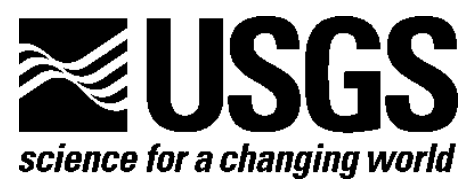

\title{
Laharz_py: GIS Tools for Automated Mapping of Lahar Inundation Hazard Zones
}

By Steve P. Schilling

Open-File Report 2014-1073

U.S. Department of the Interior U.S. Geological Survey 


\section{U.S. Department of the Interior \\ SALLY JEWELL, Secretary}

\section{U.S. Geological Survey \\ Suzette M. Kimball, Acting Director}

U.S. Geological Survey, Reston, Virginia: 2014

For more information on the USGS-the Federal source for science about the Earth, its natural and living resources, natural hazards, and the environment-visit

http://www.usgs.gov or call 1-888-ASK-USGS

For an overview of USGS information products, including maps, imagery, and publications, visit $h$ ttp://www.usgs.gov/pubprod

To order this and other USGS information products, visit http://store.usgs.gov

Suggested citation:

Schilling, S.P., 2014, Laharz_py-GIS tools for automated mapping of lahar inundation hazard zones: U.S. Geological Survey Open-File Report 2014-1073, 78 p., http://dx.doi.org/10.3133/ofr20141073.

ISSN 2331-1258 (online)

Any use of trade, firm, or product names is for descriptive purposes only and does not imply endorsement by the U.S. Government.

Although this information product, for the most part, is in the public domain, it also may contain copyrighted materials as noted in the text. Permission to reproduce copyrighted items must be secured from the copyright owner. 


\section{Contents}

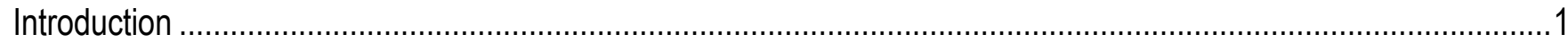

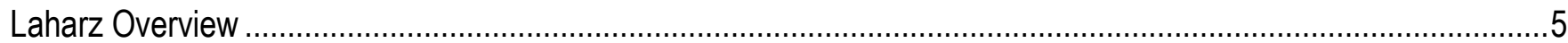

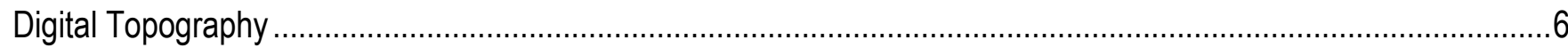

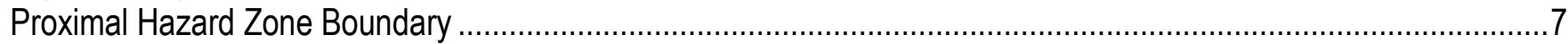

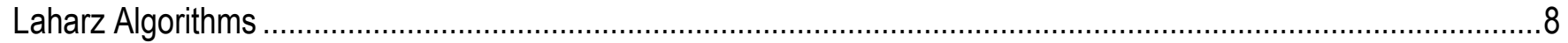

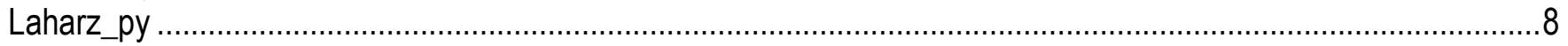

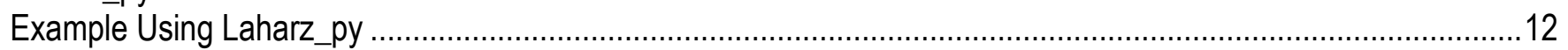

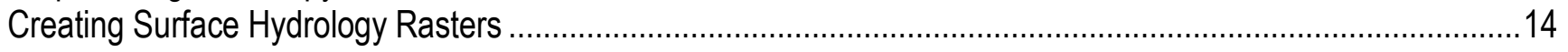

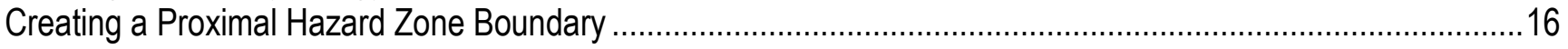

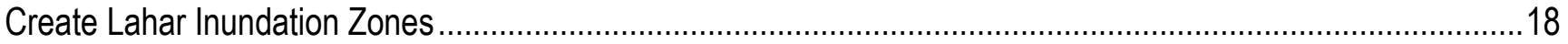

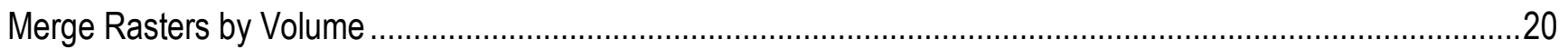

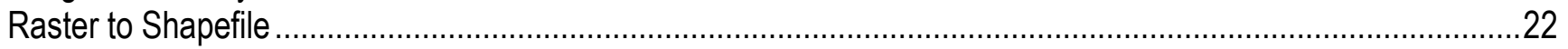

Creating Lahar Inundation Zones with Confidence Levels...........................................................................23

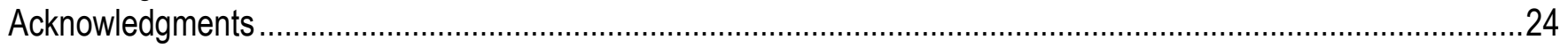

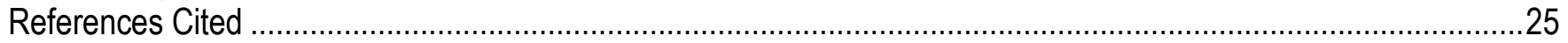

Appendix A. Strategy for Computing and Portraying Confidence Limits in Inundation Predictions

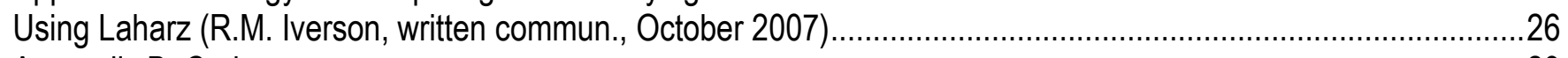

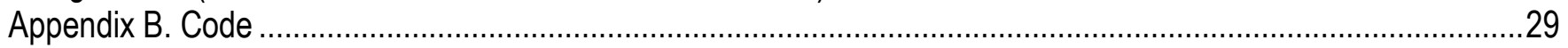

\section{Figures}

Figure 1. Photograph showing deposits left by a lahar at Mount St. Helens, Washington, 1982 ..............................2

Figure 2. Volcano hazard map of Mount Rainier, Washington (Scott and others, 1995) .....................................3

Figure 3. Photograph showing difference between maximum lahar discharge and lahar deposit ...........................3

Figure 4. Scatter plots showing (a) inundated valley cross-sectional area, $A$, as a function of lahar volume $V$.........4

Figure 5. Diagram showing association between dimensions of an idealized lahar and cross-sectional $(A)$ and

planimetric (B) areas calculated by Laharz_py for a hypothetical volcano ......................................................5

Figure 6. Diagram of part of a digital elevation model (DEM) and corresponding supplementary surface hydrology grids

Figure 7. Scatter plots showing (a) for a selected V (here 10 million cubic meters), the regression predicts the mean (red line) expected at cross-sectional area, A, and planimetric area, B; and (b) the 95-percent confidence intervals for prediction show the probable dispersion (blue lines) of future $A$ and $B$ values

Figure 8. Light Detection and Ranging (LiDAR) images showing (in upper two images) the probable range of planimetric area $(B)$ values with changing confidence limits (red is the mean value from the regression line, dark blue the upper confidence limit, light blue the lower confidence limit) from a single simulation of V (10 million cubic meters)...

Figure 9. Screen captures showing a listing of files included with Lahar_py_example (upper left); right-click menu to add Laharz_py toolbox (upper right); navigation to the Laharz_py toolbox (lower left); and seven tools in the

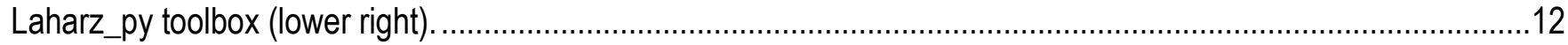

Figure 10. Screen capture showing raster datasets, mtrainfill and mtrainfillsh, added to project. .........................13

Figure 11. Screen capture showing window for creating supplementary surface hydrology rasters.......................14

Figure 12. Screen capture showing progress and completion-time window when the Create Surface Hydrology

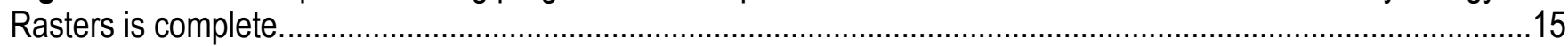

Figure 13. Screen capture showing window to generate an new stream network ...........................................15

Figure 14. Screen capture showing window to create a proximal hazard zone boundary ..................................16 
Figure 15. Screen capture showing proximal hazard zone boundary as the rasterized line, one cell in width, that marks the intersection of an $\mathrm{H} / \mathrm{L}$ or energy cone with topography (yellow)

Figure 16. Screen capture showing interface to start Lahar Distal Zones

Figure 17. Screen capture showing a partial textfile listing for one of the .pts files created from the simulations.....19

Figure 18. Screen capture showing three completed simulations .....................................................................20

Figure 19. Screen capture showing menu for the Merge Rasters by Volume tool ...............................................21

Figure 20. Screen capture showing merged raster datasets .......................................................................21

Figure 21. Screen capture showing window to convert a raster dataset to a vector shapefile using the Raster to

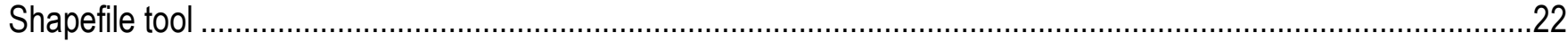

Figure 22. Screen capture showing mtr $30 \mathrm{mcm}$ shapefile ...........................................................................22

Figure 23. Screen capture showing interface to begin Laharz_py calculations with

user-selected level of confidence

Figure 24. Screen capture showing carbon_1 raster results

\section{Conversion Factors}

SI to Inch/Pound

\begin{tabular}{lcl}
\hline \multicolumn{1}{c}{ Multiply } & By & \multicolumn{1}{c}{ To obtain } \\
\hline meter $(\mathrm{m})$ & Length & \\
meter $(\mathrm{m})$ & 3.281 & foot $(\mathrm{ft})$ \\
kilometer $(\mathrm{km})$ & 1.094 & yard $(\mathrm{yd})$ \\
kilometer $(\mathrm{km})$ & 0.6214 & mile $(\mathrm{mi})$ \\
kilometer per hour $(\mathrm{km} / \mathrm{h})$ & 0.5400 & mile, nautical $(\mathrm{nmi})$ \\
\hline & 0.6214 & mile per hour $(\mathrm{mi} / \mathrm{h})$ \\
\hline cubic meter $\left(\mathrm{m}^{3}\right)$ & Volume & \\
cubic meter $\left(\mathrm{m}^{3}\right)$ & 35.31 & cubic foot $\left(\mathrm{ft}^{3}\right)$ \\
cubic meter $\left(\mathrm{m}^{3}\right)$ & 264.2 & gallon (gal) \\
cubic meter $\left(\mathrm{m}^{3}\right)$ & 0.0002642 & million gallons $(\mathrm{Mgal})$ \\
cubic meter $\left(\mathrm{m}^{3}\right)$ & 1.308 & cubic yard $\left(\mathrm{yd}^{3}\right)$ \\
& 0.0008107 & acre-foot $\left(\mathrm{acre}^{3} \mathrm{ft}\right)$ \\
\hline
\end{tabular}




\title{
Laharz_py: GIS Tools for Automated Mapping of Lahar Inundation Hazard Zones
}

\author{
By Steve P. Schilling
}

\section{Introduction}

"Lahar" is an Indonesian term for large debris flows that originate on volcano flanks; contain primarily water, mud and rock debris; and have a density often compared to wet concrete. To form a lahar, there must be adequate water and abundant unconsolidated debris along with steep relief and some type of triggering mechanism (Vallance, 2000). Lahars surge down steep volcano flanks into and along river channels as gravity-driven flows that may reach speeds up to $65 \mathrm{~km} / \mathrm{h}$ (Newhall and others, 1997) and can reach tens or even hundreds of kilometers downstream. As lahars flow along the upper reaches of the stream path, they often erode and scour loose volcanic debris and vegetation and may incorporate snow, ice, or streamflow, increasing their size by several times. As lahars continue downstream to lower elevations they lose coarser components, become dilute, and decrease in size.

Lahars can flow during eruption where water is released from the interaction of hot rock on snow and ice (Nevado del Ruiz, Colombia, 1985), at the onset of volcanic activity as groundwater is rapidly expelled ahead of a rising magma intrusion (Nevado del Huila, Colombia, 2007), after an eruption where heavy rain can remobilize fresh fragemental deposits (after the large eruption of Mount Pinatubo, Philippines, 1991), or without any eruption where torrential rains cause ground failure that generate lahars (Casita Volcano, Nicaragua, 1998). Landslides may transition into lahars (Mount St. Helens, Washington, 1980) if sufficient water is present in the source material. Lahars can be hundreds of thousands to hundreds of millions of cubic meters in volume. However, deposits left by past lahars demonstrate that high consequence, low probability events can reach billions of cubic meters in volume, such as the Osceola Mudflow at Mount Rainier, Washington, that filled valleys to $200 \mathrm{~m}$ and flowed 120 km downstream (Scott and others, 1995; Vallance, 2000) or the Chillos Valley Lahar at Cotopaxi Volcano, Ecuador (Mothes and others, 1998), that filled valleys to $180 \mathrm{~m}$ and flowed more than $300 \mathrm{~km}$ downstream.

Lahars are natural processes that become hazards when they affect people and property. These flows are a hazard at many of the world's volcanoes (fig. 1), and have claimed thousands of lives at Armero, Colombia, from eruption of Nevado del Ruiz in 1985, and the towns of El Povenir and Rolando Rodriguez from flank collapse at Casita Volcano, Nicaragua, in 1998. As lahars move downstream, the largest particles within the flow tend to migrate to the front and margins where direct impact can abrade or destroy anything in their path. As a lahar comes to rest, buildings and land may be buried by layers of rock debris and mud. 


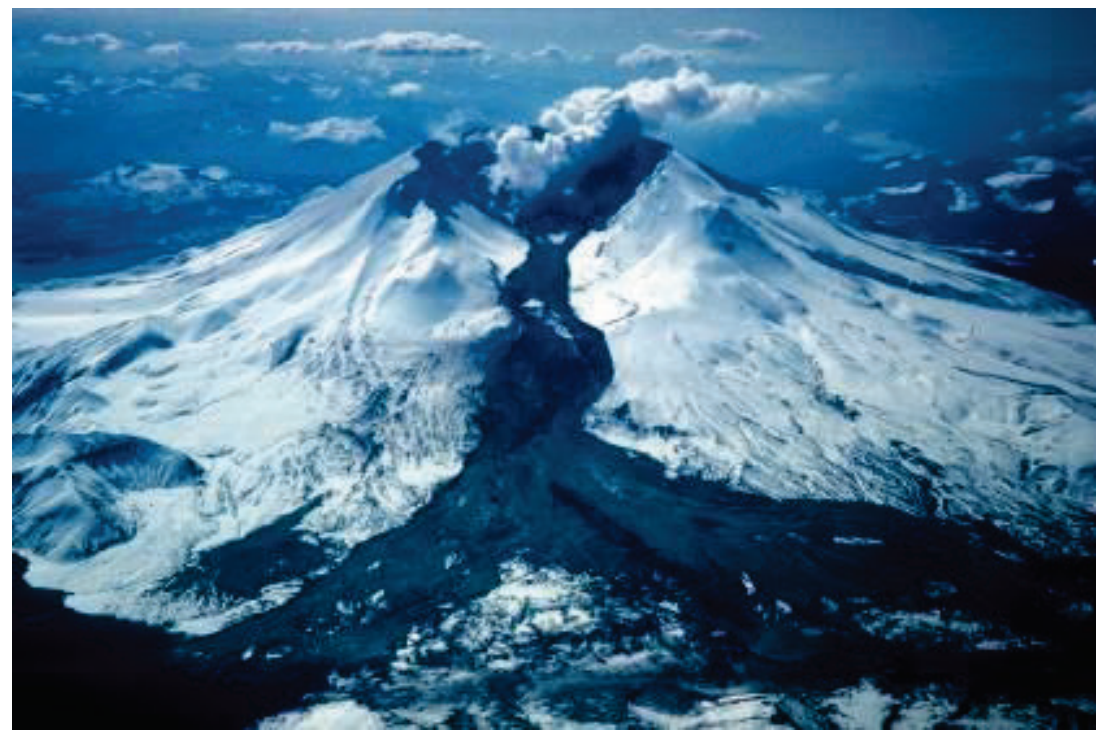

Figure 1. Photograph showing deposits left by a lahar at Mount St. Helens, Washington, 1982. The lahar (the dark deposit on the snow) flowed from the crater. Part of the lahar entered Spirit Lake (lower left corner), but most of it flowed west down the Toutle River, eventually reaching the Cowlitz River, 80 kilometers downstream.

(Photograph taken by Tom Casadevall, U.S. Geological Survey, March 21, 1982).

Volcano hazard-zonation maps (fig. 2) depict estimates of potentially hazardous areas from lahars and other volcano processes that may help mitigate impact on society and infrastructure if used for development planning or event response. For volcanoes, the hazard-zonation map often includes a proximal zone encompassing most or all of the volcano edifice. This proximal zone is susceptible to a variety of processes such as pyroclastic flows, debris flows, lava flows, and ballistic projectiles. Distal hazard zones extend away from the proximal zone surrounding the volcano edifice, most often along stream channels, typically indicating areas of potential inundation and runout by future lahars.

To aid the creation of hazard-zonation maps, Iverson and others (1998) developed an empirical and statistically based forecasting method to predict inundation and runout of lahars that is rapid, reproducible, and objective. Their central tenets of the method are the same as those used by geologists using knowledge of past lahar deposits to constrain hazard zones:

"(1) inundation by past lahars provides a basis for predicting inundation by future lahars; (2) distal lahar hazards are confined to valleys that head on volcano flanks; (3) lahar volume largely controls the extent of inundation downstream; (4) voluminous lahars occur less often than small lahars; and (5) no one can foretell the size of the next lahar to descend a given drainage" (Iverson and others, 1998).

Iverson and others (1998) assumed that far-reaching, distal lahars will originate at proximal sources and focused on sudden-onset lahars that typically evolve from rock and ice avalanches, pyroclastic flows, or lake-breakout floods that originate high on volcano flanks or at the summit. Although lahars evolve in size and composition as they move downstream, a key assumption of Iverson and others (1998) was that the maximum lahar discharge produces the maximum inundation of valley cross-sectional area, a quantity of primary interest for delineating hazard zones rather than the lahar deposit (fig. 3) that often has a much smaller cross-sectional area. 


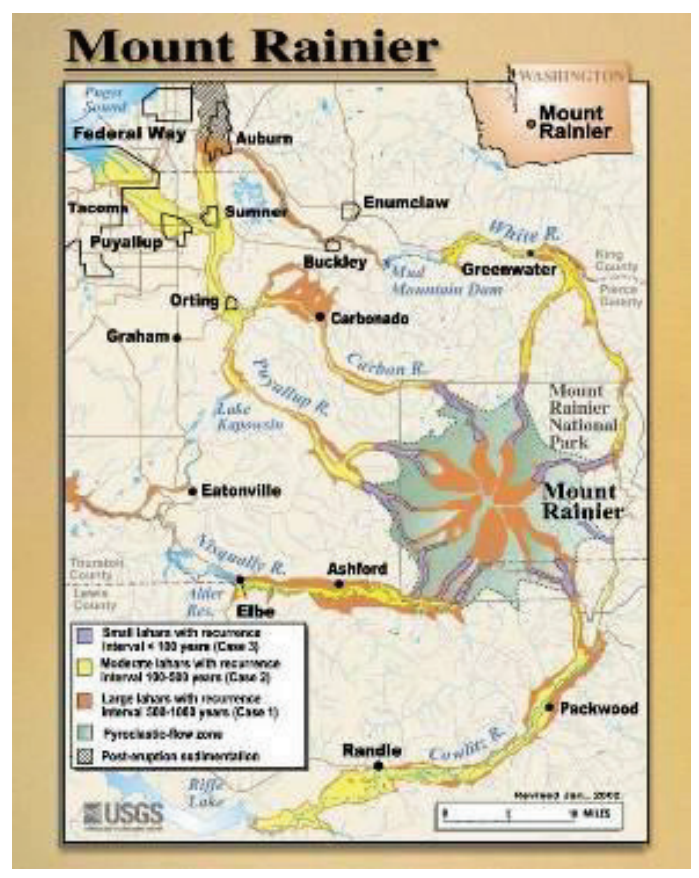

Figure 2. Volcano hazard map of Mount Rainier, Washington (Scott and others, 1995). Edifice is encircled by proximal hazard zone (green) with distal hazard zones along major drainages (yellow and red).

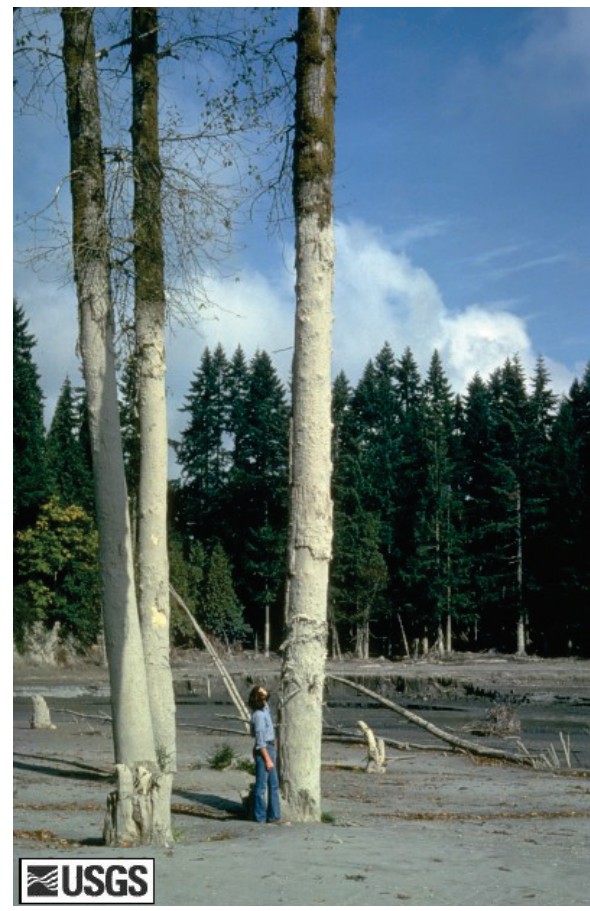

Figure 3. Photograph showing difference between maximum lahar discharge and lahar deposit. U.S. Geological Survey hydrologist (about 2 meters tall) stands on deposit and examines mudline left behind from the May 18, 1980 eruption of Mount St. Helens. (Photograph taken by Lyn Topinka, U.S. Geological Survey, 1980). 
Iverson and others (1998) used scaling analysis to predict the mathematical form of equations that relate lahar volume $(V)$ to a cross-sectional inundation area $(A)$ (fig. $4 \mathrm{a}$ ) and a planimetric inundation area $(B)$ (fig. 4b).

$$
\begin{gathered}
A=0.05 V^{2 / 3} \\
B=200 V^{2 / 3}
\end{gathered}
$$

where
A $\quad$ cross section area;
$B \quad$ planimetric area; and
V volume.

The equations were derived statistically by using data from mapping of 27 lahar paths at nine volcanoes (Iverson and others, 1998).
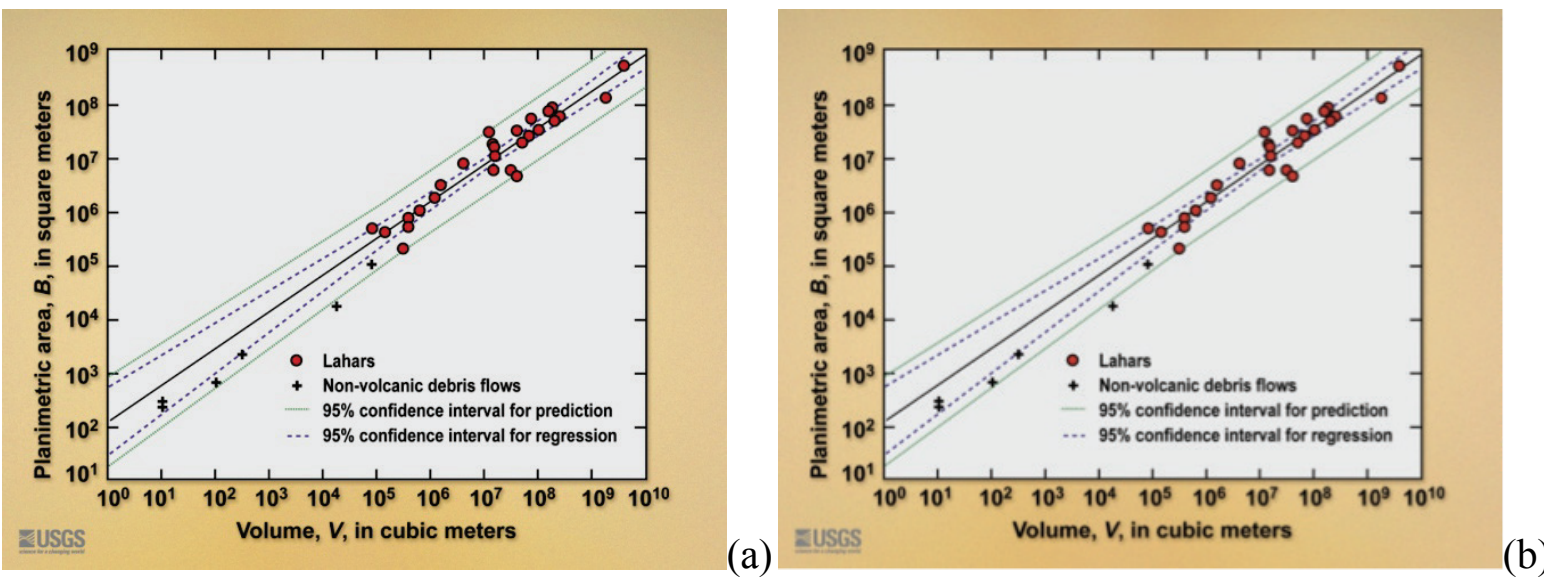

Figure 4. Scatter plots showing (a) inundated valley cross-sectional area, $A$, as a function of lahar volume $V$. The best-fit log-log regression line (solid) and 95-percent confidence intervals for regression (dashed lines) and prediction (green lines) also are shown. (b) inundated planimetric area $B$ as a function of lahar volume $V$. The bestfit log-log regression line (solid) and 95-percent confidence intervals for regression (dashed lines) and prediction (green lines) also are shown. 


\section{Laharz Overview}

Laharz (Schilling, 1998) is software designed to calculate a proximal hazard zone and automate equations (1) and (2) to run within a Geographic Information System (GIS) over three dimensional topography in order to estimate distal hazard zones. Laharz is written in the ArcInfo Macro Language (AML) that runs within the GRID portion of ArcInfo Workstation, and was designed to delimit areas of potential lahar inundation from one to four user-specified lahar volumes; producing one estimated laharinundation hazard zone for each volume over one or more stream drainages. Typically, the planimetric area of a lahar inundation hazard zone increases in width and length as lahar volume increases. Plotting hazard zones of smaller area over hazard zones having larger area (referred to as nesting of hazard zones) shows progressively larger areas of inundation from progressively larger volumes. These hazard zones can be displayed with other types of volcano hazard information in a GIS, such as a proximal hazard zone (fig. 5), infrastructure, hydrology, population, and contours or shaded relief map to produce volcano hazard-zonation maps. Such maps show proximity to and intersection of potential hazard zones with people and infrastructure.

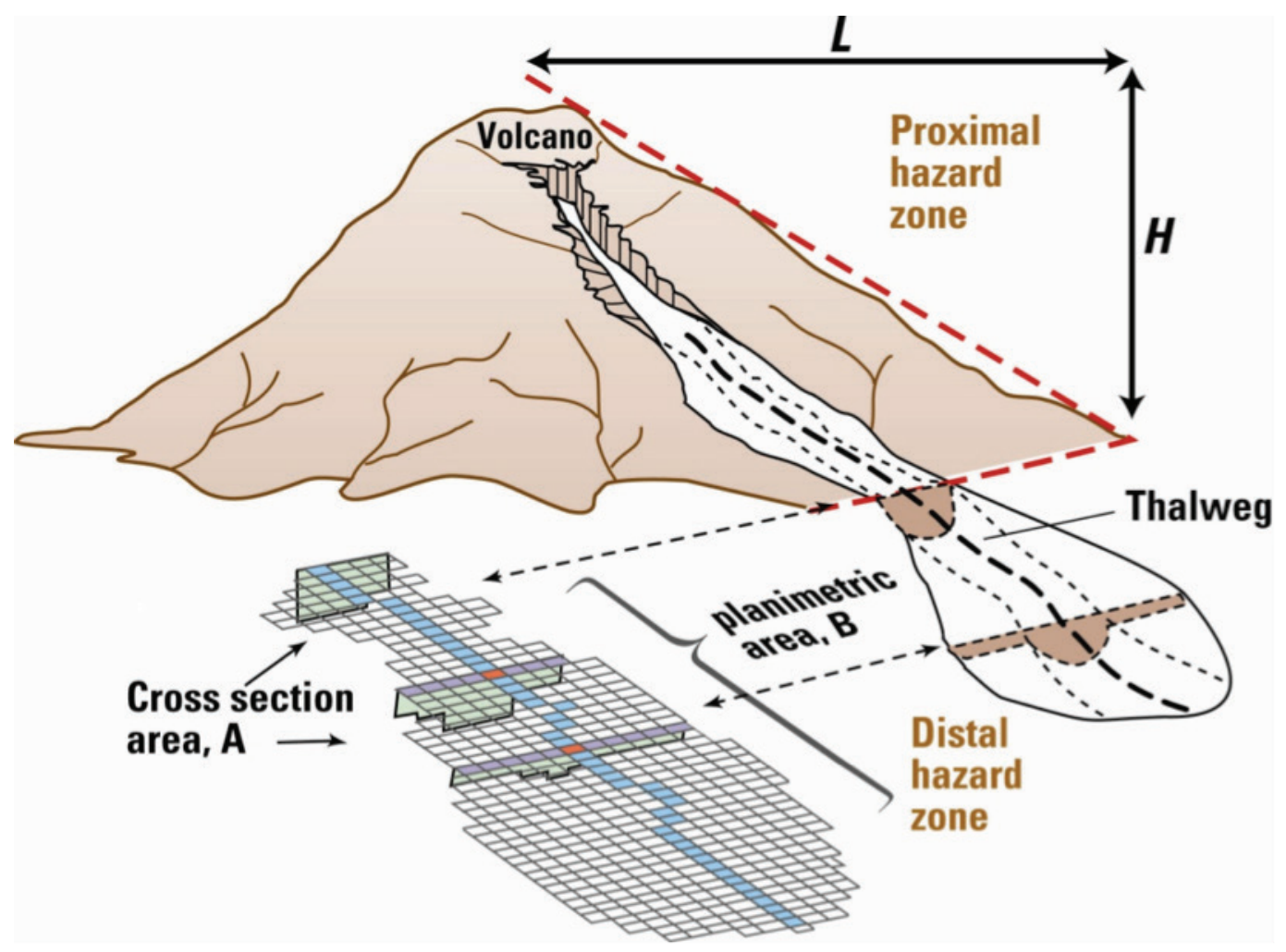

Figure 5. Diagram showing association between dimensions of an idealized lahar and cross-sectional $(A)$ and planimetric $(B)$ areas calculated by Laharz_py for a hypothetical volcano. The ratio of vertical drop $(H)$ to horizontal runout distance $(L)$ describes the extent of proximal volcano hazards. Laharz_py identifies cells where raster streams and the proximal-hazard zone boundary intersect as potential locations to begin calculations of distal laharinundation hazard zones. (Modifed from Iverson and others, 1998.) 


\section{Digital Topography}

The most important dataset required to run Laharz is an accurate digital elevation model (DEM), a regular array of cells where each cell stores an elevation value and when combined compose three dimensional topography for a portion of the Earth. DEMs are available from many sources and vary in accuracy, resolution (size of cell), projection, and extent. Regardless of source, Laharz requires a DEM that has X-, Y-, and Z-coordinate values in units of meters. In addition, the extent of the DEM used to create lahar-inundation hazard zones should include the volcano edifice as well as the downstream extent of major stream drainages. Finally, even though DEMs vary in resolution, it is important to have a cell size that is appropriate for calculations. DEMs having cells with kilometer resolution will not be useful if a drainage of interest is $500 \mathrm{~m}$ wide. Generally, resolutions ranging between 1 and $30 \mathrm{~m}$ yield reasonable results for volcano topography. There is a tradeoff when considering resolution of a DEM; calculations for potential inundation along a river channel using larger sized cells accomplish the task quicker than when using smaller sized cells, whereas DEMs having smaller cells usually represent topography with greater precision.

Laharz documentation (Schilling, 1998) describes how the software can correct potential elevation errors (where flow direction is undefined) by use of a function to iterate across the DEM automatically, filling depressions that are shallower than a specified threshold value (Environmental Systems Research Institute, 1994). Often depressions in DEMs are erroneous elevations, referred to as "sinks," are often created during the generation of a DEM and inhibit surface-flow routing. However, some sinks may represent real surface depressions, such as quarries or natural erosional potholes (Jenson and Domingue, 1988). Thus, the user must be familiar with land features represented by the DEM to determine whether sinks in their DEM are errors. The resultant depressionless grid is then used to generate supplementary surface hydrology (flow routing) raster datasets.

These flow routing functions derive three raster datasets (fig. 6) from the DEM of flow direction, flow accumulation, and stream delineation that form the means to traverse a channel downstream and calculate areas of potential lahar inundation. Laharz begins calculations of lahar-inundation hazard zones at user specified X,Y coordinates, typically where a raster stream intersects the proximal-hazard zone boundary. 


\section{Surface Hydrology Grids}

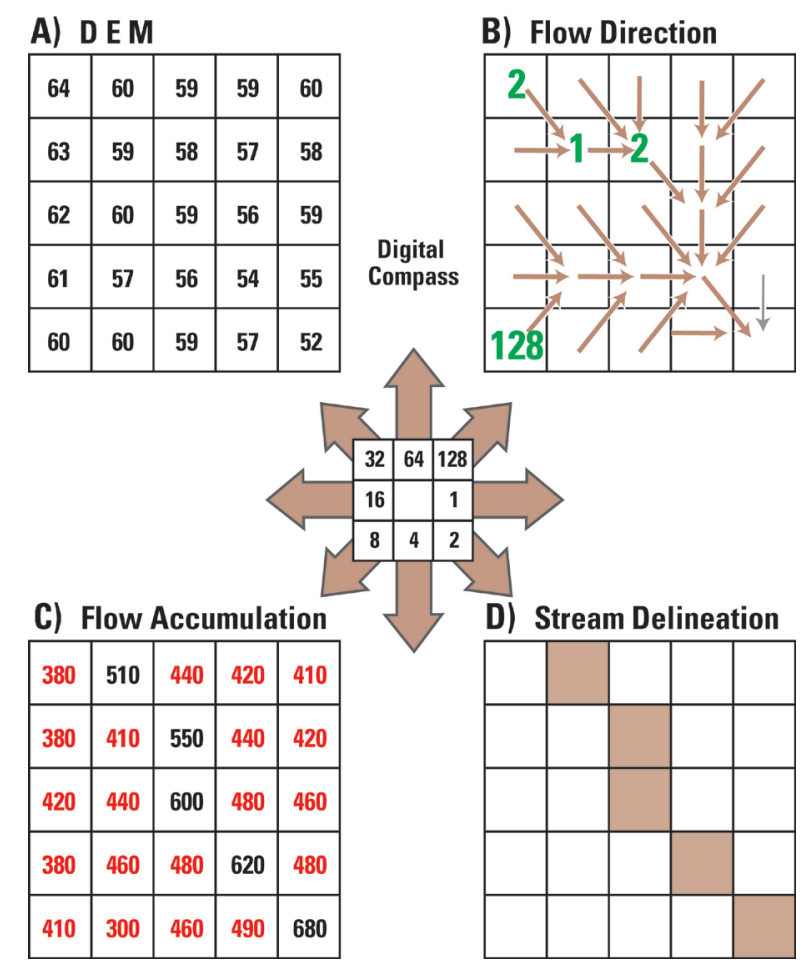

Figure 6. Diagram of part of a digital elevation model (DEM) and corresponding supplementary surface hydrology grids. (a) DEM where cells store values of elevation, in meters. (b) Flow direction grid derived from the DEM. Arrows represent the direction of flow; tails of arrows identify each individual cell; and arrowheads lie within the adjacent lowermost downstream cell. (c) The flow accumulation function uses the flow direction raster to calculate, for each cell, the number of upstream cells that flow into it. (d) Cells in the flow accumulation dataset with values (black text) greater than or equal to a user-specified stream delineation threshold (in this example a value of 500 cells) to identify stream cells (brown) in a stream raster.

\section{Proximal Hazard Zone Boundary}

Height/length runout $(\mathrm{H} / \mathrm{L})$ cones, sometimes referred to as energy-line or mobility cones (Sheridan, 1979), have an apex that usually coincides with a volcano summit and a slope determined by a ratio of vertical drop $(\mathrm{H})$ to horizontal runout distance $(\mathrm{L})$ characteristic for different volcano processes. The intersection of the cone with topography describes the predicted distance traveled (runout) by debris avalanches that originate on volcano flanks (Siebert, 1984) or summits (Hsu, 1975) and by pyroclastic flows (Sheridan, 1979; Beget and Limke, 1988). Values of H/L ratios typically range from about 0.1 to 0.3 yielding a cone that mathematically intersects topography. This line of intersection defines a boundary around a volcano edifice often used as a proximal hazard zone, depending on the size and type of the proximal event (Hayashi and Self, 1992). Laharz assumes that lahar inundation (primarily deposition) begins at the boundary of the proximal hazard zone and continues downstream, away from, or distal to, the volcano. 


\section{Laharz Algorithms}

Laharz calculates a cross-sectional area and a planimetric area from user specified volumes according to equations (1) and (2). Although the cross-sectional area remains constant throughout a channel length, emulating the maximum discharge of a lahar, the shape of each cross section will vary downstream. Laharz uses the elevation values of the DEM to determine the shape of each cross section, beginning each section typically at the lowest cell elevation in the profile, a stream cell that represents the stream thalweg. The software (Schilling, 1998) builds each cross section upward using values of the DEM and tracks cell elevations progressively outwards from the thalweg stream cell. Laharz stores the $\mathrm{X}$ and $\mathrm{Y}$ (planimetric) locations of cells it encounters as it constructs a cross section. Laharz stops calculation of the cross section when the area of the cross section is greater than or equal to the calculated cross-sectional inundation area $(A)$. A key concept of using a DEM is that each cell used to calculate a cross section occupies an finite area and thereby a fraction of the predicted planimetric area $(B)$. As stream channels meander, cell locations from one cross section may coincide with cell locations stored from a previous cross section. In these cases, even though a single cell may contribute to many cross sections, a cell location contributes to planimetric area calculations only once. When cross sections for a stream cell are complete, the locations of cells occupied during construction form, in total, the planimetric inundation area. Laharz stops constructing the current inundation zone when the area of the current inundation zone is greater than or equal to the planimetric area $(B)$.

\section{Laharz_py}

Laharz py is written in the Python ${ }^{\mathrm{TM}}$ programming language (Python Software Foundation, 2013) and runs within ArcGIS (version 10 or later; Environmental Systems Research Institute,, 2012) as a set of scripts (hereinafter referred to as tools) that are grouped within an ArcMAP toolbox. These seven tools are:

1. Create Surface Hydrology Rasters (creates supplementary raster datasets for calculations),

2. Generate New Stream Network (creates a new raster stream network using a user defined stream threshold),

3. Hazard Zone Proximal (creates a proximal hazard zone),

4. Lahar Distal Zones (creates areas of potential inundation from user supplied volumes),

5. Lahar Distal Zones with Conf Levels (creates areas of potential inundation from a user supplied volume and two additional inundation areas showing range of possible results based on user-selected level of confidence),

6. Merge Rasters by Volume (combines areas along separate drainages derived from one volume), and

7. Raster to Shapefile (converts raster to vector dataset).

Three of the tools prepare initial datasets, two of the tools use statistically based empirical equations to forecast areas of potential inundation by future lahars, and two of the tools convert datasets to different forms. Laharz_py uses redesigned algorithms for the potential inundation tools. The software tracks cells encountered for multiple cross sections from one or more input volumes simultaneously, rather than the time-consuming process of iterating individual volumes in the earlier version. As a result, multi-volume scenarios that have taken minutes to hours in the previous version now take seconds. Although the use of each tool will be demonstrated in the following section as an exercise at Mount Rainier, Washington, new approaches for the two lahar inundation tools that calculate distal hazard zone areas warrants some description. 
The Lahar Distal Zones tool operates similarly to the previous version of Laharz. However, now users can input up to seven volumes and identify multiple starting locations using a textfile. In addition, Laharz_py can calculate areas of potential inundation for several volcano processes. Griswold and Iverson (2008) used statistics to derive equations that relate inundation areas to flow volumes for debris flows, equations (3) and (4), and for rock avalanches, equations (5) and (6); where $(A)$ is cross sectional inundation area, $(B)$ is planimetric inundation area, and $(V)$ is volume. With this tool, users choose whether to calculate potential inundation areas from lahars debris flows or rock avalanches.

$$
\begin{aligned}
& A=0.01 V^{2 / 3} \\
& B=20 V^{2 / 3} \\
& A=0.02 V^{2 / 3} \\
& \mathrm{~B}=20 V^{2 / 3}
\end{aligned}
$$

where

$$
\begin{array}{ll}
A & \text { cross-sectional area; } \\
B & \text { planimetric area; and } \\
V & \text { volume. }
\end{array}
$$

The previous version of the Laharz software and the new Lahar Distal Zones tool, take a userspecified volume $(V)$, and uses the regression to predict the mean expected $(A)$ and $(B)$ (fig. 7a). The 95percent confidence intervals for prediction (green lines in fig. 7a) show the probable range of $(A)$ and $(B)$ values for a given volume.

The Lahar Distal Zones with Conf Levels tool allows the user to input a single volume and to select the confidence level appropriate for their problem. The purpose of calculating and displaying the range of lahar inundation possible for a given volume is to convey to the user of the data some of the uncertainties that are inherent to this empirical method of hazard estimation. As the confidence level changes, so does the range of corresponding $(A)$ and $(B)$ values, such that the range of statistically valid values grows if greater confidence is specified, or is reduced if lesser confidence is selected. After a level of confidence is selected, the Lahar Distal Zones with Conf Levels tool calculates the upper and lower confidence limits for the input volume $(V)$ and from these values, the tool calculates two additional sets of $(A)$ and $(B)$ values (fig. 7b). 

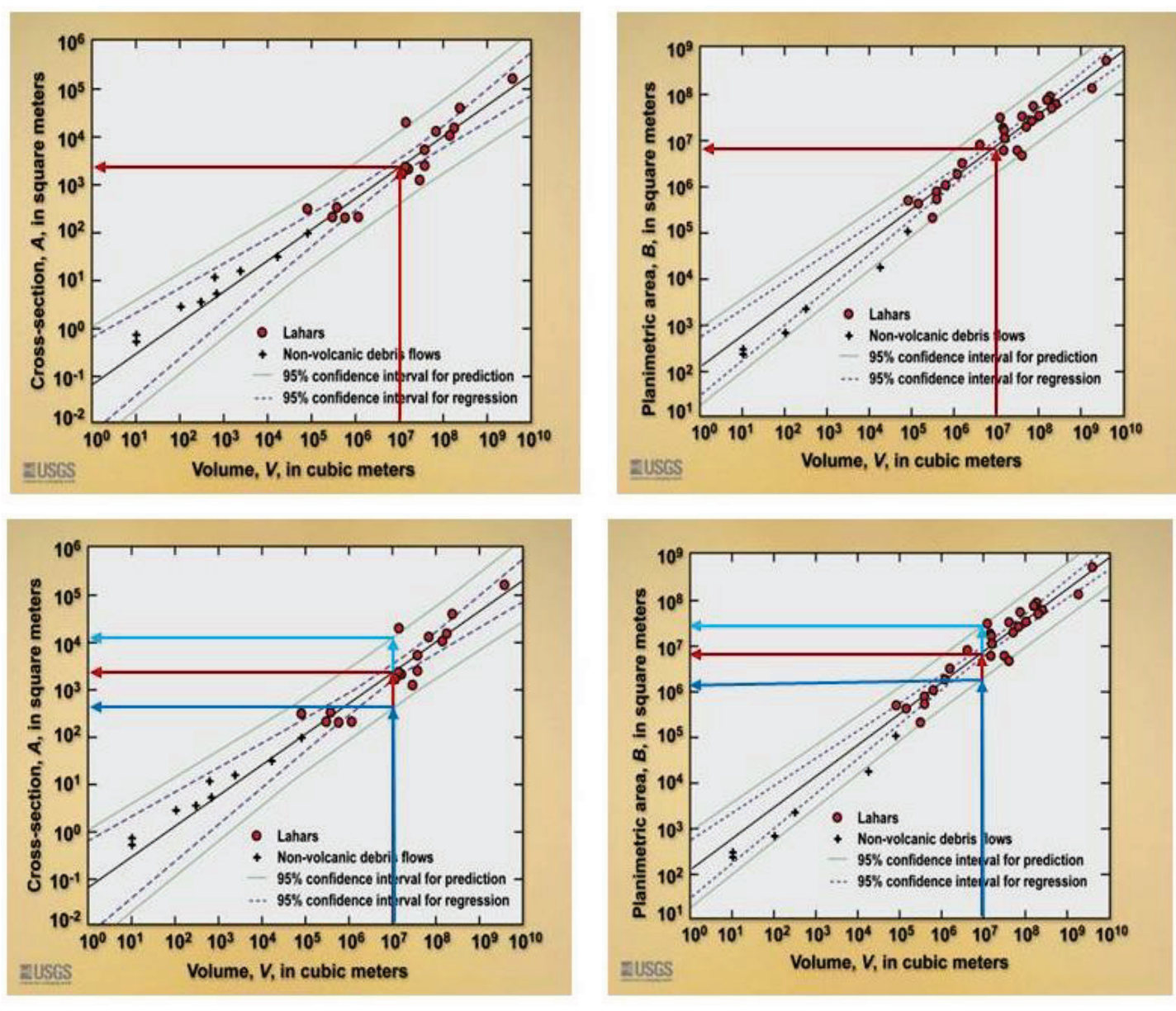

(a)

(b)

Figure 7. Scatter plots showing (a) for a selected $V$ (here 10 million cubic meters), the regression predicts the mean (red line) expected at cross-sectional area, $A$, and planimetric area, $B$; and (b) the 95-percent confidence intervals for prediction show the probable dispersion (blue lines) of future $A$ and $B$ values. This dispersion increases if greater confidence is specified.

Three areas of potential inundation are calculated from a single volume, one showing the mean value of the regression, the other two showing the upper and lower confidence levels (fig. 8). During this process, the software opens and reads three text files (py_xxplanb.txt, py_xxsecta.txt, and py_xxttabl.txt) to calculate some basic statistical quantities described in detail in appendix A. Plotting all three areas of potential inundation forms a visual representation of the range of probable $(A)$ and $(B)$ values for the selected level of confidence, a useful visualization for decision making. 

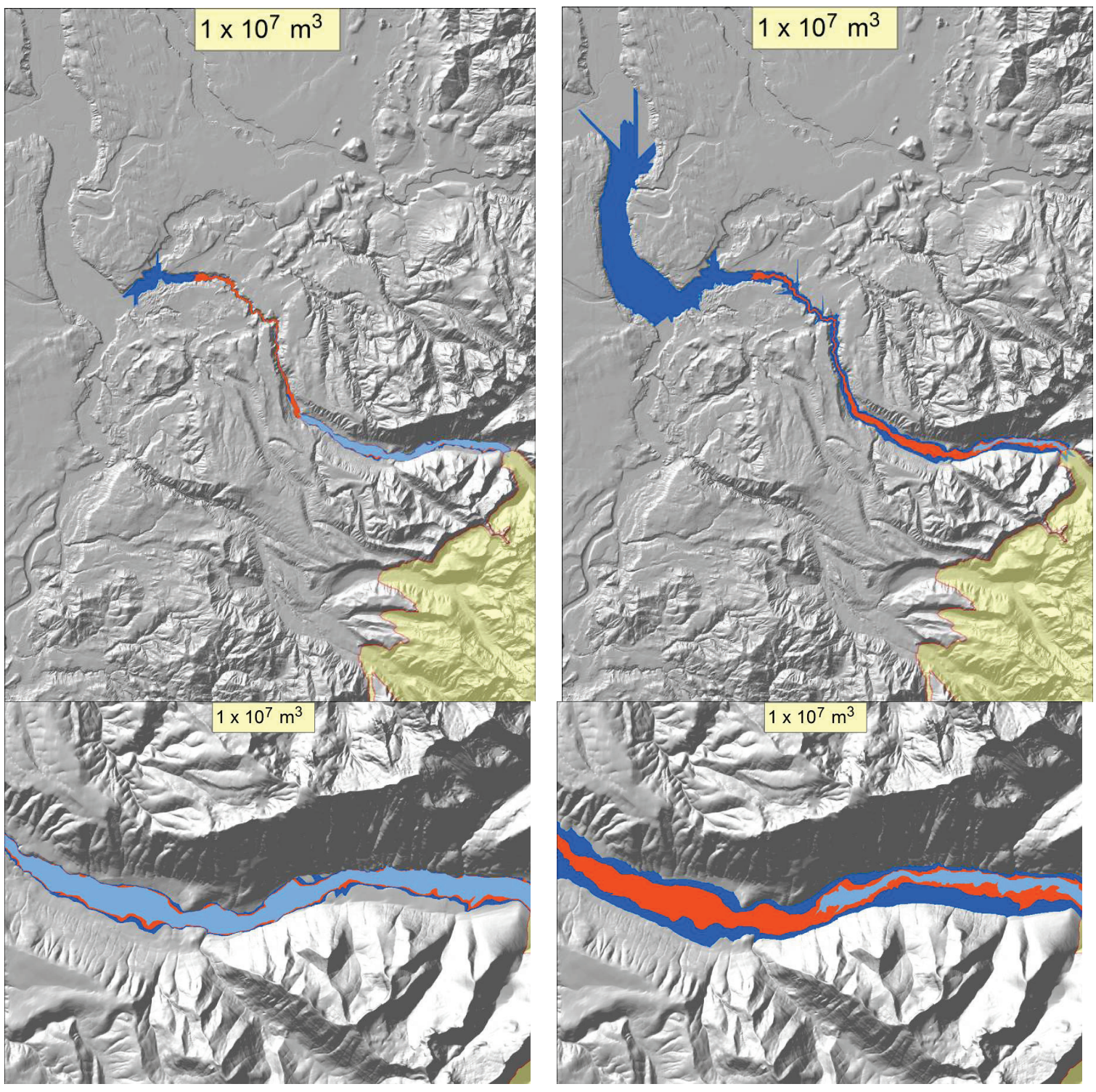

Figure 8. Light Detection and Ranging (LiDAR) images showing (in upper two images) the probable range of planimetric area $(B)$ values with changing confidence limits (red is the mean value from the regression line, dark blue the upper confidence limit, light blue the lower confidence limit) from a single simulation of $V$ (10 million cubic meters). The level of confidence shown is 50 percent (left upper image) and 99 percent (right upper image). The lower two images show the probable range of cross-sectional area $(A)$ values with changing confidence limits (red is the mean value from the regression line, dark blue the upper confidence limit, light blue the lower confidence limit) from a single simulation of $V$ (10 million cubic meters). The level of confidence shown is 50 percent (left lower image) and 99 percent (right lower image). This example is on the Carbon River, northwest flank of Mount Rainier, Washington. 


\section{Example Using Laharz_py}

Figure 9 shows the files included in the distribution of Laharz_py_example that contains four subdirectories: laharz_py (contains Python ${ }^{\mathrm{TM}}$ scripts, hereinafter referred to as tools, for use with ArcGIS, version 10 or later), laharz_shapefiles (is empty), laharz_textfiles (contains text files used to run the software; note that the three text files with names beginning py_xx should be left unchanged as they are used by the confidence level version of Laharz_py to run properly), and mtrain_example (includes files and data to run this example for Mount Rainier, Washington) and Laharz_py.tbx a file that is an ArcGIS toolbox. The mtrain_example directory contains two raster datasets (mtrainier, the DEM, and mtrainiersh, a shaded relief dataset derived from the DEM). It also contains two subdirectories, laharz_textfiles and laharz_shapefiles that have been copied into this example directory. These two subdirectories must be copied into any Workspace directory in order for Laharz_py to function properly.

\begin{tabular}{|c|c|c|}
\hline Name - & Size & Type \\
\hline Glaharz_py & & File Folder \\
\hline Glaharz_shapefiles & & File Folder \\
\hline$\square$ laharz_textfiles & & File Folder \\
\hline$\square$ mtrain_example & & File Folder \\
\hline Laharz_py.tbx & $38 \mathrm{~KB}$ & ArcGIS Toolbox \\
\hline
\end{tabular}
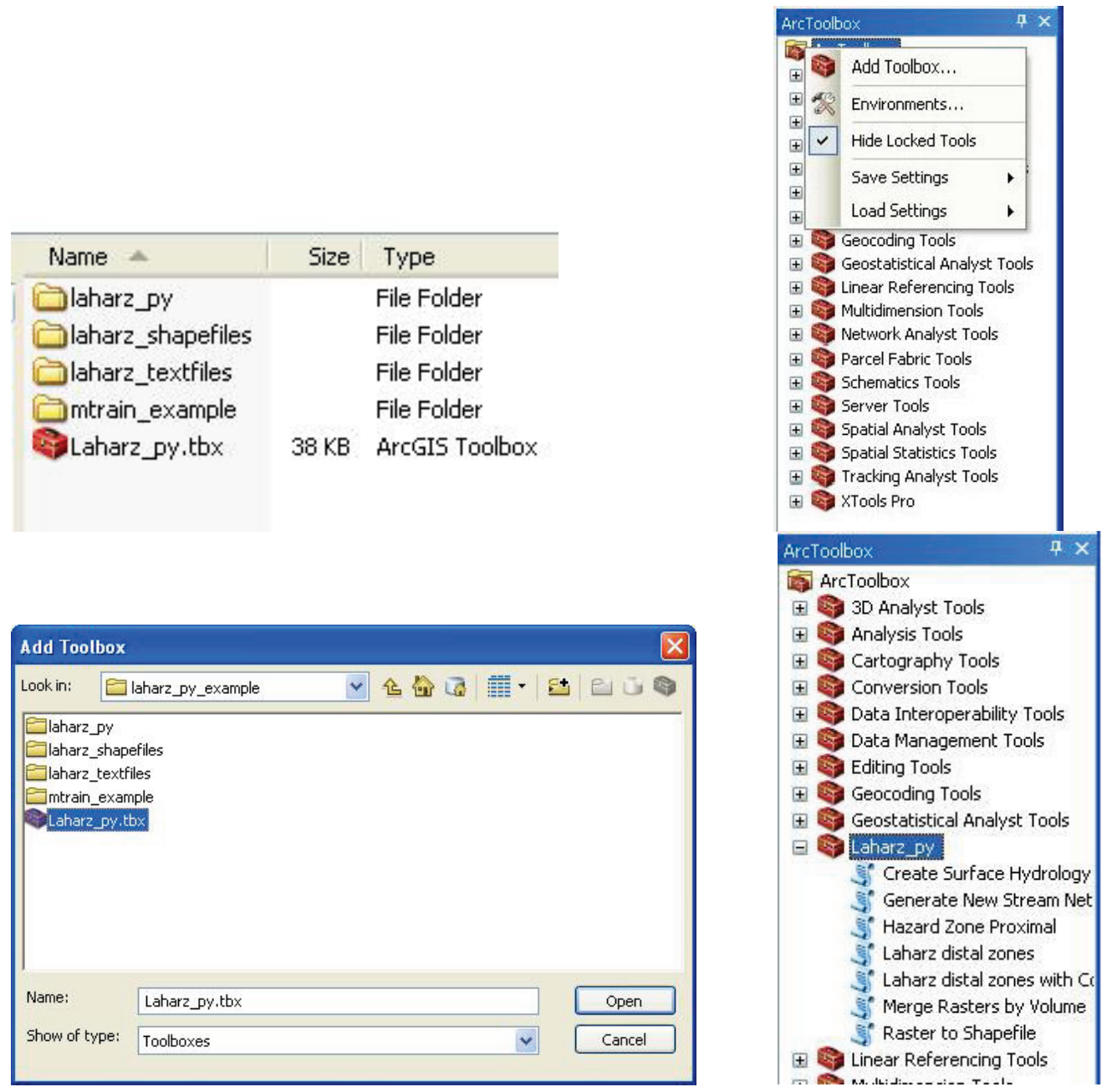

Figure 9. Screen captures showing a listing of files included with Lahar_py_example (upper left); right-click menu to add Laharz_py toolbox (upper right); navigation to the Laharz_py toolbox (lower left); and seven tools in the Laharz_py toolbox (lower right). 
To begin using the Laharz py software, start ArcMap and ensure the ArcToolbox window is open. In this example, it is affixed to the right part of the ArcMap interface. Right-click the root entry in the ArcToolbox tree, within the ArcToolbox window, at the top and select "Add toolbox..." from the popup menu (fig. 9). In the small window that appears, navigate to the Laharz_py_example directory and select Laharz_py.tbx toolbox (fig. 9). Within the ArcToolbox window, click on the small plus sign to the left of the Laharz_py toolbox to display the seven tools in the Laharz_py toolbox (fig. 9).

Each tool uses a similar graphical user interface (GUI) to enter or select appropriate inputs. The Laharz_py toolbox displays seven tools: Create Surface Hydrology Rasters, Generate New Stream Network, Hazard Zone Proximal, Lahar Distal Zones, Lahar Distal Zones with Conf Levels, Merge Rasters by Volume, and Raster to Shapefile. The first three tools typically are run once for a project to generate necessary datasets used for project simulations. The Merge Rasters by Volume and Raster to Shapefile tools are usually run after all simulations are complete. The Lahar Distal Zones tools are run as often as needed, typically once for each stream drainage.

For this example, click the Add Data button in ArcMap and navigate to the mtrain_example directory. Add the raster datasets mtrainier (DEM) and mtrainiersh (hillshade) to the project. The hillshade should be visible in the ArcMap window (fig. 10).

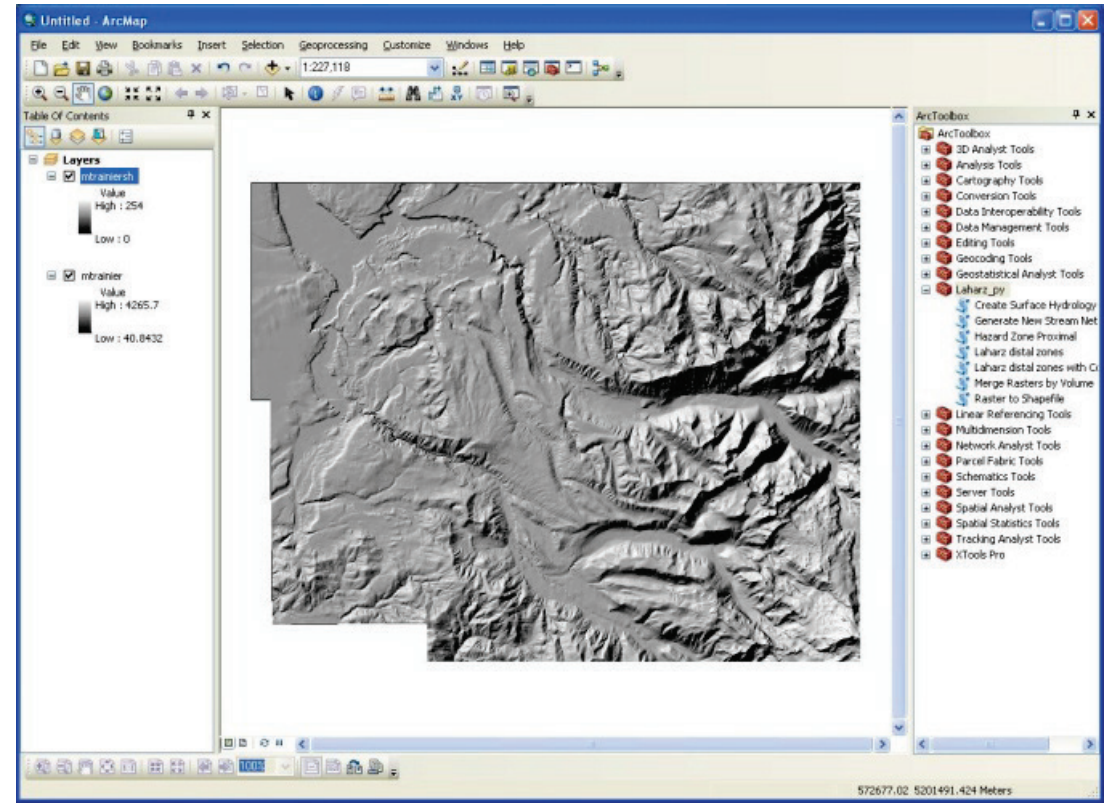

Figure 10. Screen capture showing raster datasets, mtrainfill and mtrainfillsh, added to project. 


\section{Creating Surface Hydrology Rasters}

The first tool is labeled, Create Surface Hydrology Rasters. Double-click the tool to open a window to input field values (fig. 11). Enter or navigate to an ArcGIS Workspace, a directory that holds datasets for the project, then select a DEM from the current Workspace and enter a short prefix for names of supplementary raster datasets the tool will generate. Specify a stream threshold value (cells have greater than or equal to the threshold number of upstream cells flowing into it). Click on the $\mathbf{O K}$ button to start processing.

The tool creates a stream raster identifying cell locations where the flow accumulation raster is greater than or equal to the stream threshold value. As the tool runs, it will fill sinks in the DEM ensuring flow over the surface (fig. 6), and generate a flow direction, flow accumulation, and stream raster. The suffix "fill" is appended to the prefix to name the filled DEM, "dir" to name the flow direction raster, "flac" to name the flow accumulation raster, and "str" to name the stream delineation raster. For example, if the name of the input DEM is mtrainier and the user enters "mtr" as a prefix string, Laharz_py will name the four new rasters, mtrfill, mtrdir, mtrflac, and mtrstr; and store the rasters in the current workspace. The user must remember to use the filled, or depressionless, DEM for the rest of the program, rather than the original DEM.

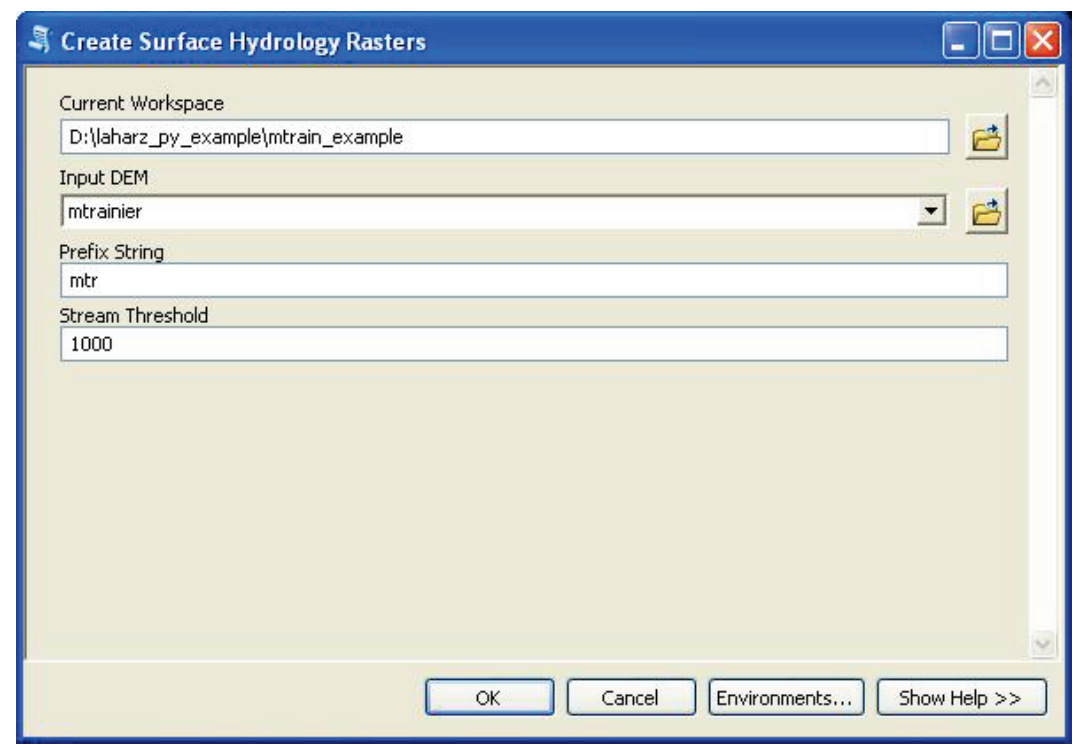

Figure 11. Screen capture showing window for creating supplementary surface hydrology rasters. Navigate to a Workspace (directory) that stores existing and new data sets for a project, then locates a DEM for the project and enters a prefix for supplementary raster data sets (keeping in mind that Arclnfo Grid names are restricted to 13 characters). The user also must specify a stream threshold value. Laharz_py will store locations of cells in a stream network where corresponding cells in the flow accumulation grid contain a value at or above the stream threshold. The software will run the FILL function to fill sinks (cell having undefined flow directions) in the DEM. The FILL function will fill sinks having a depth less than or equal to a threshold of 100 meters. 
While each tool is running, a window displays progress (fig. 12) and the processing time when the tool is finished. When the tool is finished, the user can add these to the ArcMap session for viewing.

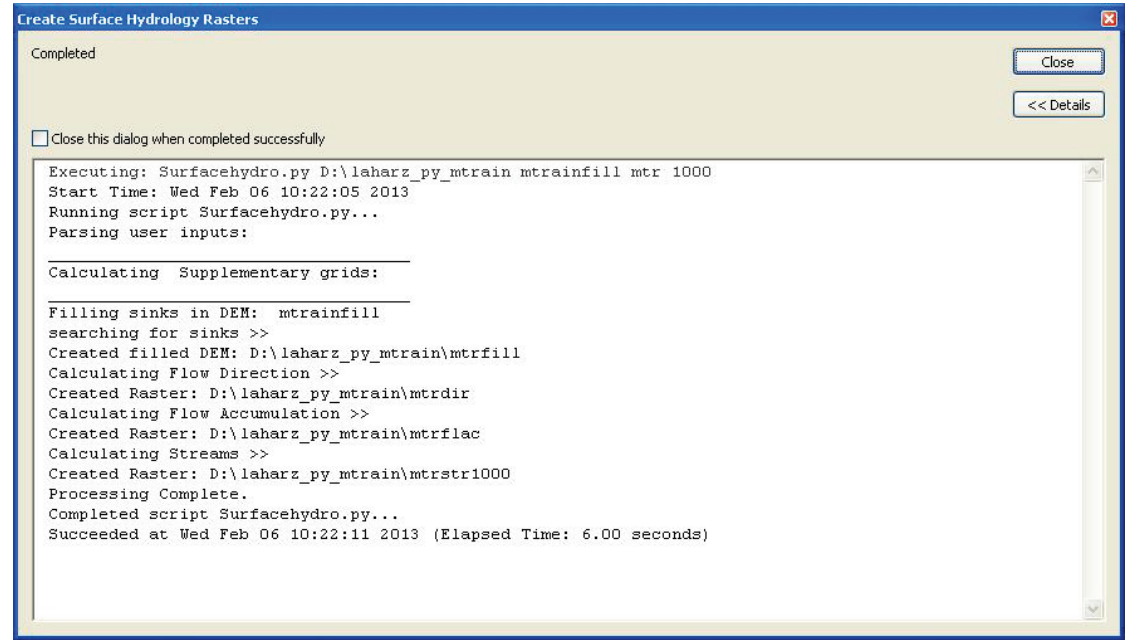

Figure 12. Screen capture showing progress and completion-time window when the Create Surface Hydrology Rasters is complete.

If necessary, run the Generate New Stream Network tool (fig. 13) to generate another stream network using a different threshold than was produced with the Create Surface Hydrology Rasters tool.

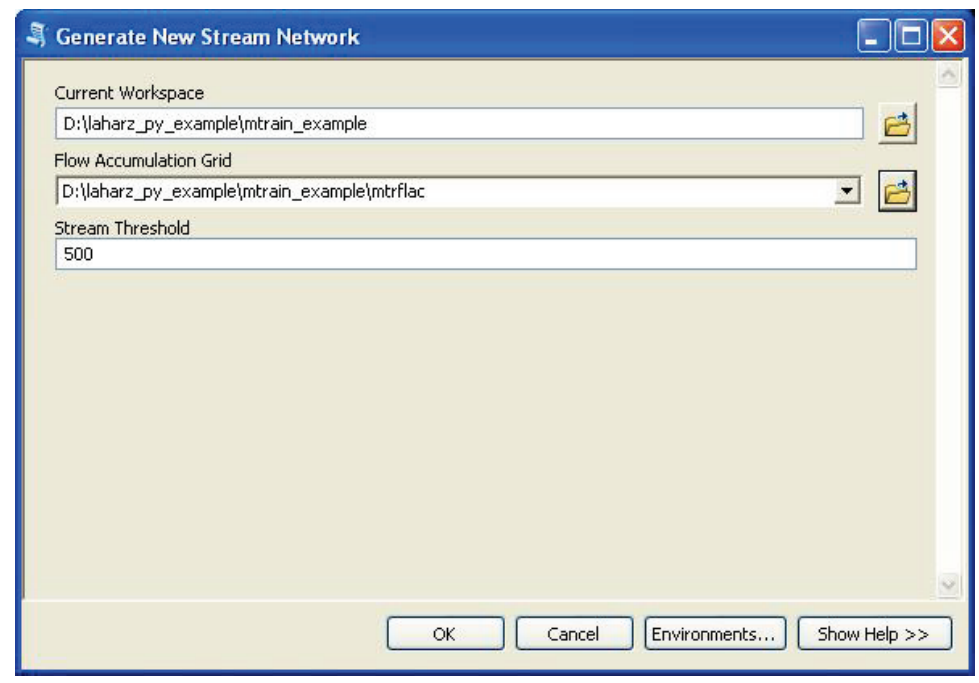

Figure 13. Screen capture showing window to generate an new stream network. The user enters or navigates to the Workspace, selects or navigates to a flow accumulation raster, and enters a stream threshold. The software labels the completed file with the same prefix as the flow accumulation raster, the letters "str" and the threshold value (for this example mtrstr500). 


\section{Creating a Proximal Hazard Zone Boundary}

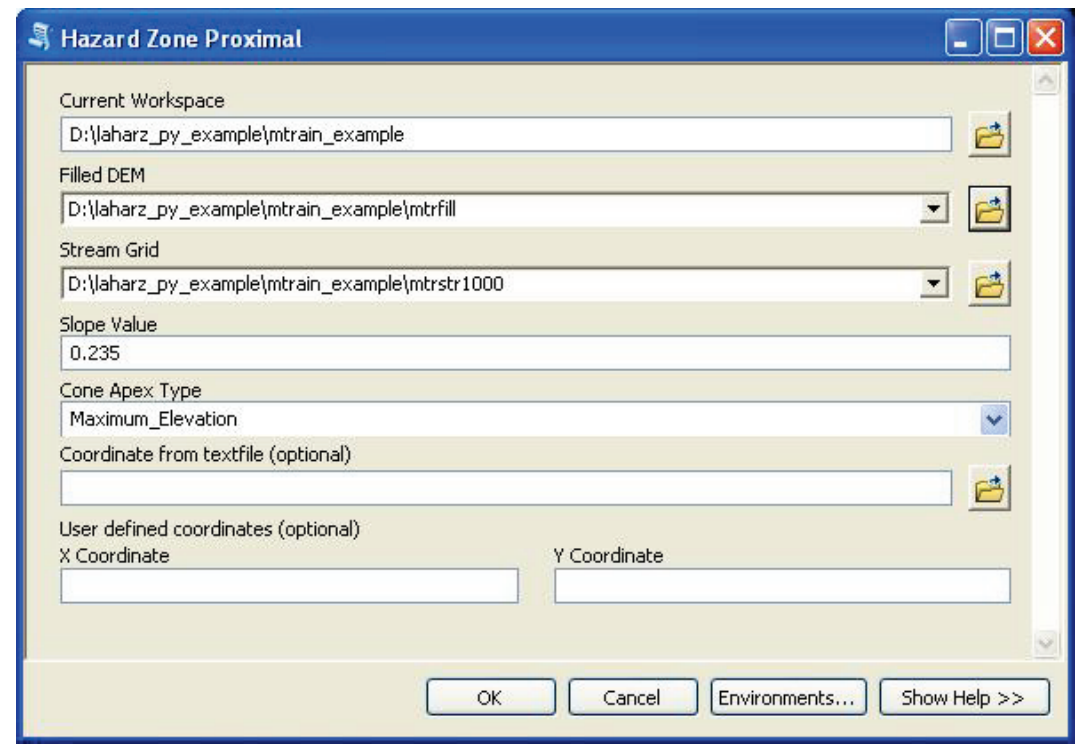

Figure 14. Screen capture showing window to create a proximal hazard zone boundary. Navigate to a Workspace, selects or enters a filled digital elevation model, selects or enters a stream raster and specifies a ratio of $\mathrm{H}$ to $\mathrm{L}$ (slope of $\mathrm{H} / \mathrm{L}$ cone). A pull-down menu offers three alternatives to identify the location of the energy cone apex. The user can select the maximum elevation automatically (Maximum_Elevation), identify a textfile that contains $X, Y$ coordinates (Textfile), or can type the coordinates manually ( $X Y$ coordinates) as the location of the energy cone apex.

The Proximal Hazard Zone Boundary tool displays a window (fig. 14) to create a proximal hazard zone boundary. When the line of intersection between the energy cone and topography is completed, Laharz_py identifies all X,Y coordinates of cells where the cone boundary and streams intersect. Specify a Workspace, a filled DEM, a Stream raster, and a ratio of $H$ to $L$ (slope of the $H / L$ cone). A pull-down menu offers three alternatives to identify the location of the cone apex. This choice determines whether the tool selects the maximum elevation automatically (Maximum_Elevation), identifies it from a textfile that contains X,Y coordinates (Textfile) of the apex, or accepts user-typed coordinates from the menu (XY coordinates) of the H/L cone apex. The simplest choice for the user is the Maximum_Elevation selection, provided that the highest elevation corresponds to the presumed volcanic vent location.

After the user identifies the apex location and the slope of the cone (specified using the Slope Value field on the Proximal Hazard Zone Boundary menu). The Proximal Hazard Zone Boundary tool calculates elevations of each cell in the cone raster according to the equation:

$$
H_{A p}-h_{\text {cell }} / L_{X, \text { Yap }}-l_{X, \text { Ycell }}=S
$$

where

$\begin{array}{ll}\mathrm{H}_{\mathrm{Ap}} & \text { height of the user-identified cone apex; } \\ \mathrm{h}_{\text {cell }} & \text { cone height of the cell; } \\ \mathrm{L}_{X, Y a p} & \text { location of the user-identified cone apex; } \\ \mathrm{l}_{\mathrm{X}, \text { Ycell }} & \text { location of the cell; and } \\ \mathrm{S} & \text { user-identified slope. }\end{array}$


The tool uses the height and location of the cone apex and the slope that have been provided by the user. The tool calculates the denominator of equation (7) using a Euclidean distance algorithm (Environmental Systems Research Institute, 1994) and solves for $h_{\text {cell }}$ at each cell in the raster.

The tool compares the values of the H/L raster with the elevations of the DEM at each cell location. In a temporary raster, the tool assigns the cells a unique arbitrary value where the H/L value is greater than the DEM elevation and a second unique arbitrary value where cell values are less than the DEM elevation. The tool uses these unique arbitrary values to create a polygon that marks the intersection between the $\mathrm{H} / \mathrm{L}$ cone and the DEM, and is referred to as the Proximal Hazard Zone Boundary. The polygon boundary is converted back into a raster dataset, with the naming convention of hlcone $<$ slope $>$ g, where $<$ slope $>$ is a user-specified slope value (for example, hlcone235_g is a cone having slope 0.235). As a final step, the Laharz_py software checks every cell to identify those cells where the proximal hazard zone boundary and the stream cells intersect (fig. 15). The X and Y coordinates of each of these cells is stored in a raster dataset, a shapefile, and a textfile.

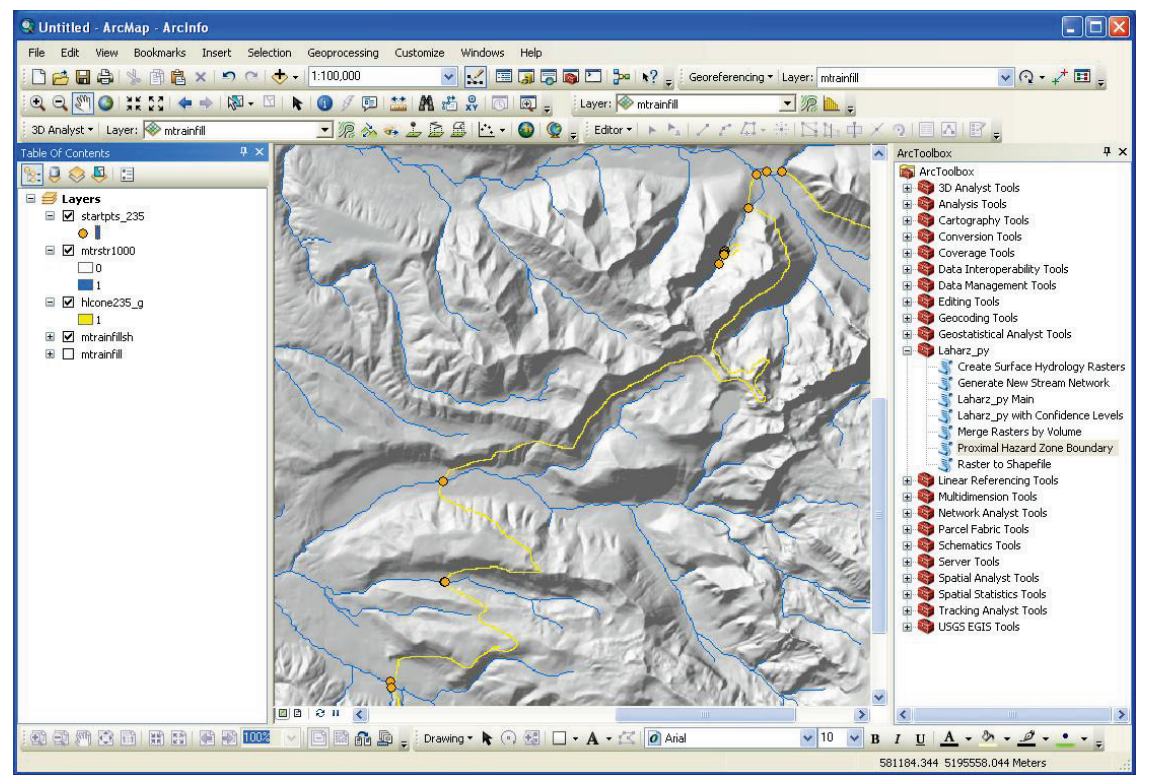

Figure 15. Screen capture showing proximal hazard zone boundary as the rasterized line, one cell in width, that marks the intersection of an $\mathrm{H} / \mathrm{L}$ or energy cone with topography (yellow). The Laharz_py software calculates the boundary and identifies and stores $X, Y$ coordinates where the boundary and streams (blue) intersect. 


\section{Create Lahar Inundation Zones}

The Lahar Distal Zone tool will calculate areas of potential inundation for each drainage from user-specified X,Y coordinates, for each user-supplied debris volume. The tool creates a raster dataset for each drainage that can be plotted with other datasets such as a shaded relief map. Each raster dataset is named using the convention $<$ drainage prefix identifier $><$ number $>$. The user supplies the drainage prefix identifier, the number begins at 1 for the first coordinates supplied, 2 for the second coordinates, and so on. After the previous tools generate their datasets, double-click on the Lahar Distal Zones tool to display the tool menu (fig. 16). For this example, specify a textfile (volumesbig.txt, containing volumes of 10 and 30 million cubic meters) in the Volume File field. The file must contain between one and seven lahar volumes, specified in a comma-separated list, in cubic meters, on a single line. Users determine appropriate volumes on the basis of experience, judgment, fieldwork (if possible), and knowledge of the particular volcano (Iverson and others, 1998). In addition, the window requires fields of a Workspace, a filled DEM, prefix for the drainage (puycarb_in this example), and a textfile containing X,Y coordinates of initiation sites for the simulations (threepnts_235.txt for this example). The Type of Flow pull-down menu offers three flow types: Lahar, Debris_Flow, and Rock_Avalanche. For this example, select Lahar (fig. 16) from the pull-down menu. The tool uses the equations (1) and (2) to calculate the cross-sectional area $(A)$ and total planimetric area $(B)$ (Iverson and others, 1998) for each of the user-specified lahar volumes. The tool will use equations (3) and (4) if the user selects

Debris_Flow from the pull down menu, and equations (5) and (6) if the user chooses Rock_Avalanche.

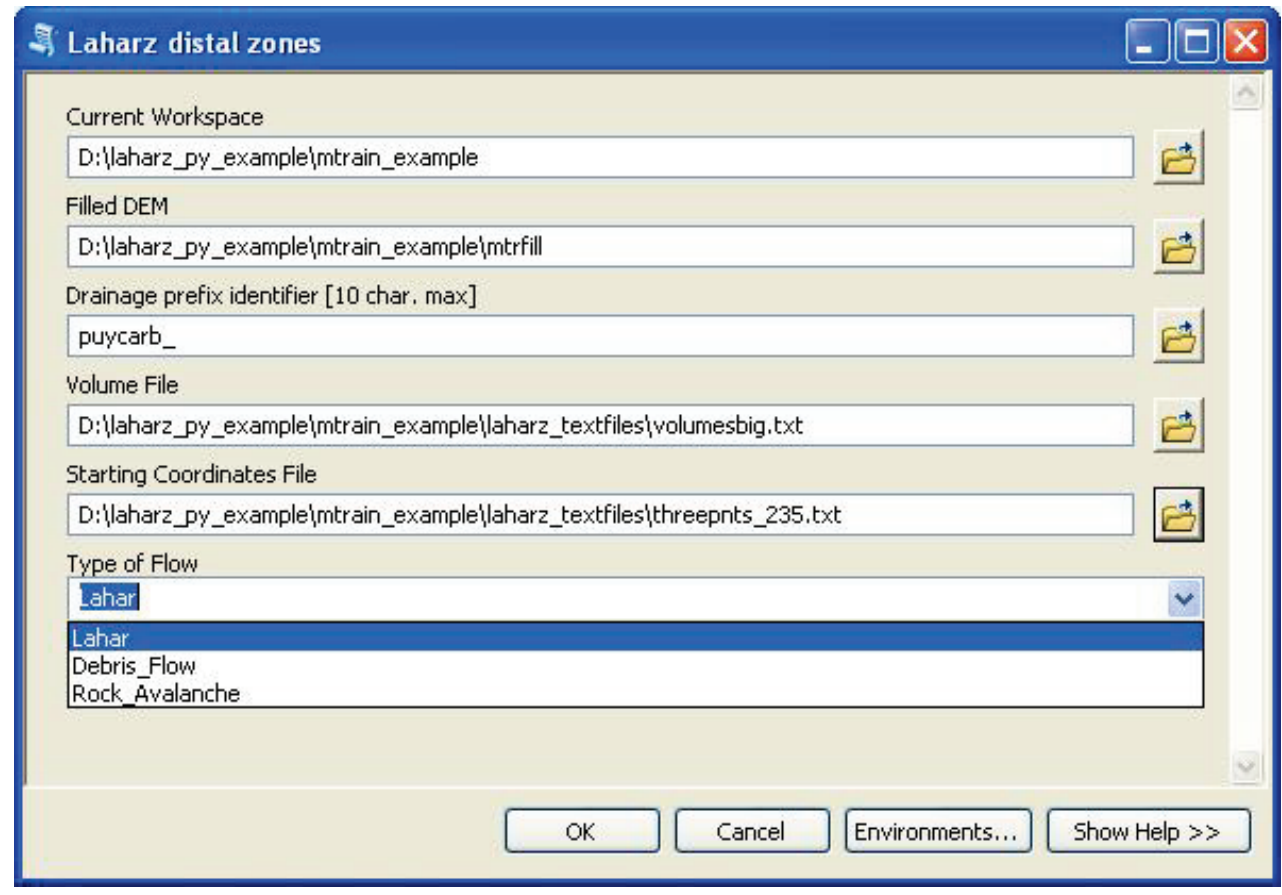

Figure 16. Screen capture showing interface to start Lahar Distal Zones. The user is required to fill in all fields. The user selects, navigates to, or enters a Workspace, a filled DEM, a filename prefix for the drainage (PuyallupCarbon River drainage, for the Mount Rainier example), a textfile that contains the volumes (volumesbig.txt contains volumes of 10 and 30 million cubic meters) and a textfile containing $X, Y$ coordinates of initiation sites for the simulations (threepnts_235.txt contains $X$ and $Y$ coordinates). A pull-down menu offers three alternative flow types: Lahar, Debris_Flow, and Rock_Avalanche. For this example, the user selects the flow type: Lahar. 
When processing of inundation zones is complete, the tool creates a textfile, with the ".pts" file extension, and a raster of the inundated area for each drainage, for each lahar volume. The text files, named $<$ drainage prefix identifier $><$ run number $>$.pts, contains a list of the user-specified volumes, the cross-sectional and planimetric area values calculated by Laharz_py from user-specified volumes, and a list of decreasing planimetric areas, one row of values per stream cell.

The textfile (puycarb_1.pts) for the first drainage area and volume setting is shown in figure 17. Each raster is named using the drainage prefix identifier appended to a suffix of a sequential number (for example, 1,2,3, and so on).

\begin{tabular}{|c|c|}
\hline puycarb_1.pts - Notepad & $-\square x$ \\
\hline File Edit Format Yiew Help & \\
\hline $\begin{array}{l}\text { DRAINAGE NAME ENTERED: puycarb } \\
\text { VALUES SORTED LARGEST TO SMALLEST } \\
\text { VOLUMES ENTERED: } \\
30000000.0: 10000000.0\end{array}$ & \\
\hline $\begin{array}{l}\text { CROSS SECTION AREAS : } \\
\text { 4827.0 : } 2321.0 \\
\text { PLANIMETRC AREAS }: \\
19309788.0: 9283178.0\end{array}$ & \\
\hline DECREASING PLANIMETRIC AREAS LISTED BELOW & \\
\hline $\begin{array}{ll}19232388.0, & 9226478.0 \\
19174788.0, & 9180578.0 \\
19149588.0, & 9160778.0 \\
19109988.0, & 9132878.0 \\
19073088.0, & 9106778.0 \\
19040688.0, & 9084278.0 \\
19011888.0, & 9063578.0 \\
18985788.0, & 9046478.0 \\
18963288.0, & 9030278.0 \\
18941688.0, & 9014978.0 \\
18920988.0, & 9000578.0 \\
18893088.0, & 8979878.0 \\
18874188.0, & 8969078.0 \\
18850788.0, & 8959178.0\end{array}$ & \\
\hline
\end{tabular}

Figure 17. Screen capture showing a partial textfile listing for one of the .pts files created from the simulations. When a simulation is complete the decreasing planimetric area for a simulation is less than zero. 
Use the Add Data button to view the potential lahar-inundation rasters over a shaded relief version of the DEM in ArcMap (fig. 18). This example results with a raster and a textfile for each drainage.

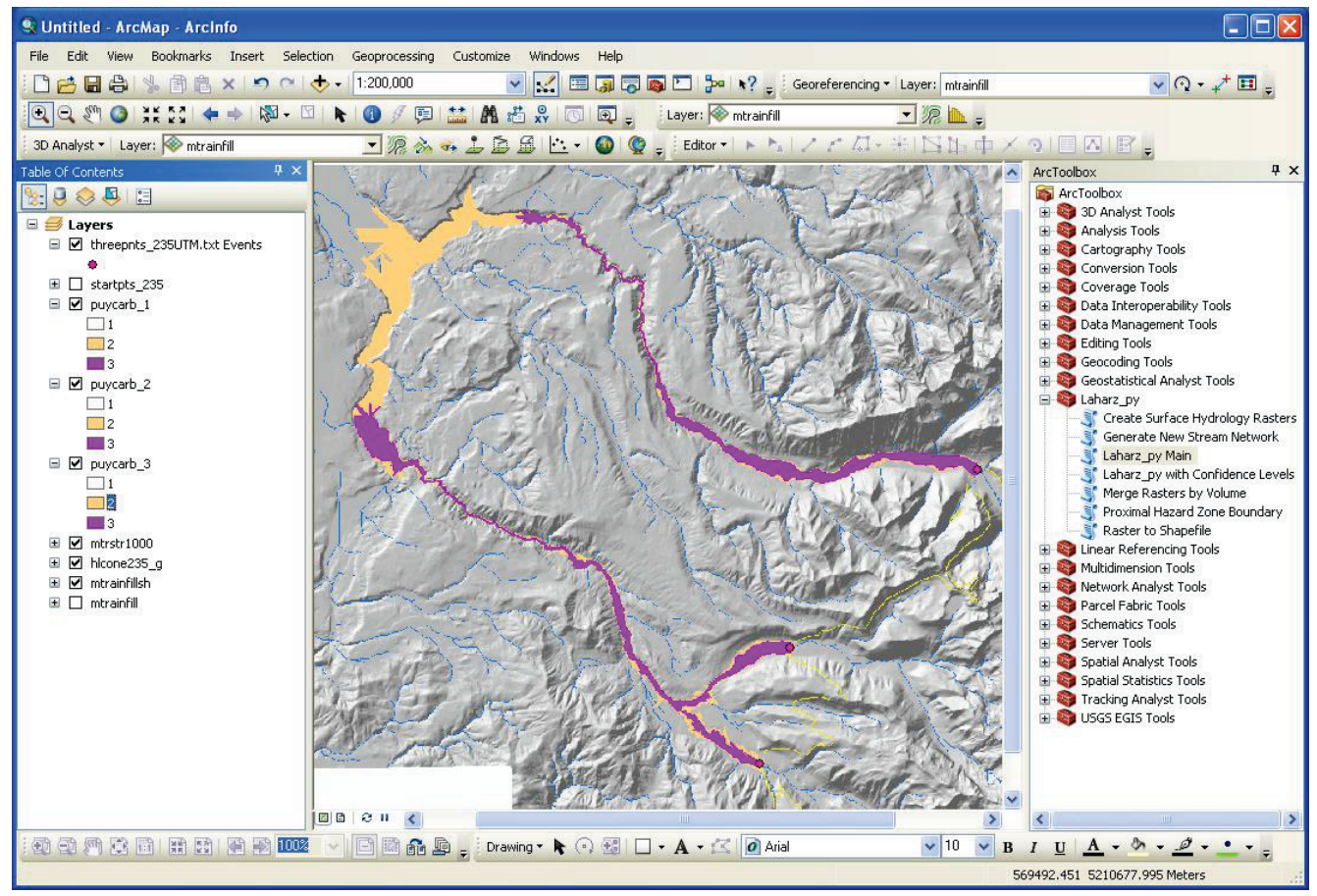

Figure 18. Screen capture showing three completed simulations. Smaller volumes are shown in purple, larger volumes are shown in orange.

\section{Merge Rasters by Volume}

After Lahar Distal Zones tool is complete, there are three rasters (puycarb_1, puycarb_2, and puycarb_3), one for each of the three drainages. Each raster contains the results for two volumes. Users may wish to combine the 10 million cubic meter results for the three drainages, and the 30 million cubic meter results for the three drainages. Double-clicking the Merge Rasters by Volume tool will display a menu (fig. 19). Specify a Workspace, a filled DEM, a filename of the textfile containing the list of rasters to merge (for this example the textfile is laharzruns.txt, the list of rasters to merge includes puycarb_1, puycarb_2, and puycarb_3), and a textfile that contained the input flow volumes named volumesbig.txt. Users can add the resulting two rasters, merge_2 and merge_3 (one for each volume) to the ArcMap project for viewing (fig. 20). These generic names can be changed to something more meaningful using ArcCatalog. 


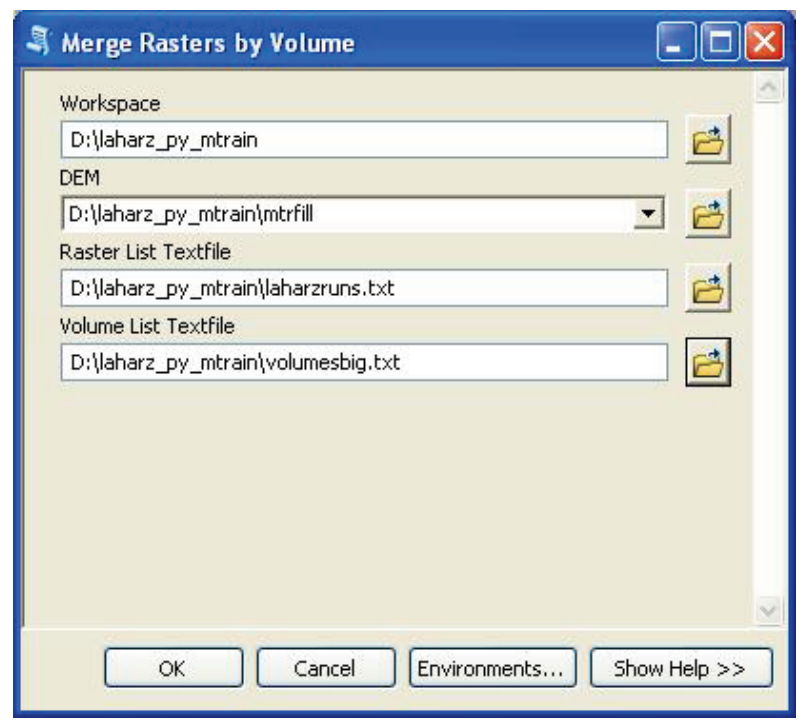

Figure 19. Screen capture showing menu for the Merge Rasters by Volume tool. A user specifies a Workspace, a filled digital elevation model, a textfile that lists the rasters to merge (for this example the textfile is laharzruns.txt, the rasters to merge are puycarb_1, puycarb_2, and puycarb_3), and a textfile that contains the volumes (textfile named volumesbig.txt used for the previous tool).

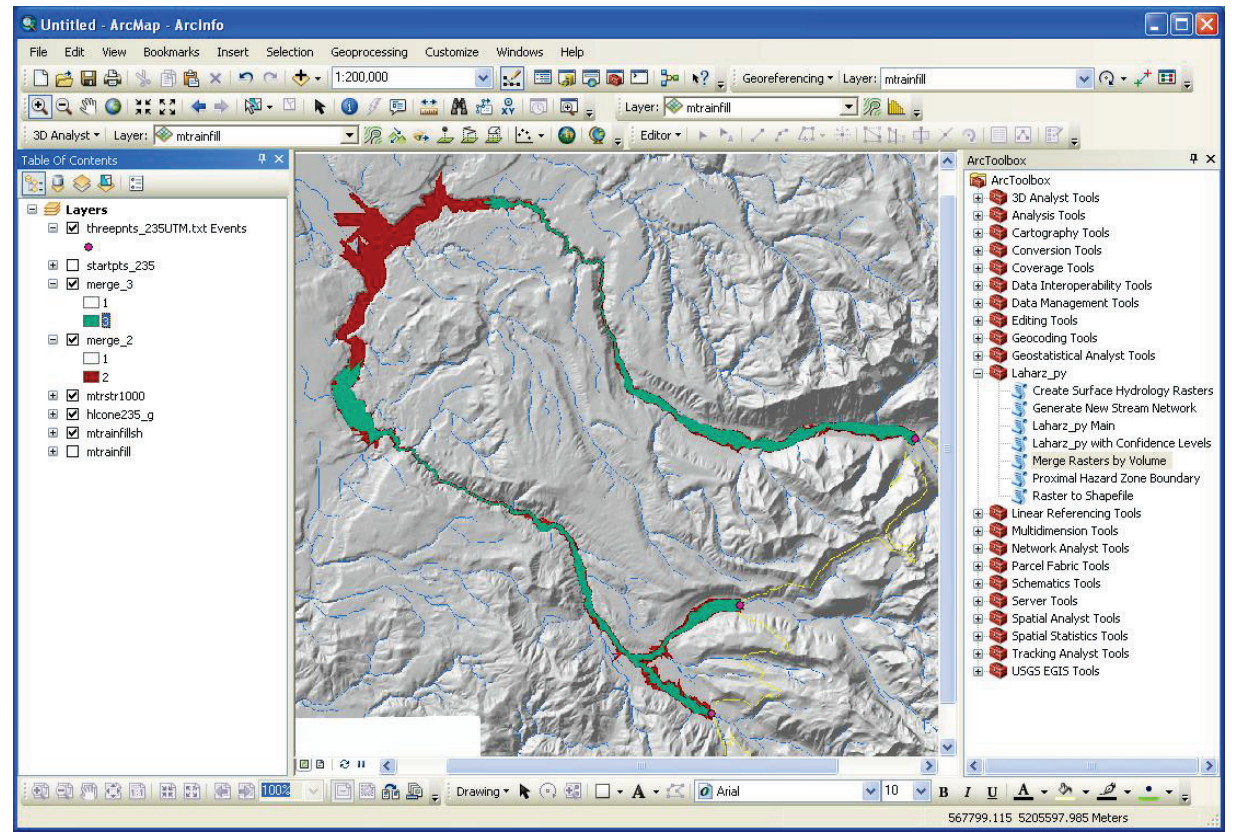

Figure 20. Screen capture showing merged raster datasets. Here the dataset merge_3 shows the 10 million cubic meter data from all three drainages (green) and Merge_2 shows the 30 million cubic meter data from all three drainages (dark red). 


\section{Raster to Shapefile}

Users may want to convert the raster dataset results to a vector shapefile, a smaller sized dataset and convenient to distribute. Double-clicking the tool Raster to Shapefile will display a menu (fig. 21). Select or navigate to a Workspace, enter a name for the new shapefile (in this example, mtr10mcm), and select or navigate to a raster data set to convert (merge_3). Users can add the resulting shapefile ( $\mathrm{mtr} 10 \mathrm{mcm})$ to the ArcMap project for viewing (fig. 22).

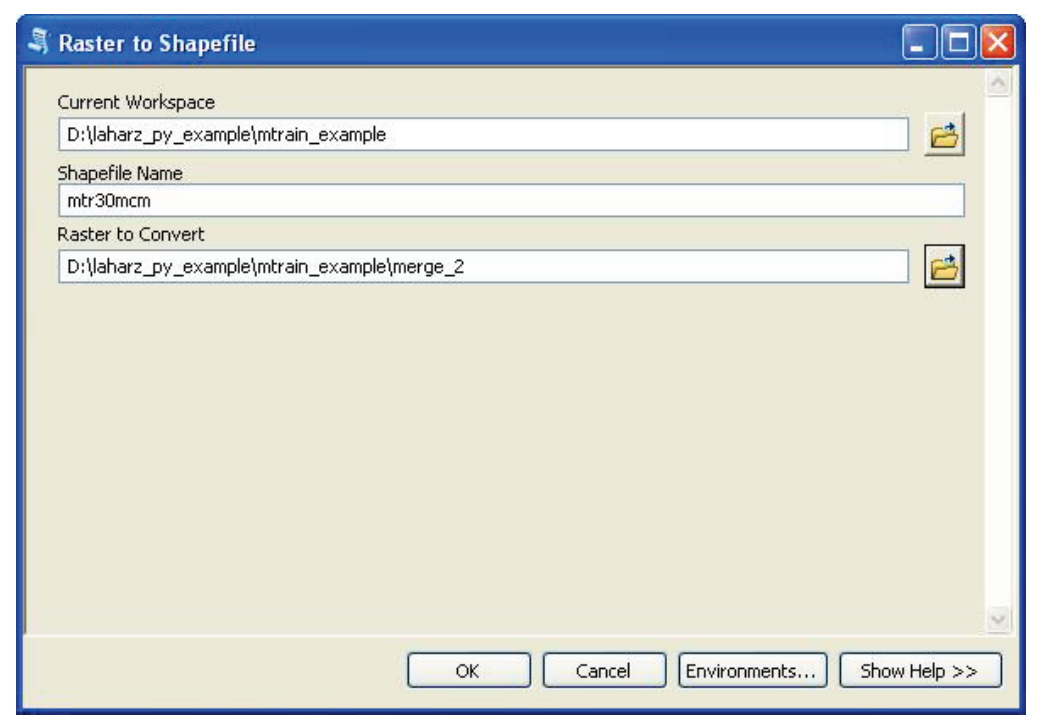

Figure 21. Screen capture showing window to convert a raster dataset to a vector shapefile using the Raster to Shapefile tool. Specify a Workspace, a name for the new shapfile (in this example, $\mathrm{mtr} 30 \mathrm{mcm}$ ), and a raster dataset to convert (merge_2).

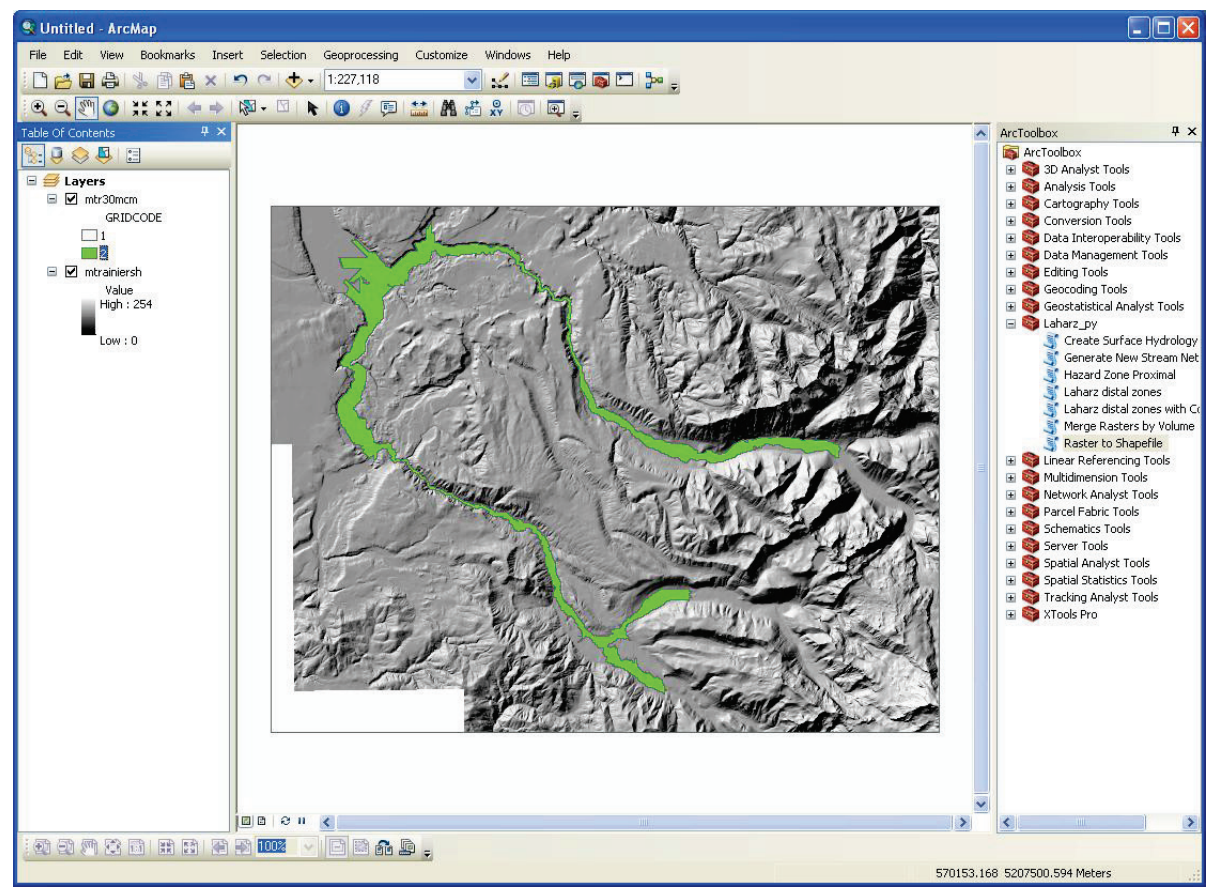

Figure 22. Screen capture showing $\mathrm{mtr} 30 \mathrm{mcm}$ shapefile. The shapefile is a polygon vector dataset colored according to the attribute GRIDCODE in the attribute table. 


\section{Creating Lahar Inundation Zones with Confidence Levels}

The Lahar Distal Zones with Conf Levels tool calculates the mean value for cross-sectional $(A)$ and planimetric $(B)$ areas as well as the probable range of possible cross-sectional $(A)$ and planimetric areas $(B)$ values with user-selected confidence limits. The user selects the Lahar Distal Zones with Conf Levels tool from the Laharz_py toolbox. From the tool menu, specify a Workspace, a filled DEM, a filename prefix for the drainage, a textfile that contains a single volume (numbers only, no commas or periods), a textfile containing $\mathrm{X}, \mathrm{Y}$ coordinates to begin the simulation, and a level of confidence from the pull-down menu in appropriate fields (fig. 23). Users can add the resulting raster (carbon_1) to the ArcMap project (fig. 24) that shows the results from the entered volume as well as results showing the range of possible $(A)$ and $(B)$ areas for the selected level of confidence.

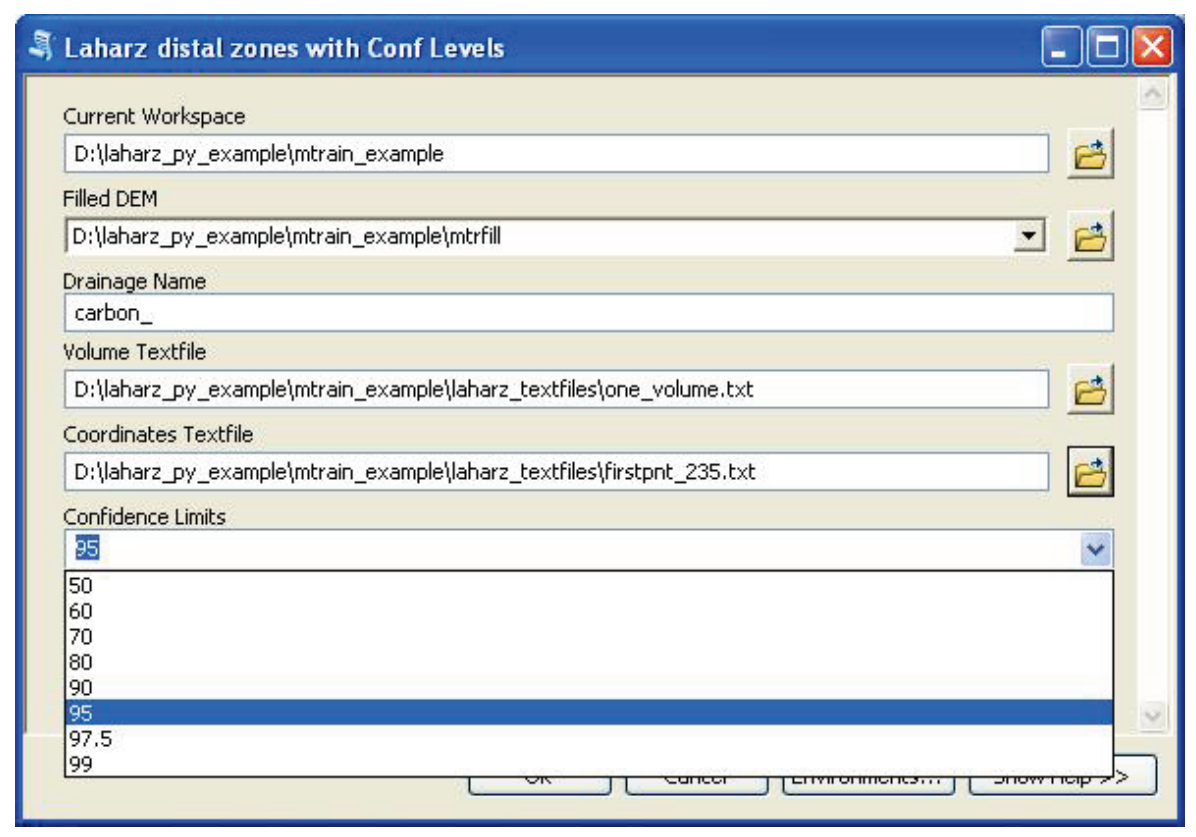

Figure 23. Screen capture showing interface to begin Laharz_py calculations with user-selected level of confidence. All fields must be filled. A user specifies a Workspace, a filled DEM, a filename prefix for the drainage (for this example, carbon_), a textfile that contains a single volume for a drainage (only numbers, no commas or periods, for this example a 1 million cubic meter volume) and a textfile containing $X, Y$ coordinates of initiation sites for the simulations (in this example, one coordinate in a file named firstpnt_235.txt). A pull-down menu offers, discrete levels of confidence ranging from 50- to 99-percent confidence (for this example, 95 should be selected). 


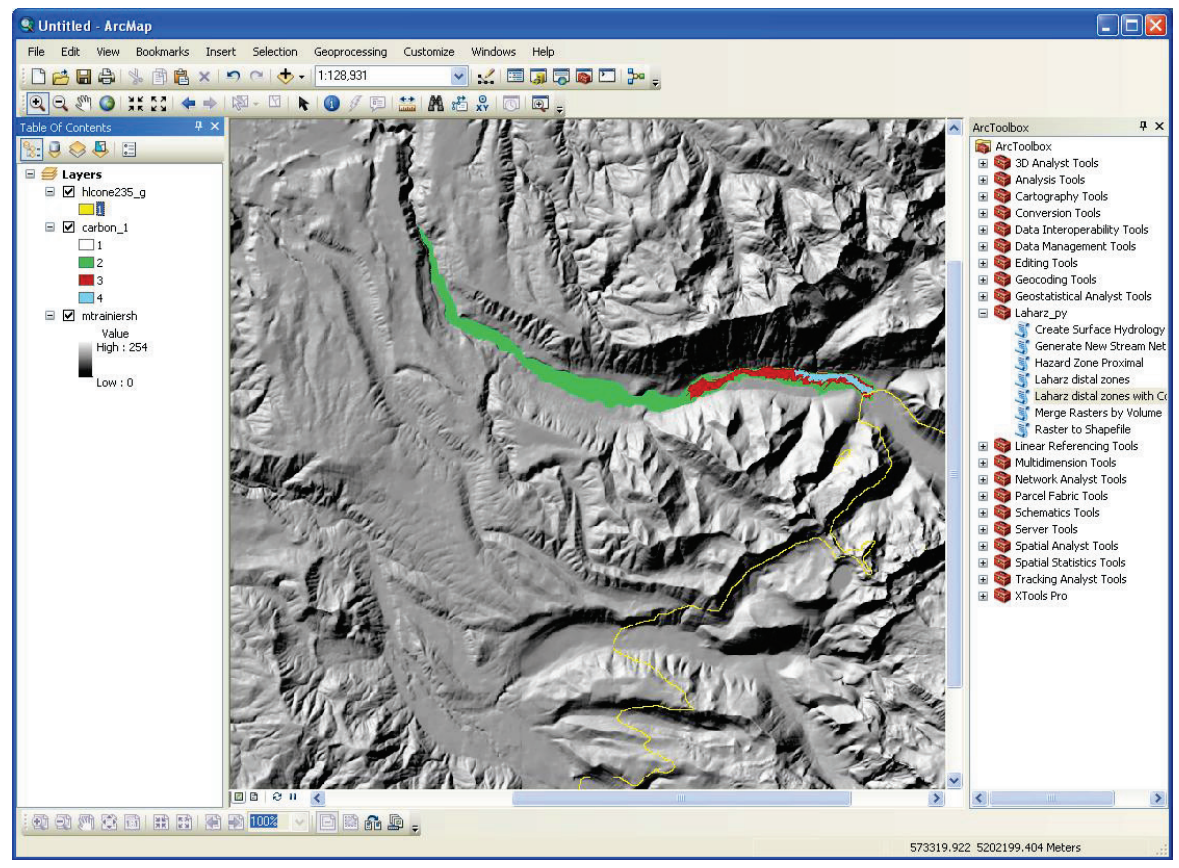

Figure 24. Screen capture showing carbon_1 raster results. The raster shows the volume entered (1 million cubic meters shown in red) as well as the results from volumes that correspond to the 95-percent confidence levels (green and light blue).

\section{Acknowledgments}

The author thanks Richard Iverson and James Vallance for their work, patience, and helpful discussions developing the original methodology. Using the levels of confidence, decision making arose from the observations in the field by Andrew Lockhart and led to a new method (appendix 1) being developed by Richard Iverson for incorporation into the software. Julie Griswold and Richard Iverson conducted the statistical work with non-volcanic debris flows and rock avalanches. This report was improved considerably by the careful and thoughtful reviews by Roland Viger and Rob Wardwell. Teaching a number of courses of Laharz with Julie Griswold, who offered thoughtful comments and good humor, as well as suggestions from many excellent students, have led to improvements of the software. 


\section{References Cited}

Beget, J.E., and Limke, A.J., 1988, Two-dimensional kinematic and rheological modeling of the 1912 pyroclastic flow, Katmai, Alaska: Bulletin of Volcanology, 50, p. 148-160.

Environmental Systems Research Institute, 1994, Cell-based modeling with GRID: Environmental Systems Research Institute Inc., Redlands, California, p. 309-327.

Environmental Systems Research Institute, 2012, ArcGIS: Environmental Systems Research Institute Inc., Redlands, California.

Griswold, J.P., and Iverson, R., 2008, Mobility statistics and automated hazard mapping for debris flows and rock avalanches: U.S. Geological Survey Scientific Investigations Report 2007-5276, 59 p.

Hayashi, J.N., and Self, S., 1992, A comparison of pyroclastic flow and debris avalanche mobility: Journal of Geophysical Research, v. 97, no. B6, p. 9063-9071.

Hsu, K.J., 1975, Catastrophic debris streams, sturzstroms, generated by rockfalls: Geological Society of America Bulletin, v. 86, p. 129-140.

Hann, C.T., 2002, Statistical methods in Hydrology, 2d edition: Iowa State University Press, Ames, Iowa, $378 \mathrm{p}$.

Iverson, R.M., Schilling, S.P., and Vallance, J.W., 1998, Objective delineation of areas at risk from inundation by lahars: Geological Society of America Bulletin, v. 110, no. 8, p. 972-984.

Jenson, S.K., and Domingue, J.O., 1988, Extracting topographic structure from digital elevation data for geographic information system analysis: Photogrammetric Engineering and Remote Sensing, v. 54, p. 1593-1600.

Mothes, P.A., Hall, M.L., and Janda, R.J., 1998, The enormous Chillos Valley Lahar-An ash-flowgenerated debris flow from Cotopaxi Volcano, Ecuador: Bulletin of Volcanology, v. 59, p. 233-244.

Newhall, C.G., Hendley II, J.W., and Stauffer, P.H., 1997, Lahars of Mount Pinatubo, Philippines: U.S. Geological Survey Fact Sheet 114-97, http://pubs.usgs.gov/fs/1997/fs114-97/.

Python Software Foundation, 2013, Python programming language-Official website: Python Software Foundation, accessed February 4, 2014, at http://python.org/

Schilling, S.P., 1998, LAHARZ - GIS Programs for automated mapping of lahar-inundation hazard zones: U.S. Geological Survey Open-File Report 98-638, 80 p.

Scott, K.M., Vallance, J.W., and Pringle, P.T., 1995, Sedimentology, behavior, and hazards of debris flows at Mount Rainier, Washington: U.S. Geological Survey Professional Paper 1547, 56 p.

Sheridan, M.F., 1979, Emplacement of pyroclastic flows-A review, in Chapin, C.E., and Elston, W.E., eds., Ash-flow tuffs: Geological Society of America Special Paper 180, p. 125-136.

Siebert, L., 1984, Large volcanic debris avalanches - Characteristics of source areas, deposits, and associated eruptions: Journal of Volcanology and Geothermal Research, 22, p. 163-197.

Vallance, J.W., 2000, Lahars, in Sigurdsson, H., Houghton, B.F., McNutt, S.R., Rhymer, H. and Stix, J., eds., Encyclopedia of Volcanoes: Academic Press, p. 601-616. 
This page left intentionally blank 


\section{Appendix A. Strategy for Computing and Portraying Confidence Limits in Inundation Predictions Using Laharz (R.M. Iverson, written commun., October 2007)}

The statistical procedures outlined here are amalgamated from several sources, primarily from Haan (2002). Steps 1-3 provide baseline statistical information necessary to calculate confidence limits for predictions. Steps 4-6 depend on user-selected flow volumes and confidence intervals.

1. If new data are added to the set reported by Iverson and others (1998), redo the linear regression and analysis of variance to obtain prediction equations of the form:

$$
\log A=\log C+\frac{2}{3} \log V
$$

The implication here is that data for $A$ and $V$ are log-transformed prior to doing the regression. To simplify ensuing equations, it is useful to rewrite (1) in the form:

$$
y=c+\frac{2}{3} x
$$

where $y=\log A, c=\log C$ and $x=\log V$.

2. The next step is to find some basic statistical quantities. The number of data pairs used in the regression is $n$. The degrees of freedom in the regression model, which has only one adjustable parameter, $c$, is therefore $n-1$. The residual sum of squares associated with the regression, calculated as described in the appendix of Iverson and others (1998), describes the sum of deviations of observed $y$ values from those predicted by the regression line (2). Here the residual sum of squares is denoted by $\Sigma e^{2}$. The standard error of the regression model is then defined as:

$$
s=\sqrt{\frac{\sum e^{2}}{n-1}}
$$

This is identical to the definition in the appendix of Iverson and others (1998).

3. To calculate prediction error, the first new quantity that needs to be defined is the standard error of the predicted mean response $(y)$ for any fixed value of $x$. (This quantity is called the standard error of the mean, $S E_{m}$.) Any arbitrary fixed value of $x$ is denoted by $x^{*}$, and our collection of $n$ observed values of $x$ is denoted by $x_{n}$. Mathematically, the standard error of the mean is defined as:

$$
S E_{m}=s \times \sqrt{\frac{1}{n}+\frac{\left(x^{*}-\bar{x}\right)^{2}}{\sum\left(x_{n}-\bar{x}\right)^{2}}}
$$

Importantly, note that this standard error varies as a function of $x^{*}$, which reflects the fact that there is more confidence in the regression line near the mean value of $x$ (that is, $\bar{x}$ ) than for larger or smaller values of $x$. (This variability is what gives rise to the curvature of the confidence limits for regression lines.) The key thing about $S E_{m}$, from an operational standpoint, is that it is a function of $x^{*}$. Therefore, $S E_{m}$ must be calculated for the full range of $x$ values that might be used in Laharz. This calculation is probably best done by systematically incrementing $x$ by some small fraction (for example, 0.001 ) of its full range and calculating $S E_{m}$ at each point. 
However, it is necessary to calculate or estimate (through interpolation) $S E_{m}$ for all values of $x$ (that is, $\log V$ ) that are to be used in making Laharz predictions. Thus, it is probably best to fit a curve to the function $S E_{m}(x)$ so that interpolation can be very precise.

4. To calculate the prediction error, the next new quantity needed is the standard error of prediction, $S E_{p}$. This quantity is defined mathematically as:

$$
S E_{p}=\sqrt{S E_{m}{ }^{2}+s^{2}}
$$

This prediction error includes the effects of uncertainty represented by the standard error of the mean $y$ (for any $x^{*}$ ) given by the calibrated regression equation as well as the error in estimation $y$ for a new (user-selected) value of $x$, which is given by $s$. Note that the standard error of prediction always exceeds the standard error of regression.

5. The final new quantity needed in order to calculate prediction error is the user-selected level of confidence. The confidence interval about the regression line is then evaluated using the statistical $t$ distribution, which assumes that true $y$ values at any $x$ are normally distributed about the mean $y$ value estimated by regression (with standard error $s$ ). For example, if we want a 90 percent confidence interval, we need the value of $t_{0.1, n-1}$, where the subscript 0.1 is the value of $\alpha=1-0.9$ for a two-tailed $t$ distribution, and the subscript $n-1$ is the degrees of freedom of the regression model. (Note that statistics books can be a bit confusing in this respect, because they commonly use one-tailed rather than two-tailed $t$ distributions. If we were using a one-tailed $t$ distribution, we would use $\alpha=1-0.95$ to calculate the 90 percent confidence limits.) Computation of $t$ distributions from first principles is complicated, as it involves evaluation of gamma functions. So instead it is more efficient to use a look-up table to find relevant values of $t$. Such a look-up table is generated quite easily using the statistical functions in $\operatorname{Excel}^{\mathbb{B}}$, for example.

6. Once the confidence level is chosen and the appropriate value of $t$ is selected from the look-up table, the confidence intervals for prediction (denoted by $y \pm$ ) are given by:

$$
y \pm=t_{\alpha, n-1} \times S E_{p}
$$

This equation provides the value of $y$ to be added or subtracted from the value predicted by regression in order to represent confidence limits for the $1-\alpha$ level. Finally, this new $y$ value (that is $A$ or $B$ value inLaharz) is used to map inundation zones that portray the $1-\alpha$ confidence limits. 


\section{Appendix B. Code}

\section{surface_hydro.py}

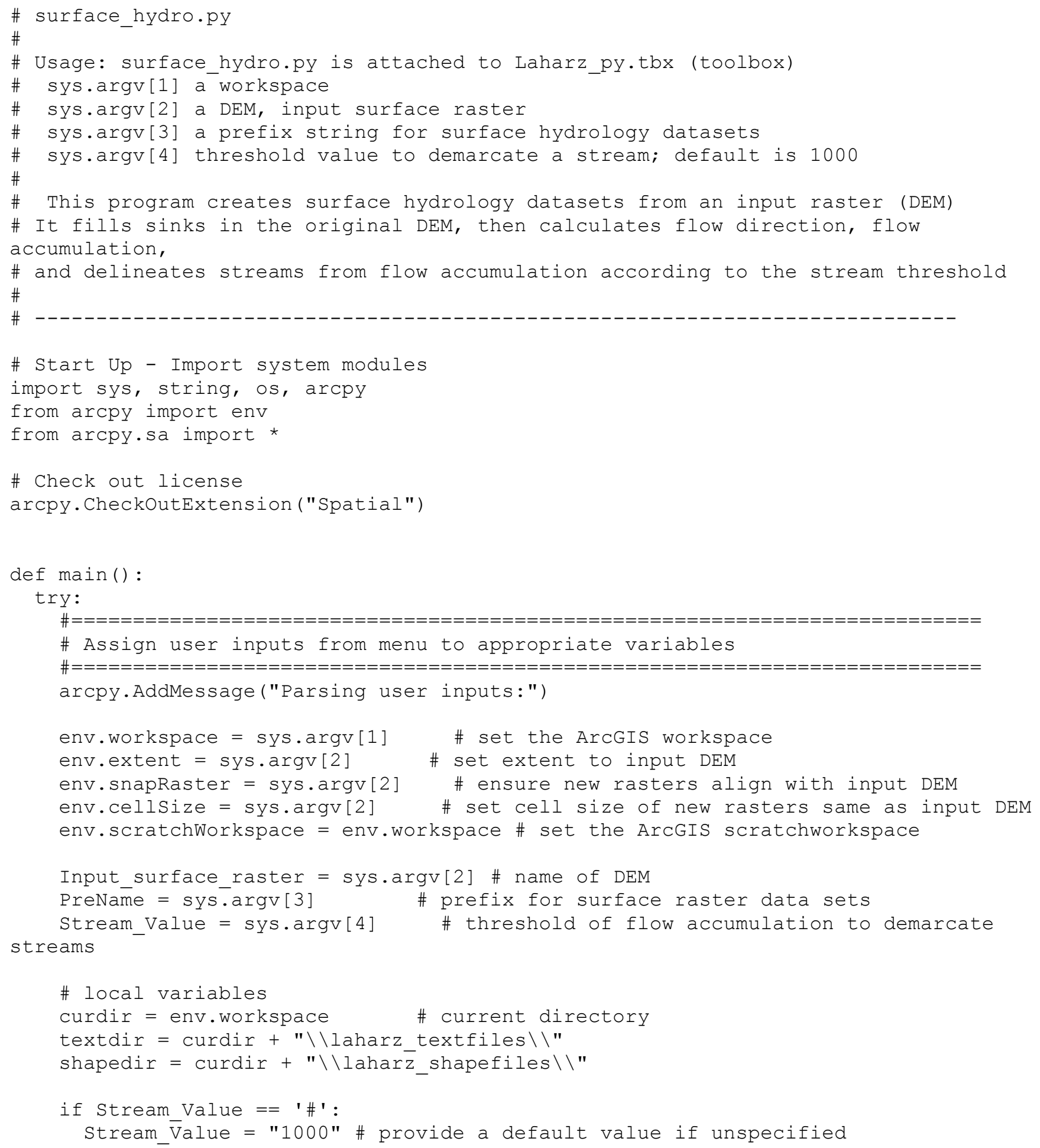




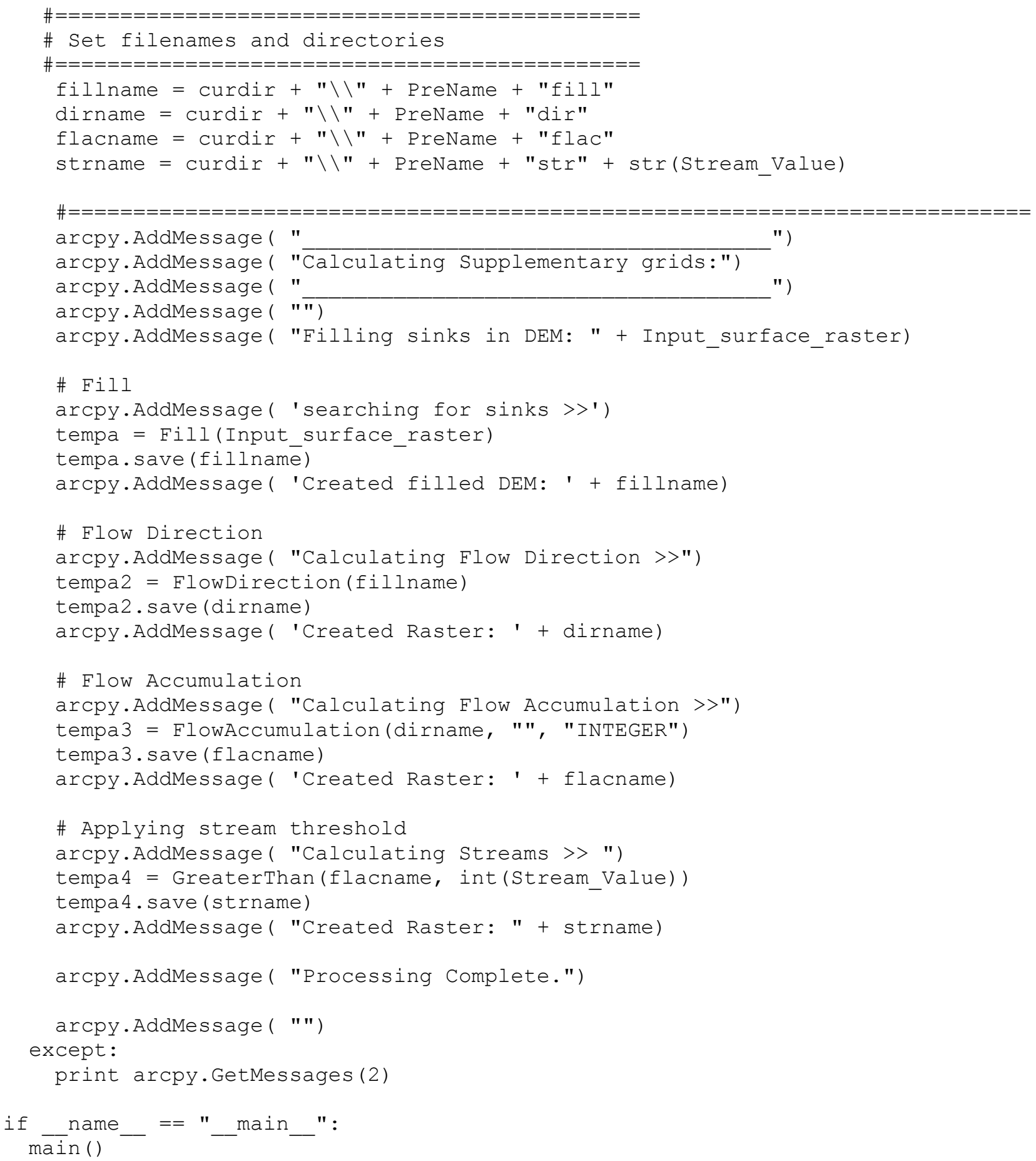




\section{new stream network.py}

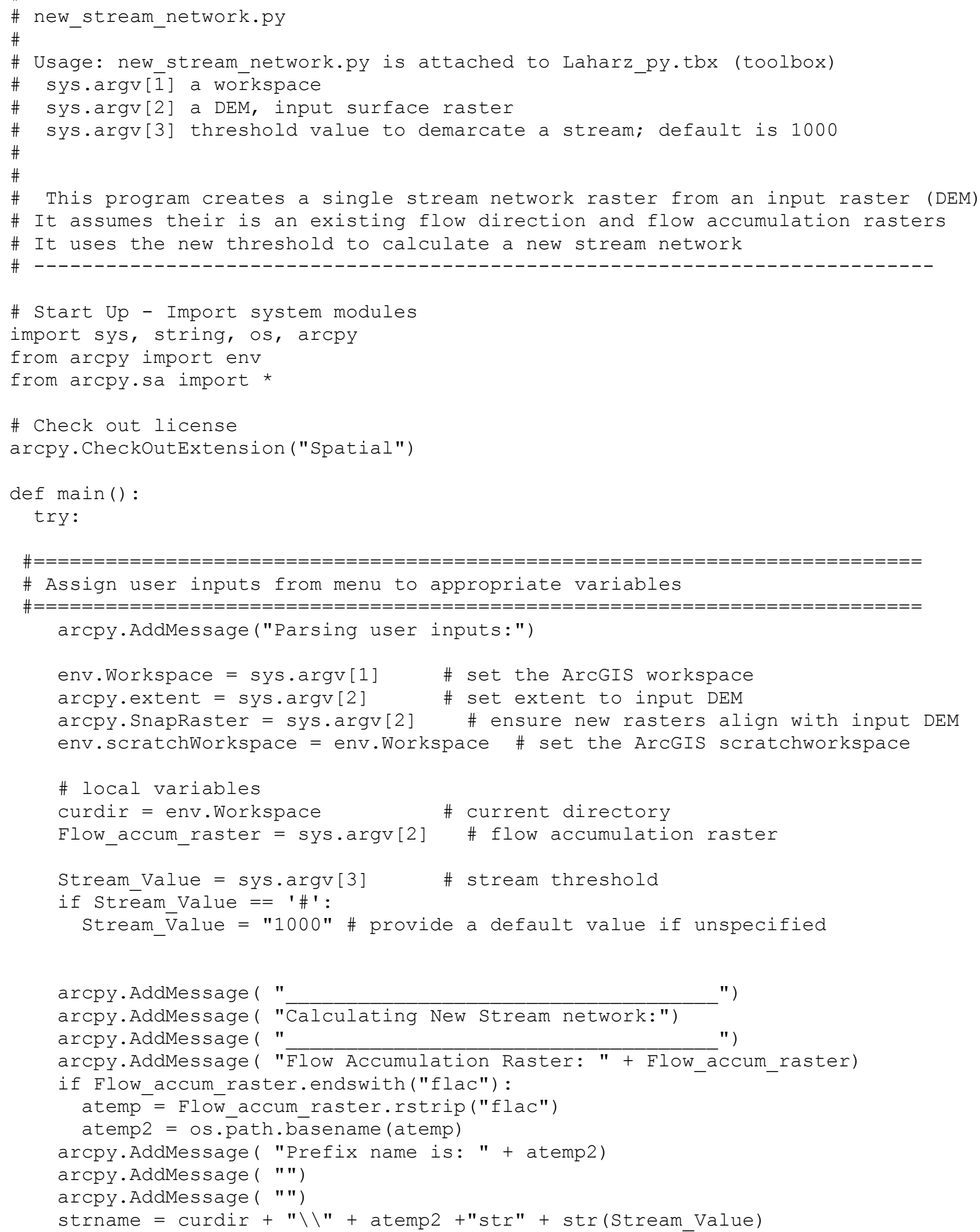




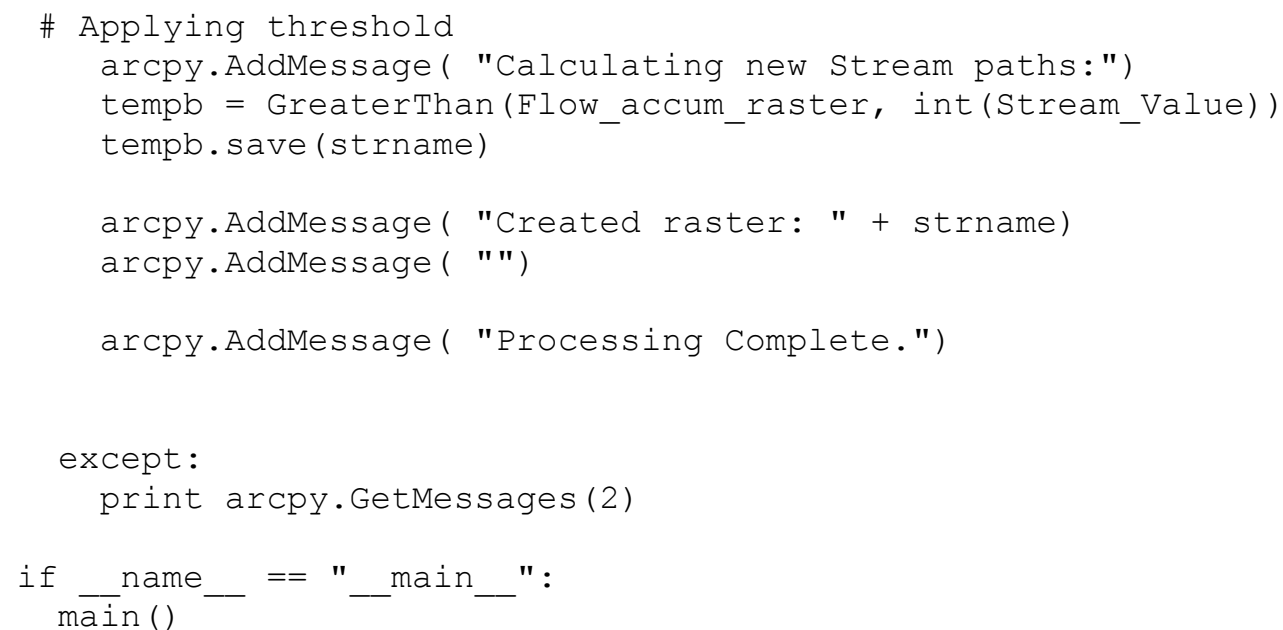


proximal_zone.py

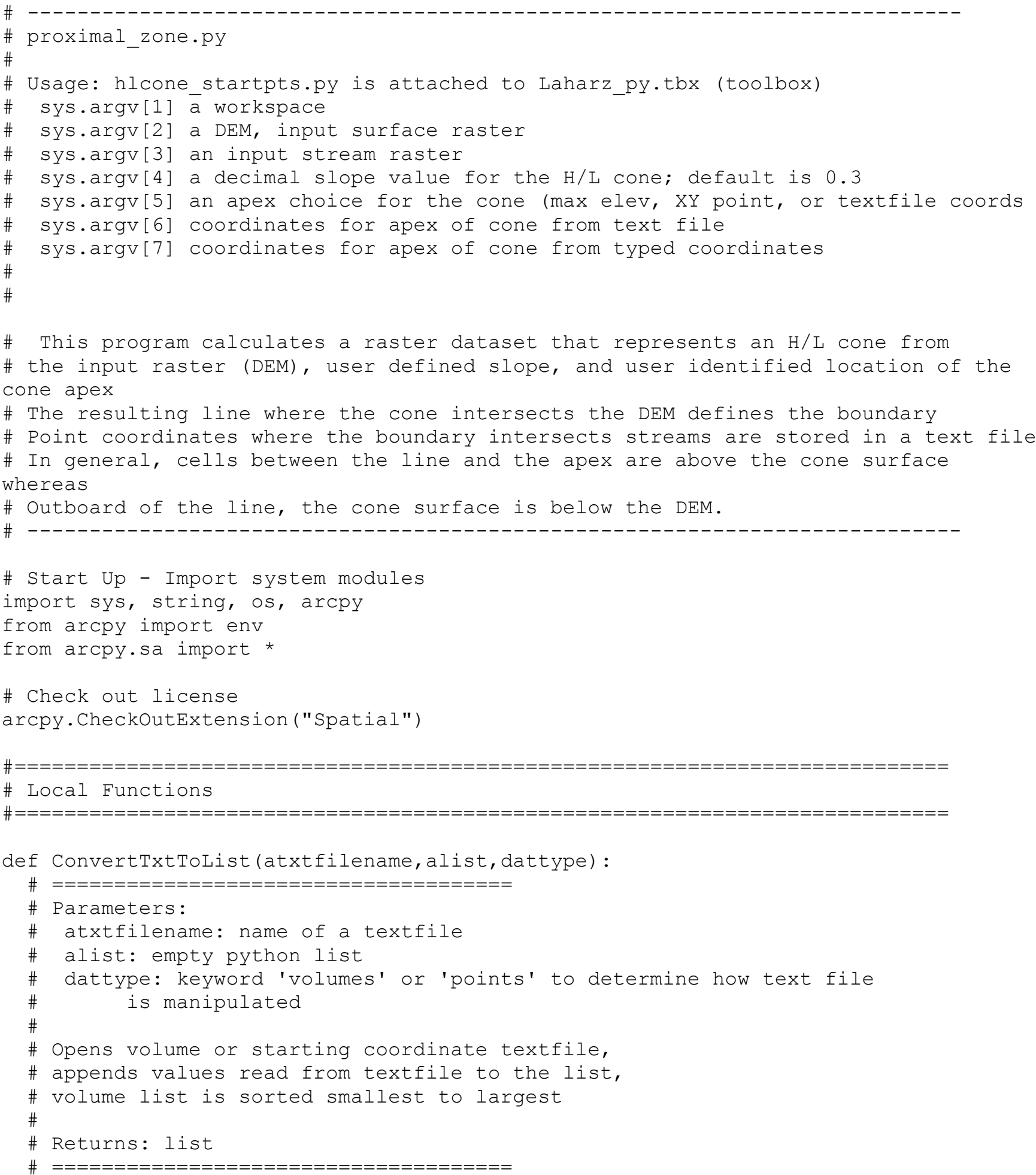




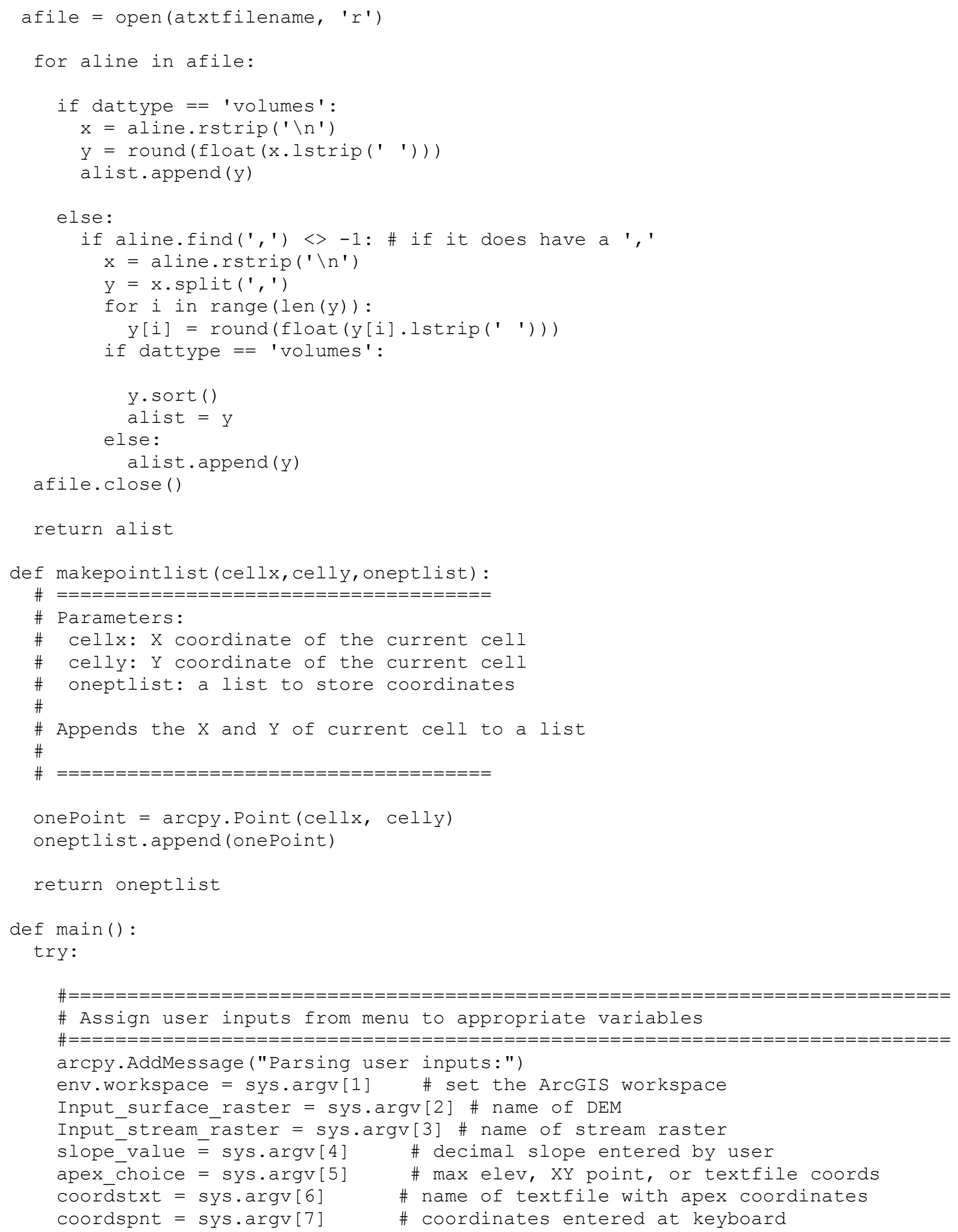




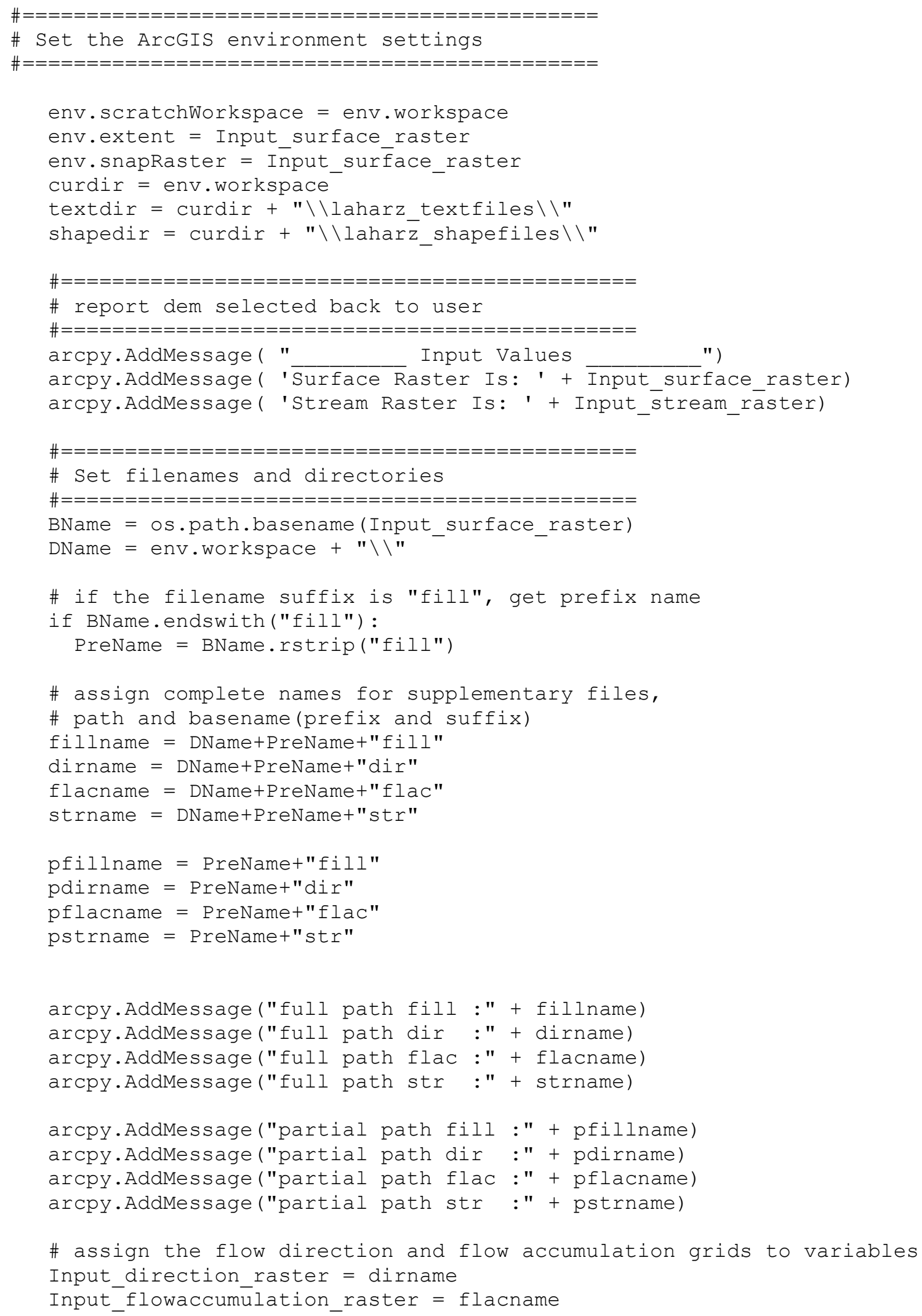


\# use slope value as part of grid and shapefile name

$y=$ slope_value.split('.')

slopename $=\operatorname{str}(y[1])$

hlconename = "hlcone"+slopename+" g"

hlshapename = shapedir + "startpts_"+slopename+".shp"

hlgridname = "stpts_g"+slopename

\# $==============================$

\# set file name for two textfiles storing $X, Y$ coordinates

\# one storing an arbitrary single starting point

\# the other file storing all stream/hl cone intersections as starting points

\# $============================$

txfileuno = textdir + "firstpnt "+slopename+".txt"

txfile = textdir + "startpnts "Flopename+".txt"

arcpy.AddMessage ( " ")

arcpy.AddMessage ( "

arcpy.AddMessage ( "Calculating H/L Cone: ")

arcpy.AddMessage ( "

arcpy.AddMessage ( " ")

arcpy.AddMessage ( "Apex Choice is :" + apex_choice)

arcpy.AddMessage ( " ")

\# variables for above and below the cone

cone gt elev = "0"

cone_lt_elev = "1"

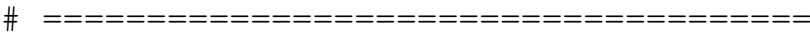

\# Apex choice is either Maximum elevation,

\# textéfile elevation, or manually entered coordinate

\# as apex of an $\mathrm{H} / \mathrm{L}$ cone

\# $=============================$

\# if maximum elevation, find it and store elevation, make const_g and cond_g

if apex_choice == "Maximum_Elevation":

arcpy.AddMessage ("Searching for Maximum Elevation:")

arcpy.AddMessage ( " ")

currhipnt = arcpy.GetRasterProperties_management(Input_surface_raster, "MAXIMUM")

arcpy.AddMessage ("Maximum Elevation Found: " + str(currhipnt))

arcpy.AddMessage ( " ")

arcpy.AddMessage("Creating grid with constant values of MAXIMUM Elevation:")

arcpy.AddMessage ( " ")

const_g = CreateConstantRaster(currhipnt, "FLOAT", Input_surface_raster,

Input_surface_raster)

arcpy.AddMessage( "Creating grid with single data value at highest

elevation:")

arcpy.AddMessage ( " ")

cond_g $=$ Con (Raster (Input_surface_raster) $==$ const_g, const_g) 


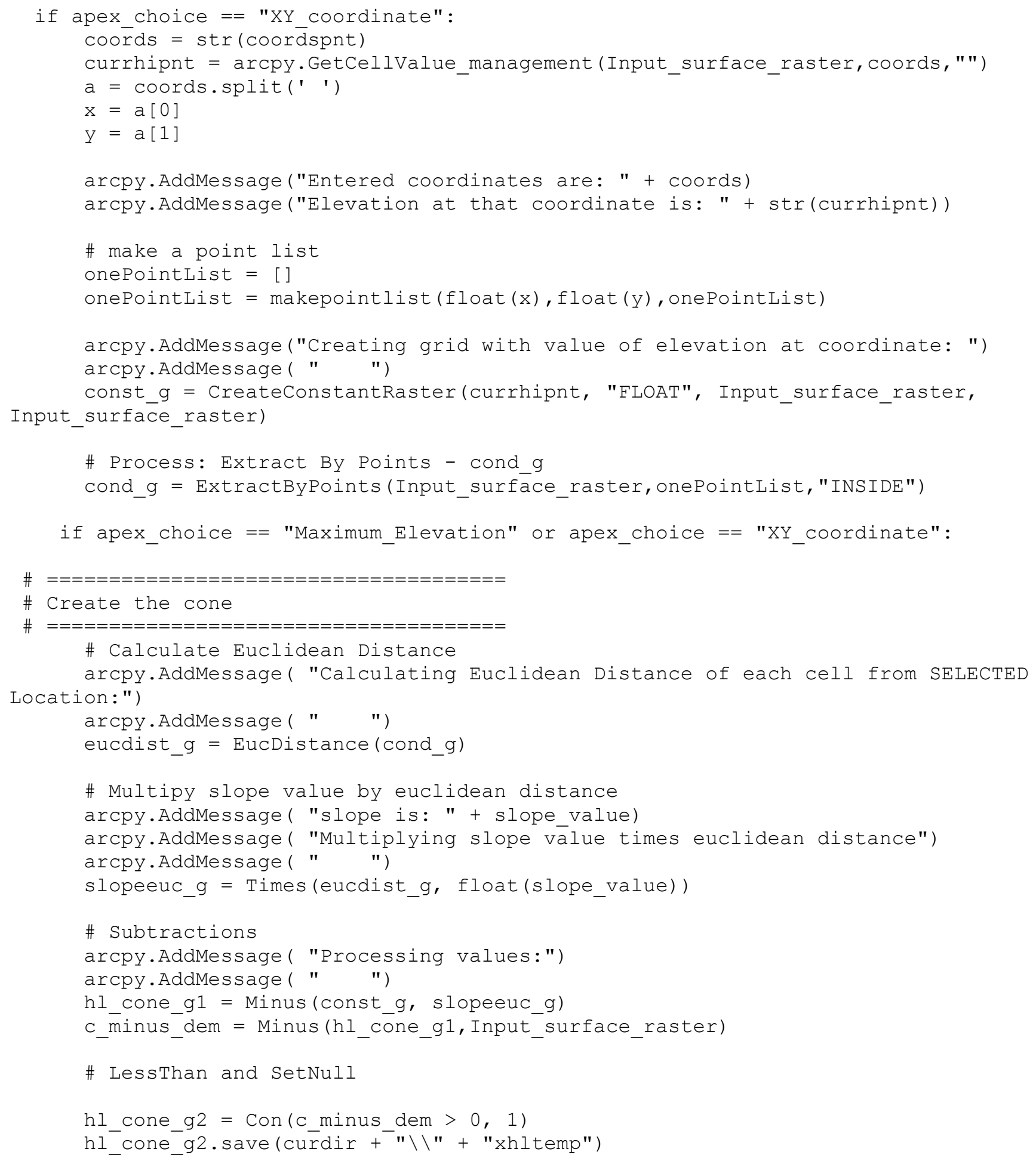




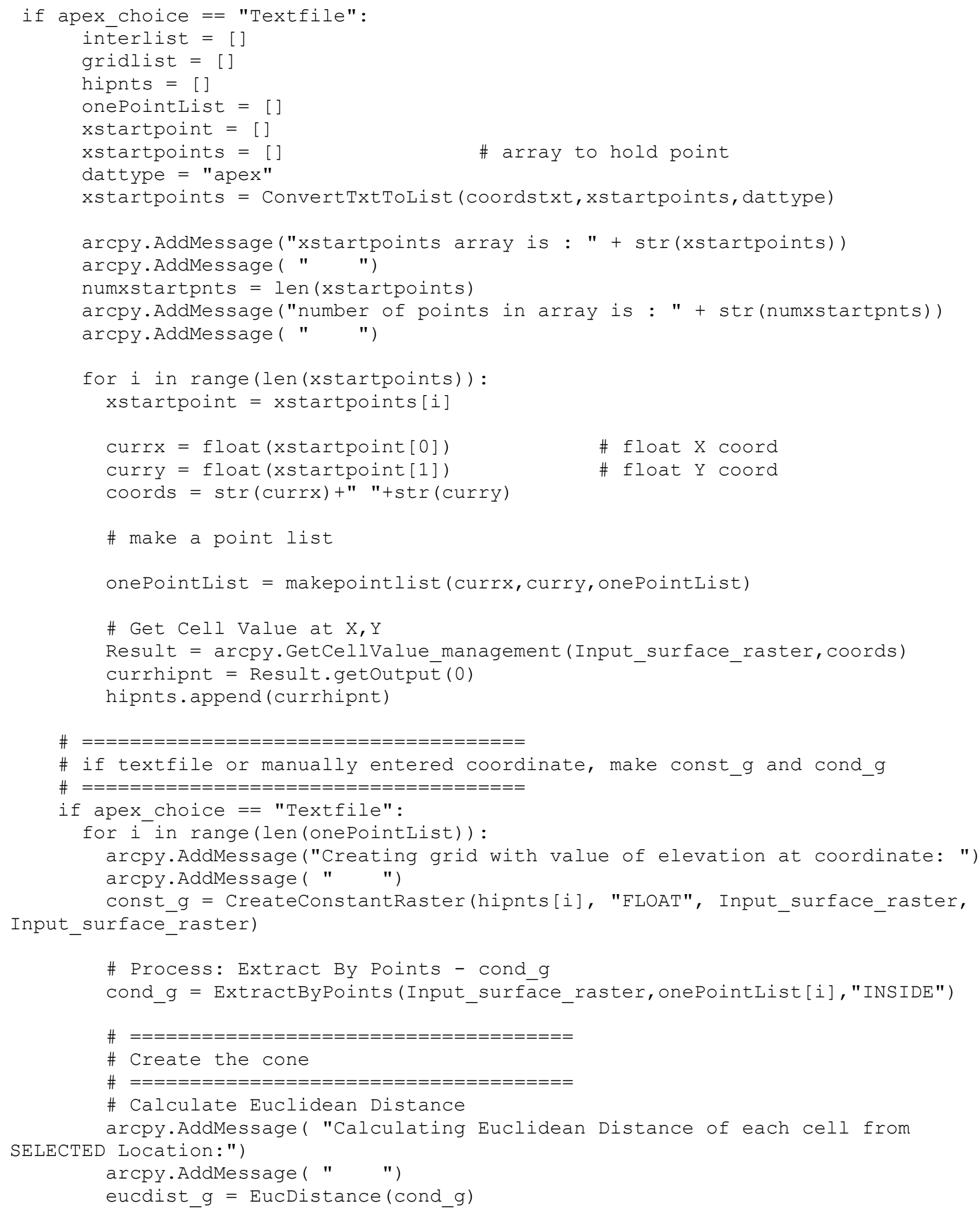




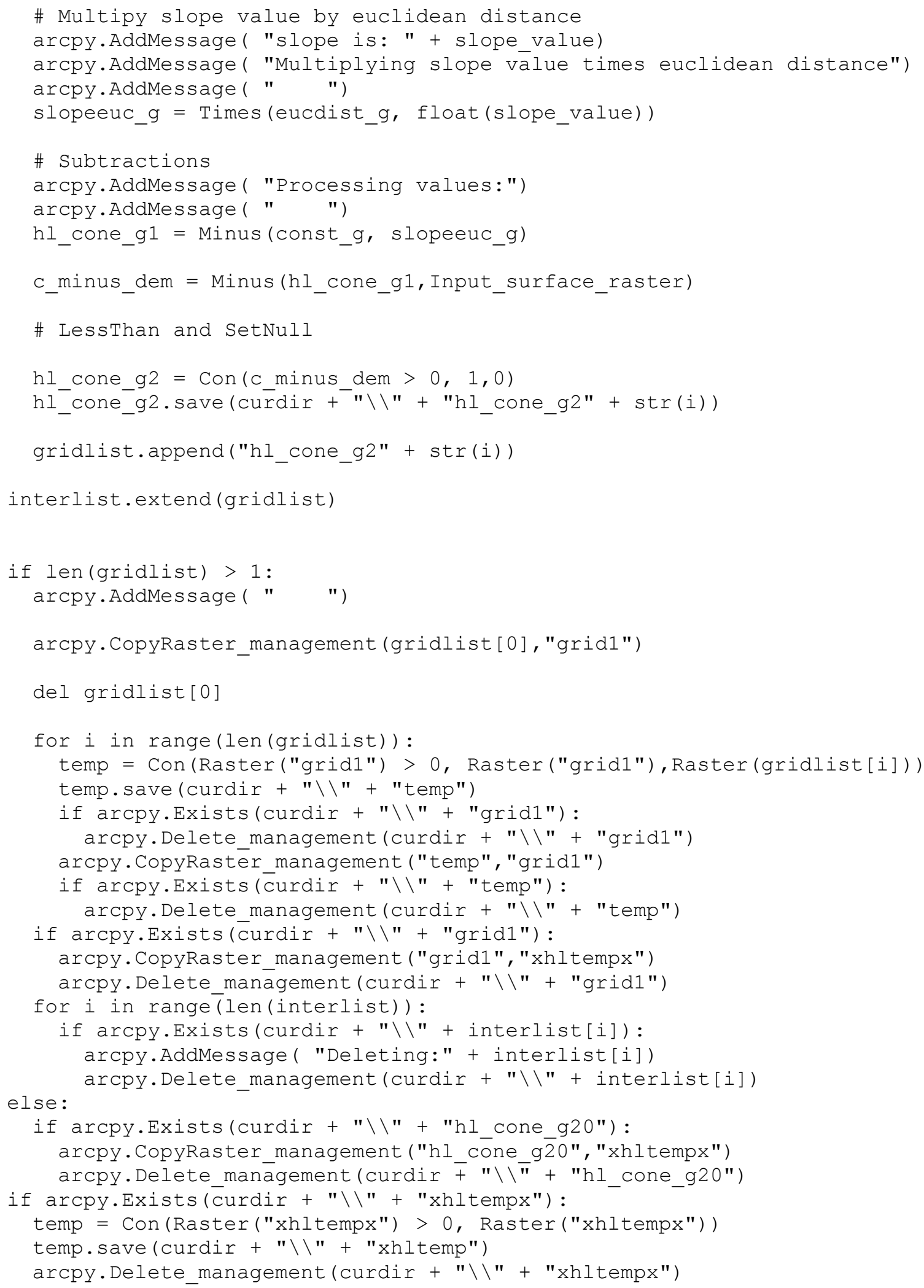




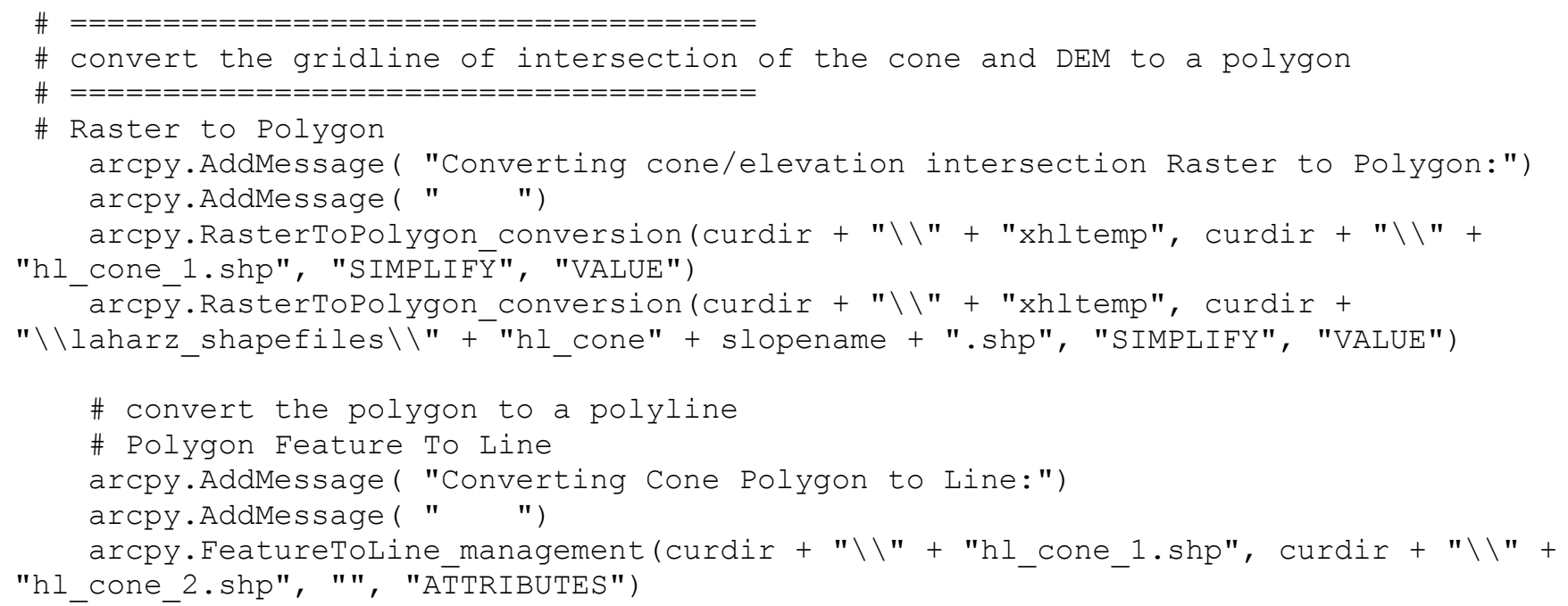




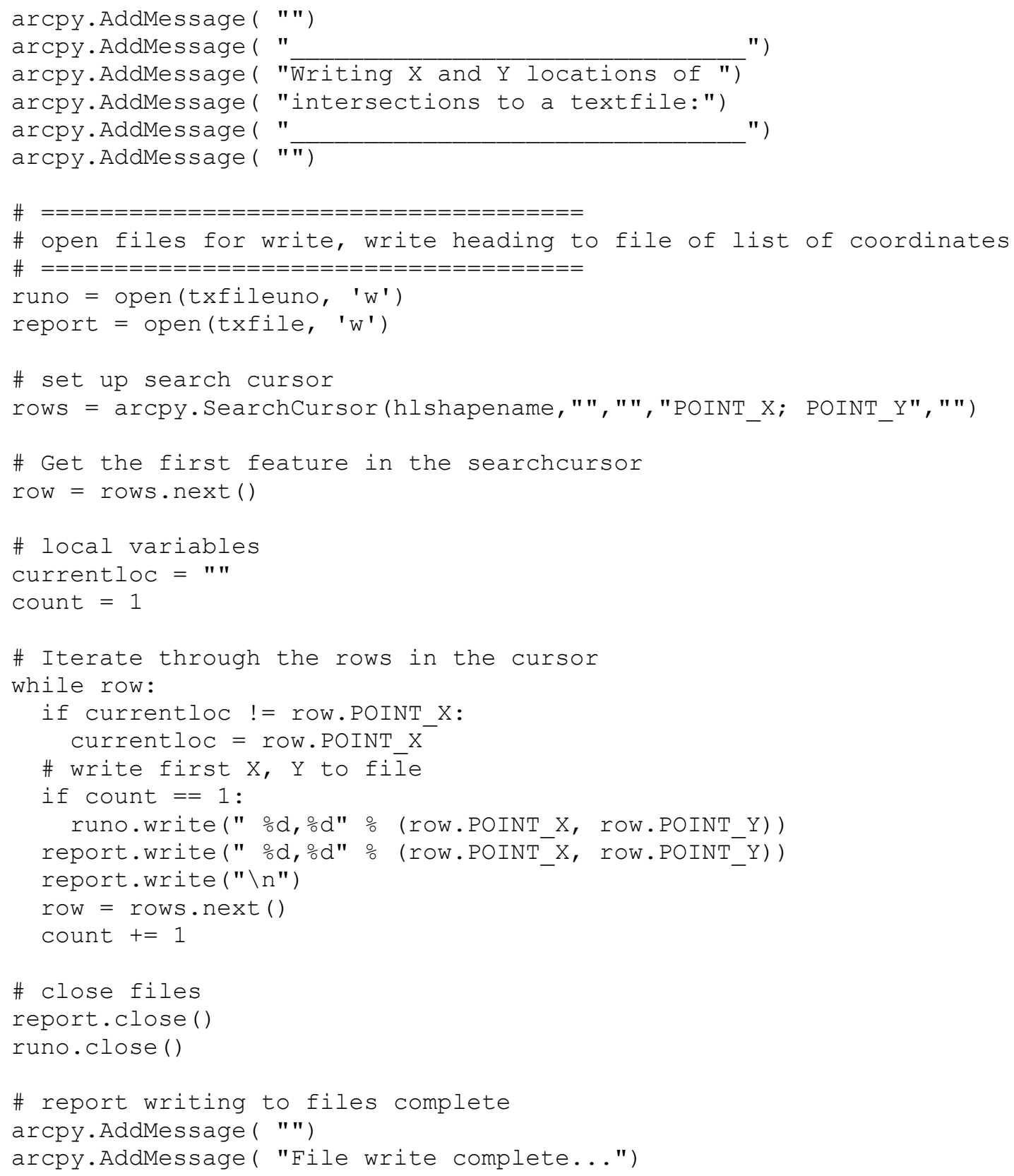




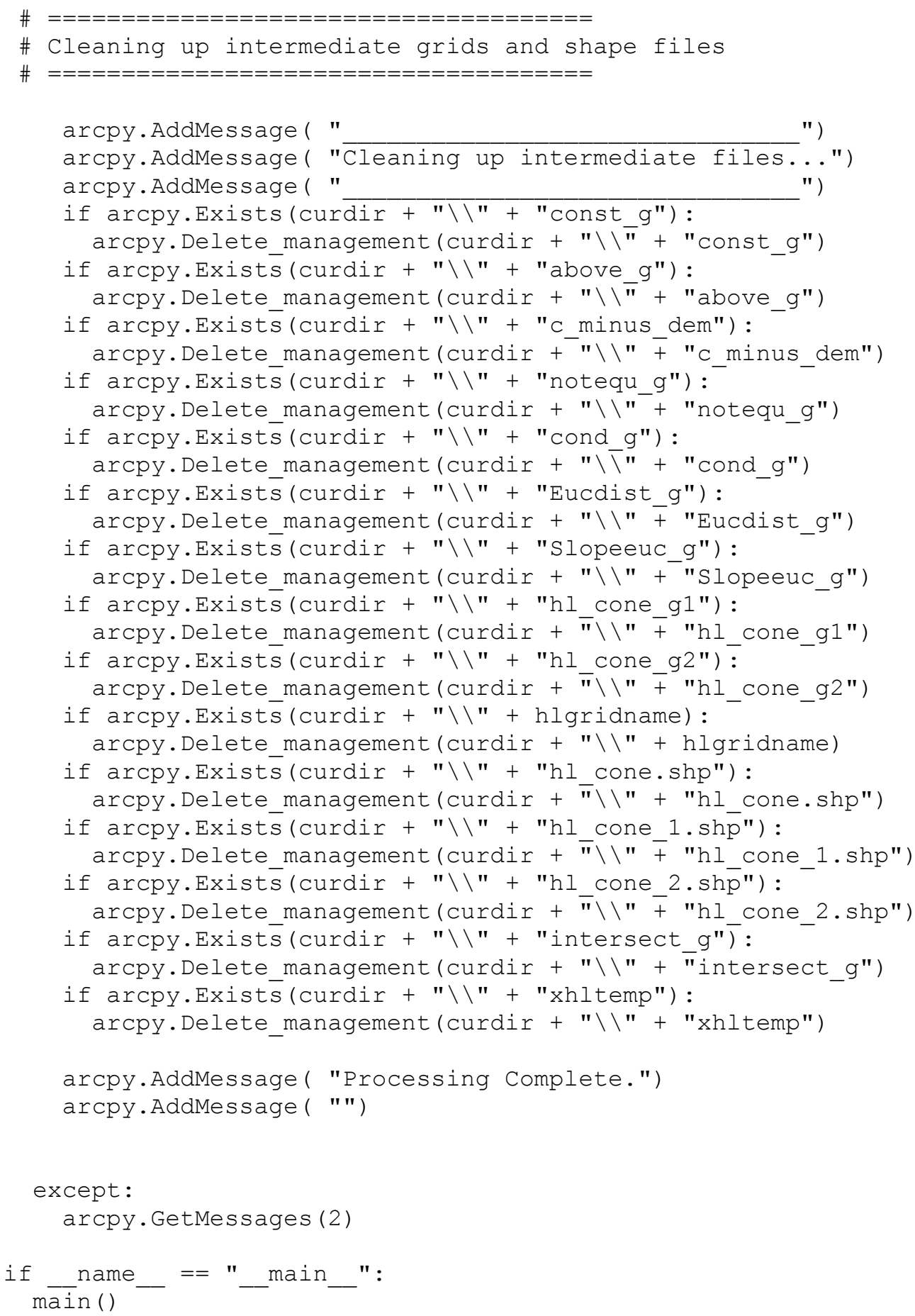




\section{distal_inundation.py}

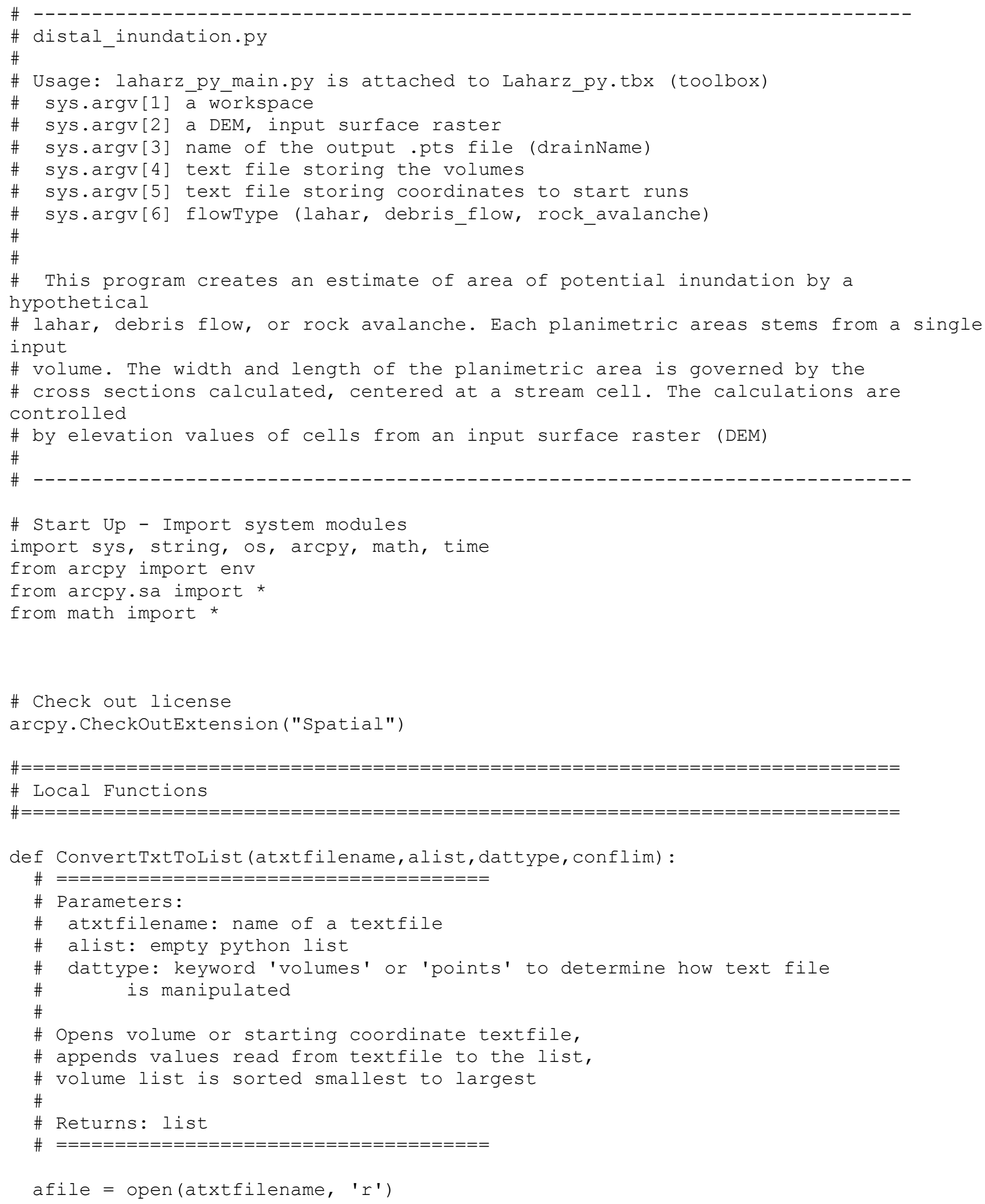




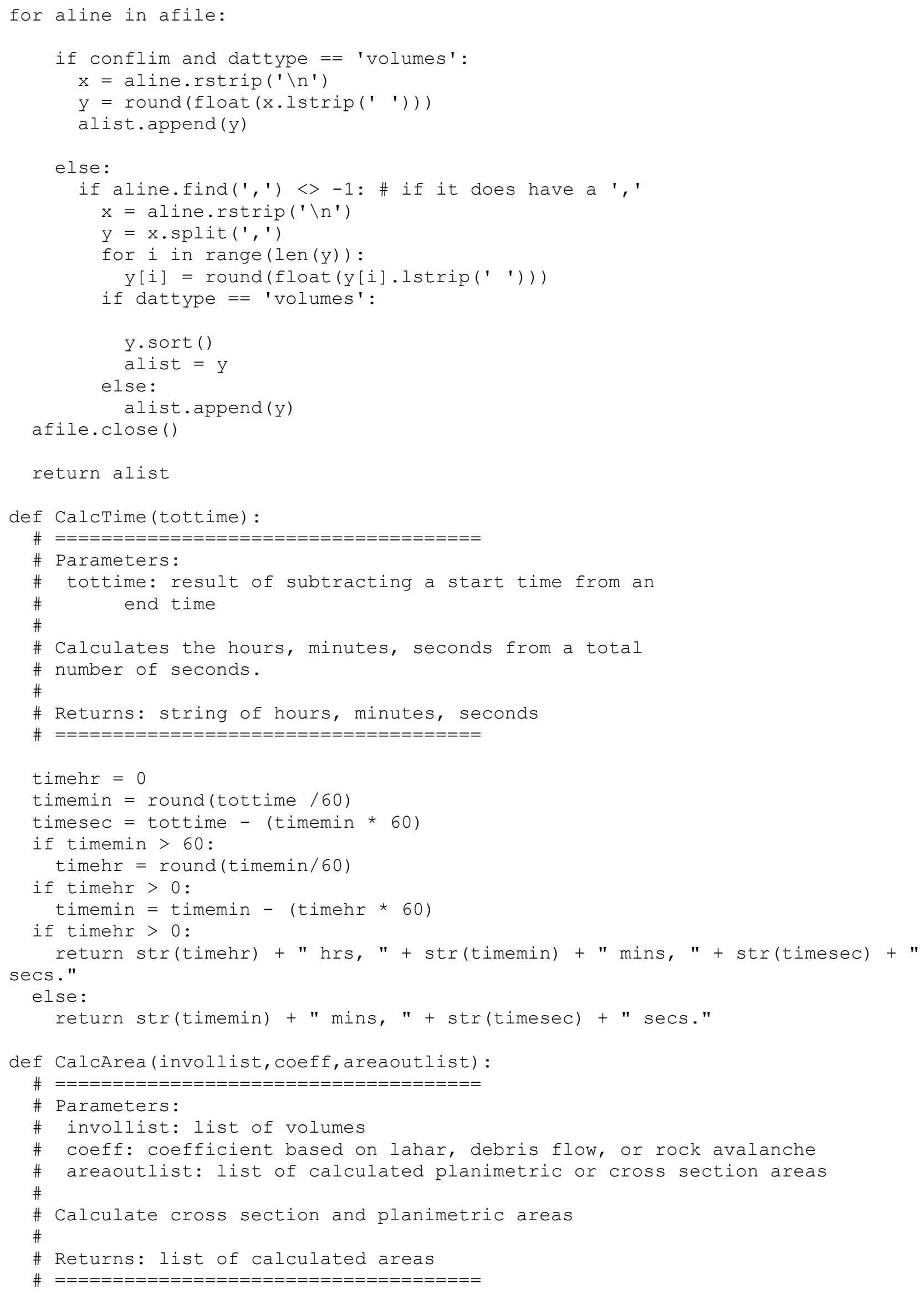




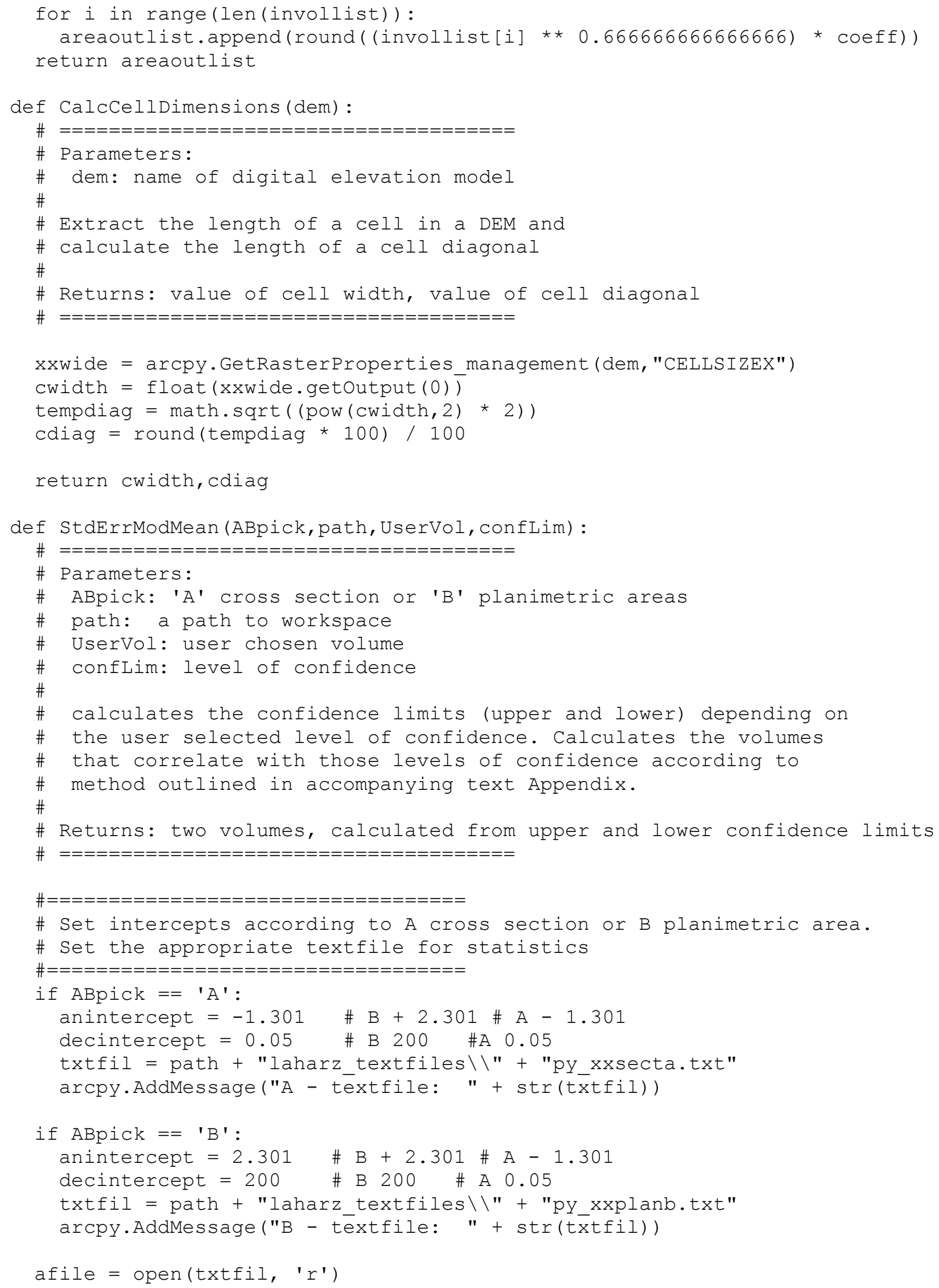




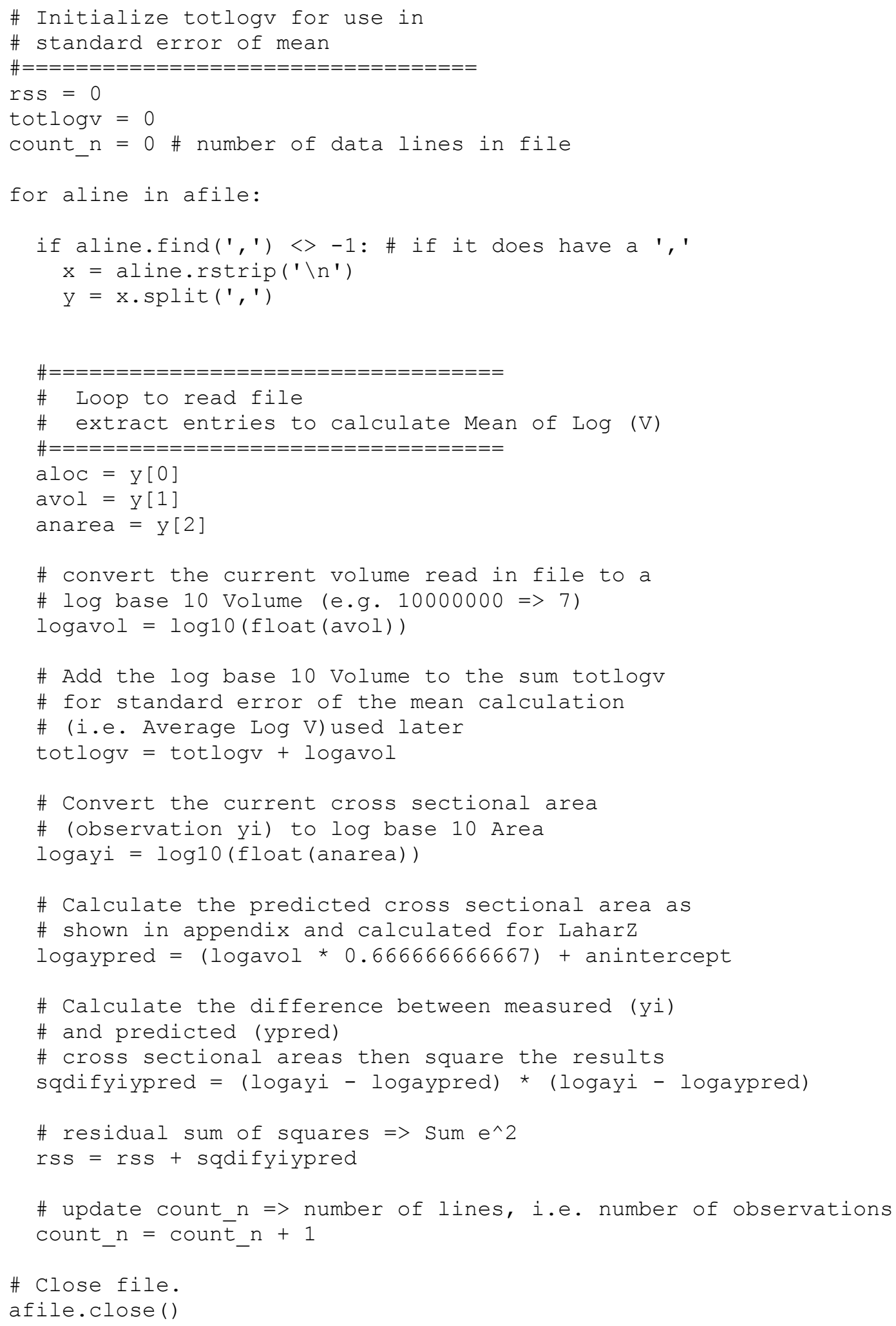




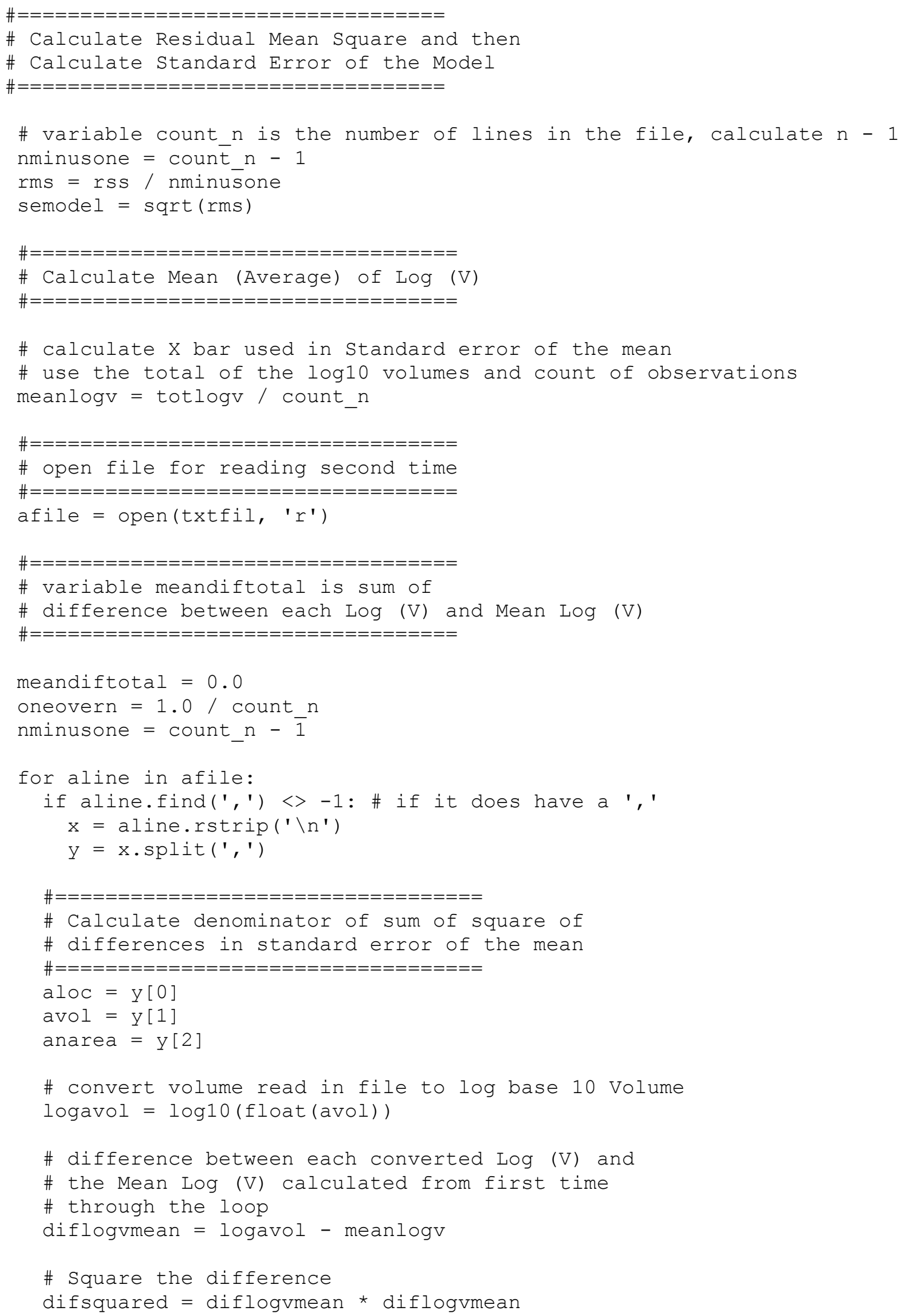




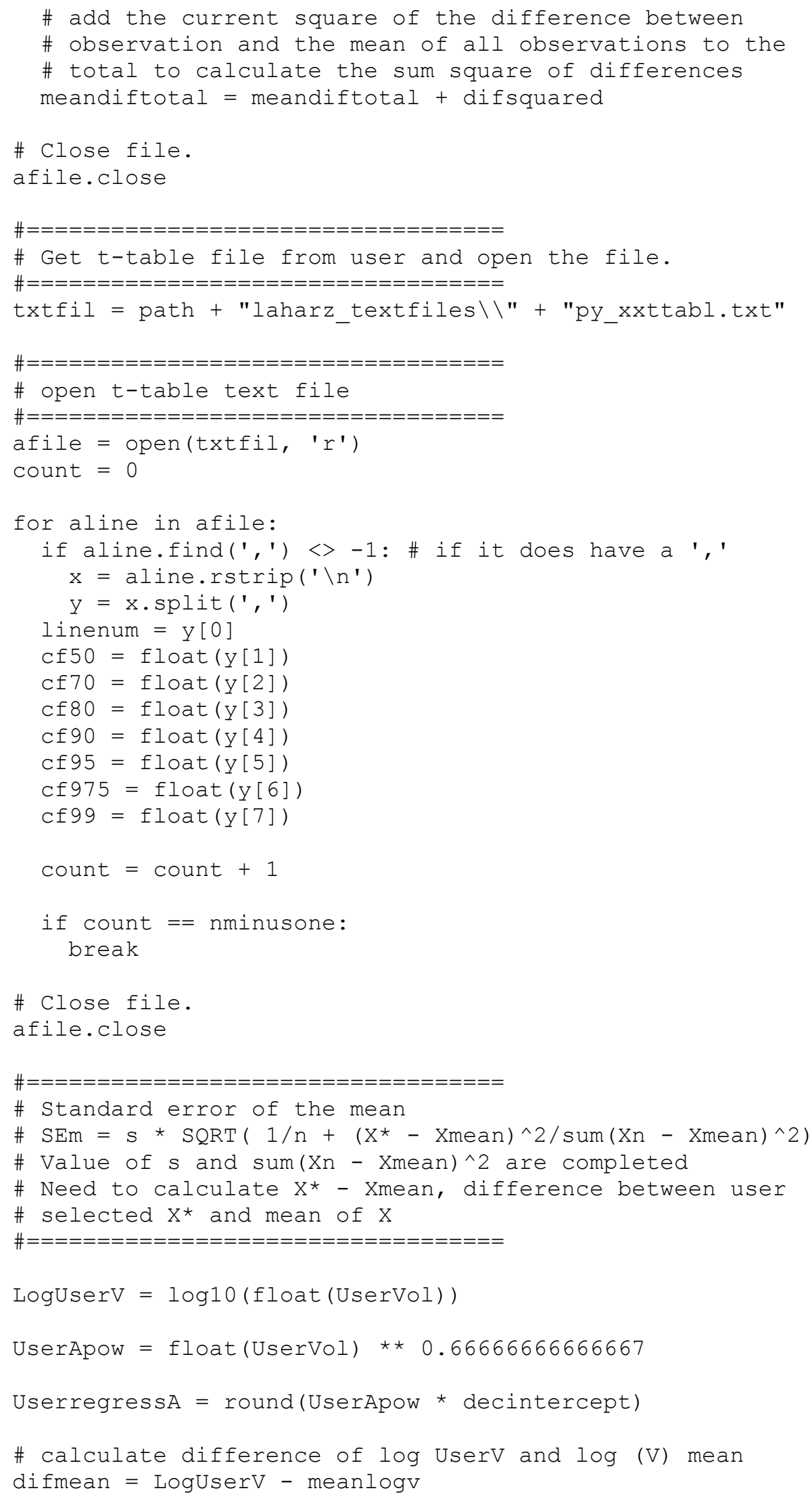




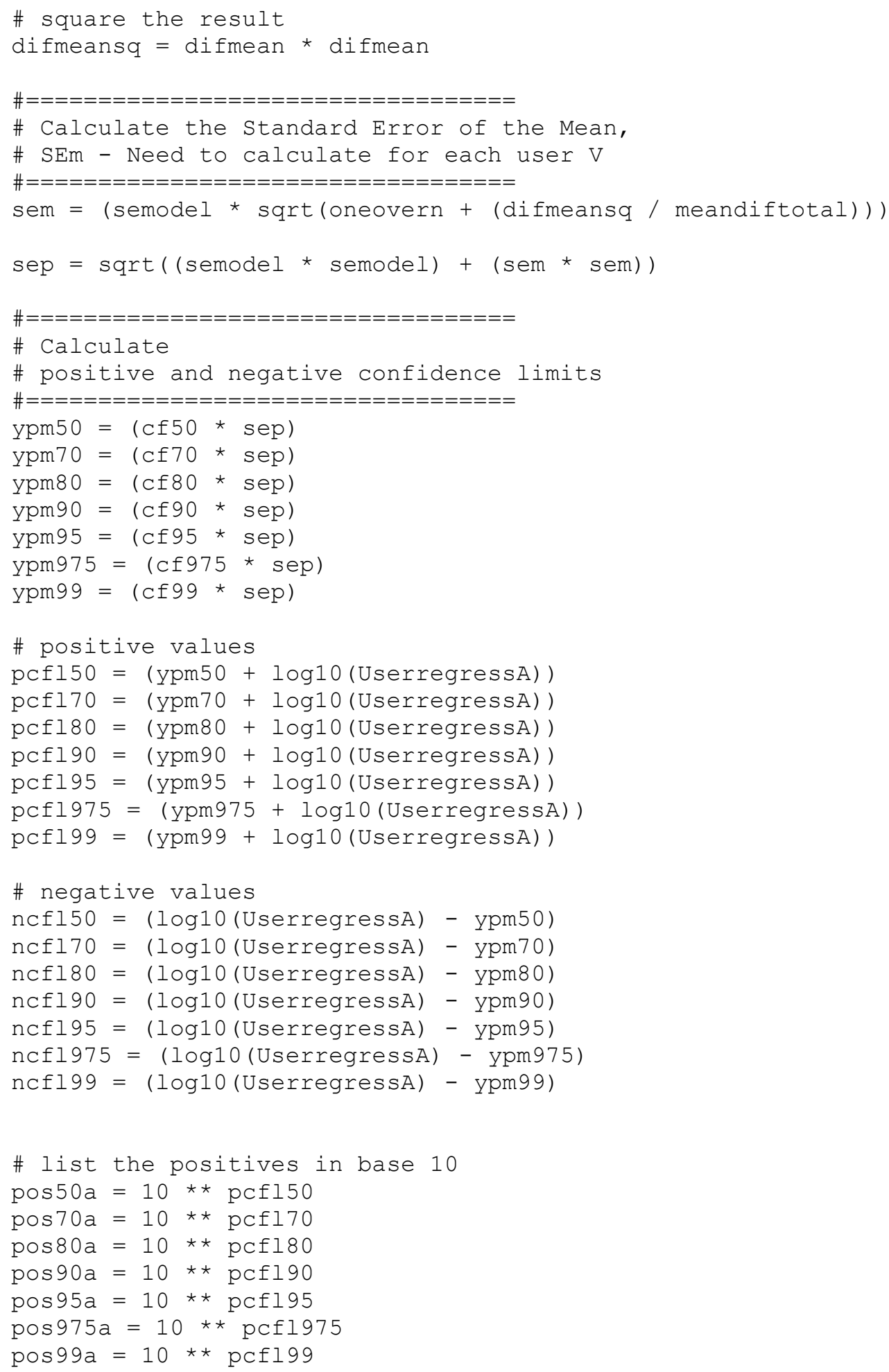


\# list the negatives in base 10

neg $50 a=10 * \star$ ncfl 50

neg70a $=10 \star \star \operatorname{ncfl} 70$

neg $80 a=10 * \star \operatorname{ncfl} 80$

neg90a $=10 * \star \operatorname{ncfl} 90$

neg $95 a=10 * *$ ncfl95

neg975a $=10 * \star \operatorname{ncfl} 975$

neg99a $=10 \star \star \operatorname{ncfl} 99$

\section{if $\mathrm{ABpick}==$ ' $\mathrm{A}$ ':}

arcpy.AddMessage("Cross Section Areas base 10")

if confLim == '50':

arcpy. AddMessage ("Upper Area " + confLim + " = " + str(pos50a))

arcpy.AddMessage ("Lower Area " + confLim + " = " + str(neg50a))

areaAup $=$ pos50a

areaAdn = neg50a

if confLim $==$ '70':

arcpy.AddMessage ("Upper Area " + confLim + " = + str(pos70a))

arcpy. AddMessage ("Lower Area " + confLim + " = " + str(neg70a))

areaAup $=$ pos70a

areaAdn $=$ neg70a

if $\operatorname{confLim}==$ '80':

arcpy.AddMessage ("Upper Area " + confLim + " = " str(pos80a))

arcpy. AddMessage ("Lower Area " + confLim + " = " + str(neg80a))

areaAup $=$ pos $80 a$

areaAdn $=$ neg $80 \mathrm{a}$

if confLim == '90':

arcpy.AddMessage ("Upper Area " + confLim + " = + str(pos90a))

arcpy.AddMessage ("Lower Area " + confLim + " = " str(neg90a))

areaAup $=$ pos90a

areaAdn = neg90a

if confLim $==$ ' 95 ':

arcpy.AddMessage ("Upper Area " + confLim + " = " + str(pos95a))

arcpy.AddMessage ("Lower Area " + confLim + " = " str(neg95a))

areaAup $=$ pos $95 a$

areaAdn $=$ neg95a

if confLim $==$ ' $975^{\prime}$ :

arcpy.AddMessage ("Upper Area " + confLim + " = " + str(pos975a))

arcpy.AddMessage("Lower Area " + confLim + " = " + str(neg975a))

areaAup $=$ pos975a

areaAdn = neg975a

if confLim == '99':

arcpy.AddMessage ("Upper Area " + confLim + " = " str(pos99a))

arcpy.AddMessage ("Lower Area " + confLim + " = " str(neg99a))

areaAup $=$ pos $99 a$

areaAdn = neg99a

if $\mathrm{ABpick}==$ 'B':

arcpy.AddMessage("Planimetric Areas base 10")

if confLim $==$ '50':

arcpy. AddMessage ("Upper Area " + confLim + " = " + str(pos50a))

arcpy. AddMessage ("Lower Area " + confLim + " = " str(neg50a))

areaBup = pos50a

areaBdn = neg50a 


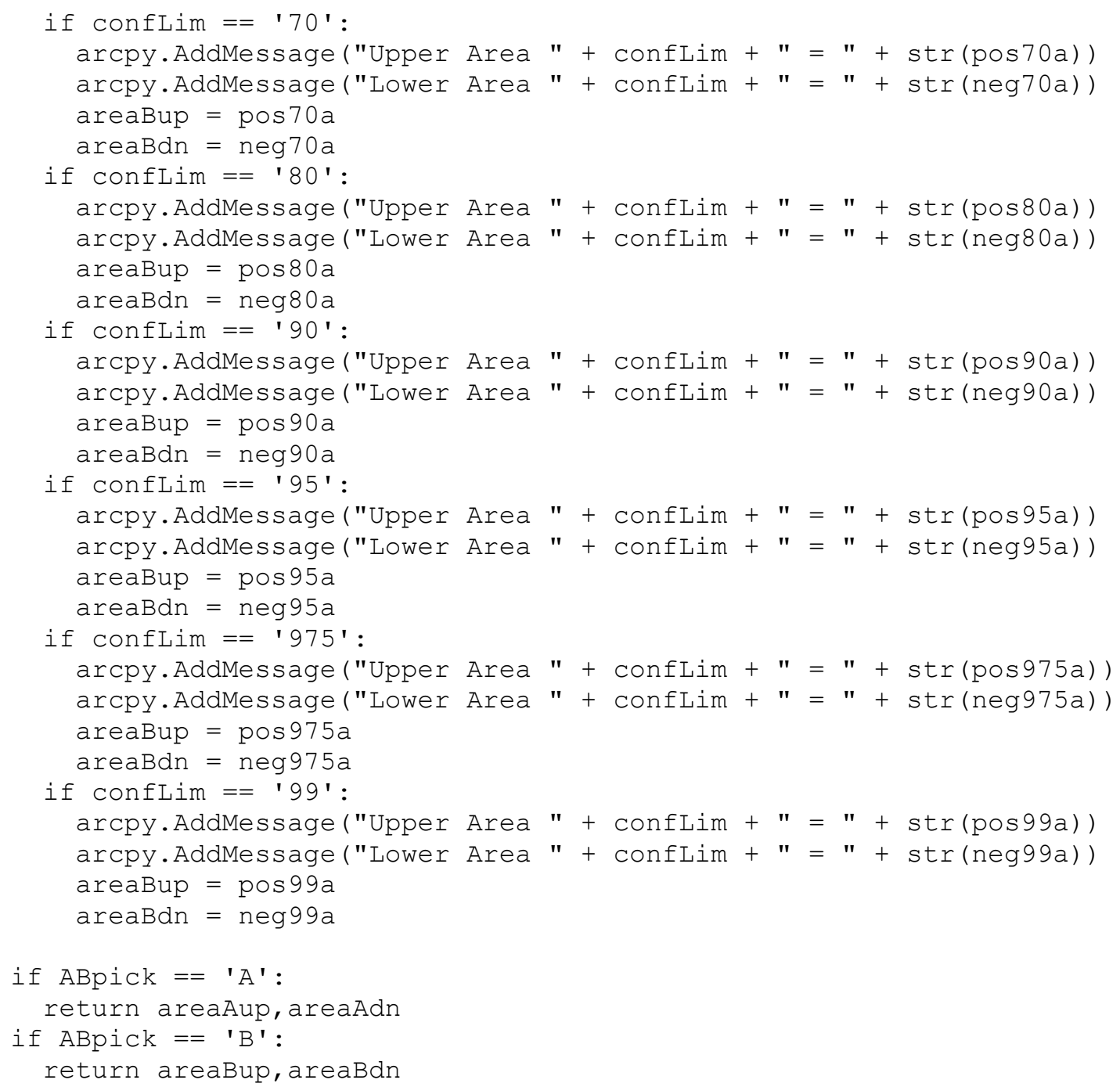

def WriteHeader(headr):

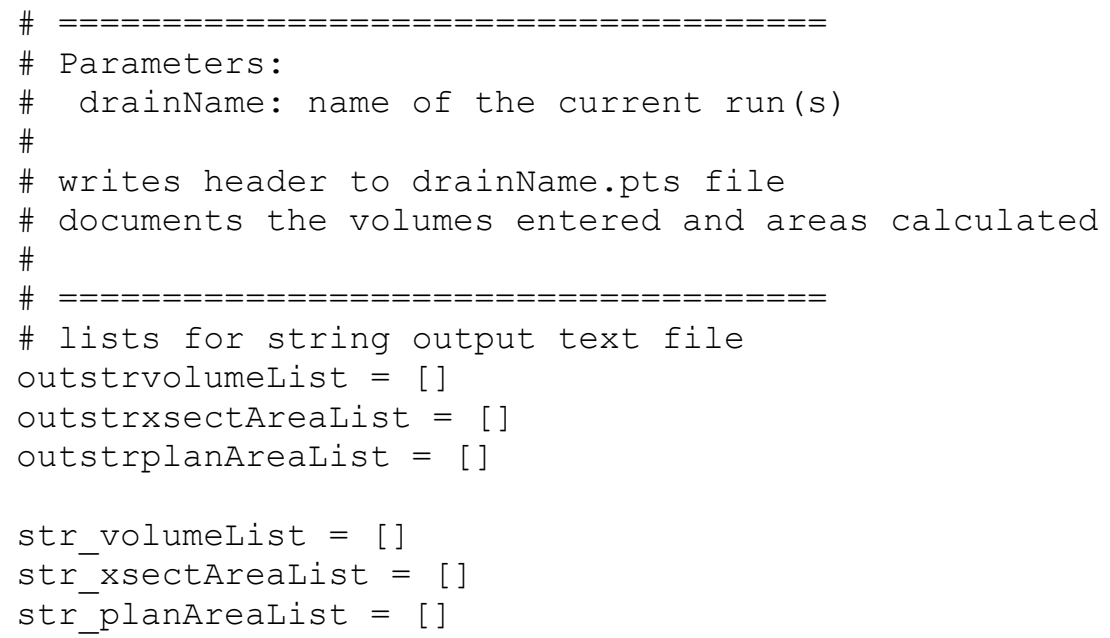


\# Get headr dictionary values

drainName=headr [ 'drainName']

ptsfilename=headr ['ptsfilename']

volumeList=headr ['volumeList']

masterXsectList=headr ['masterXsectList']

masterPlanList=headr ['masterPlanList']

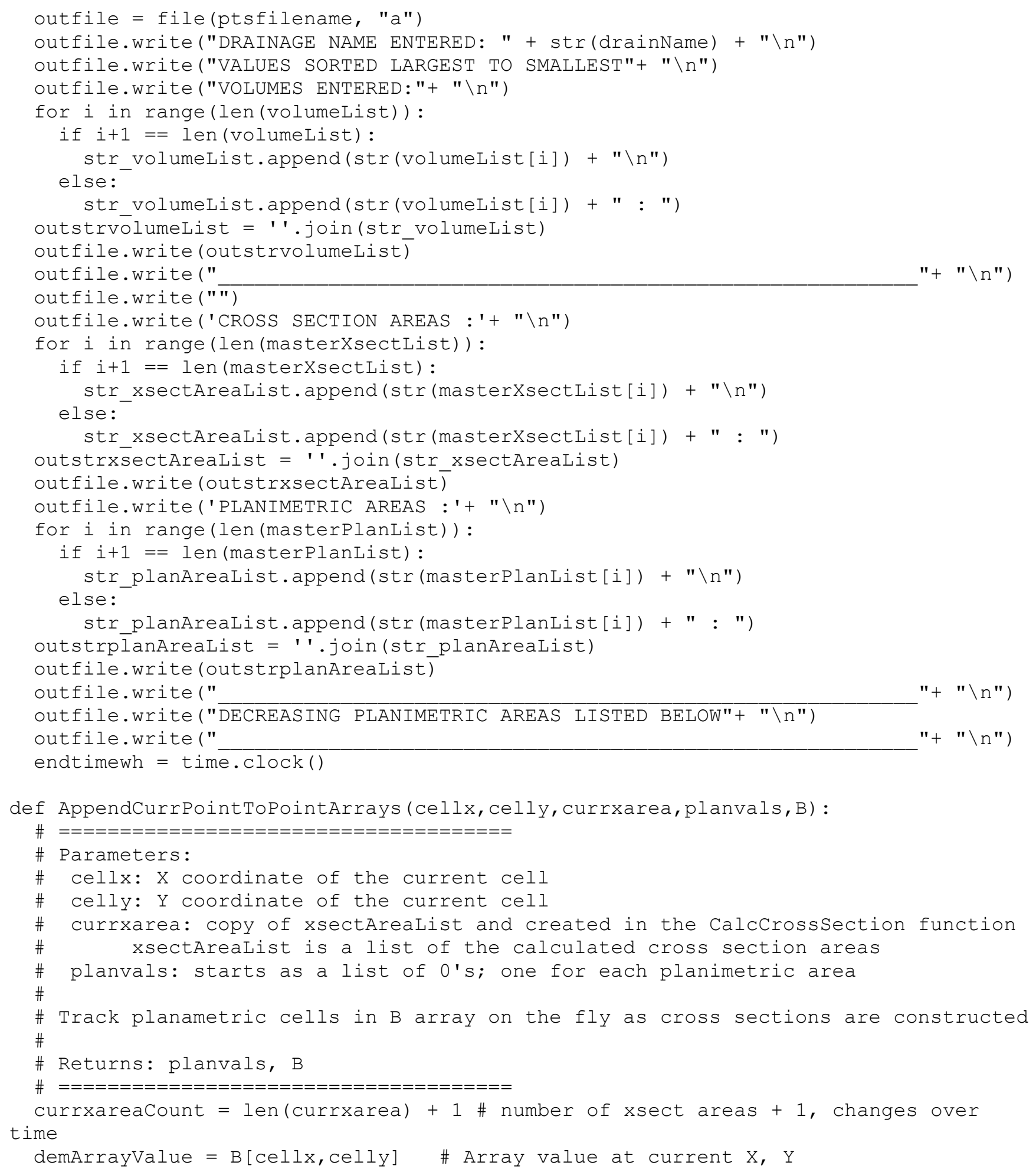




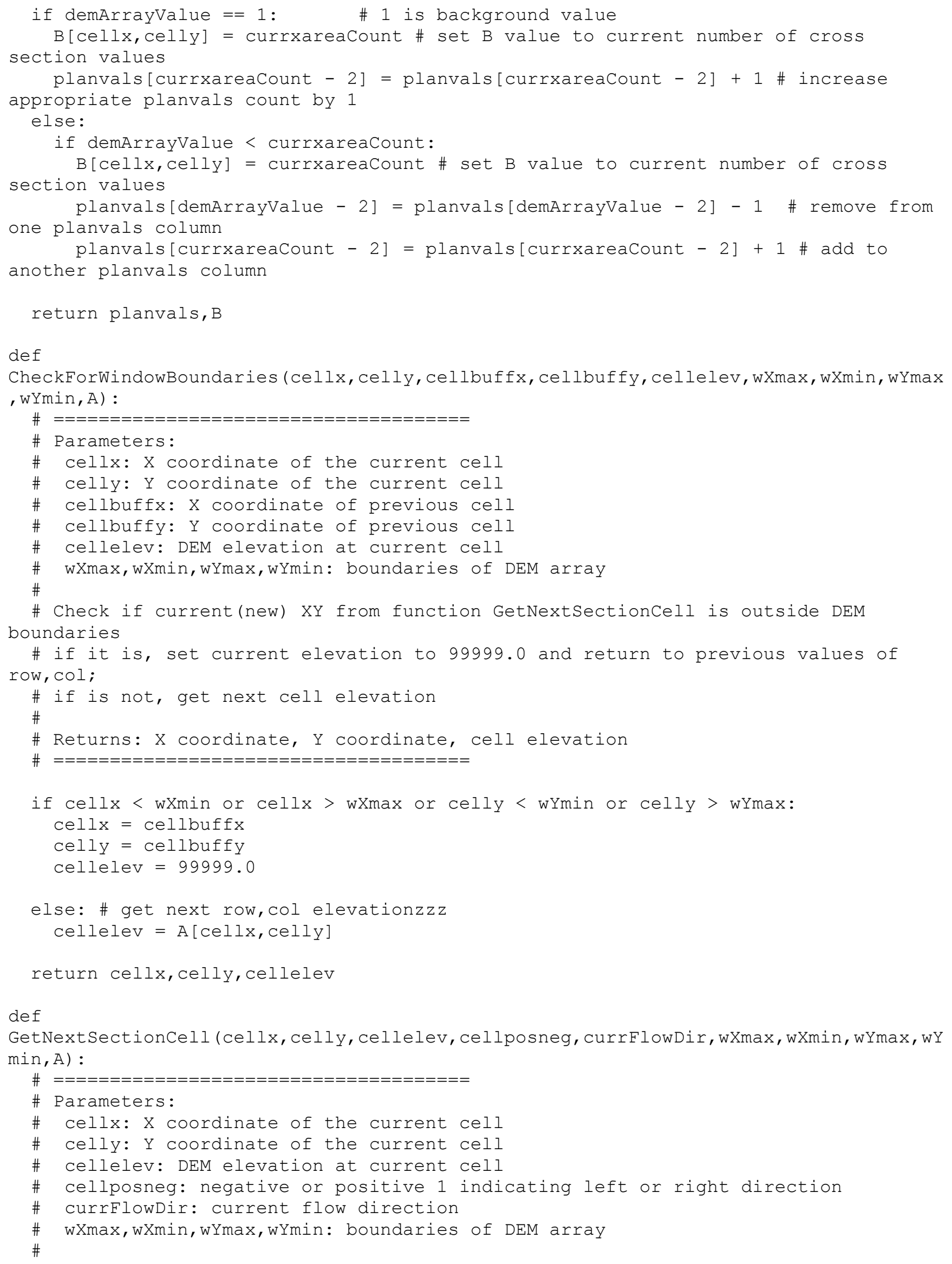




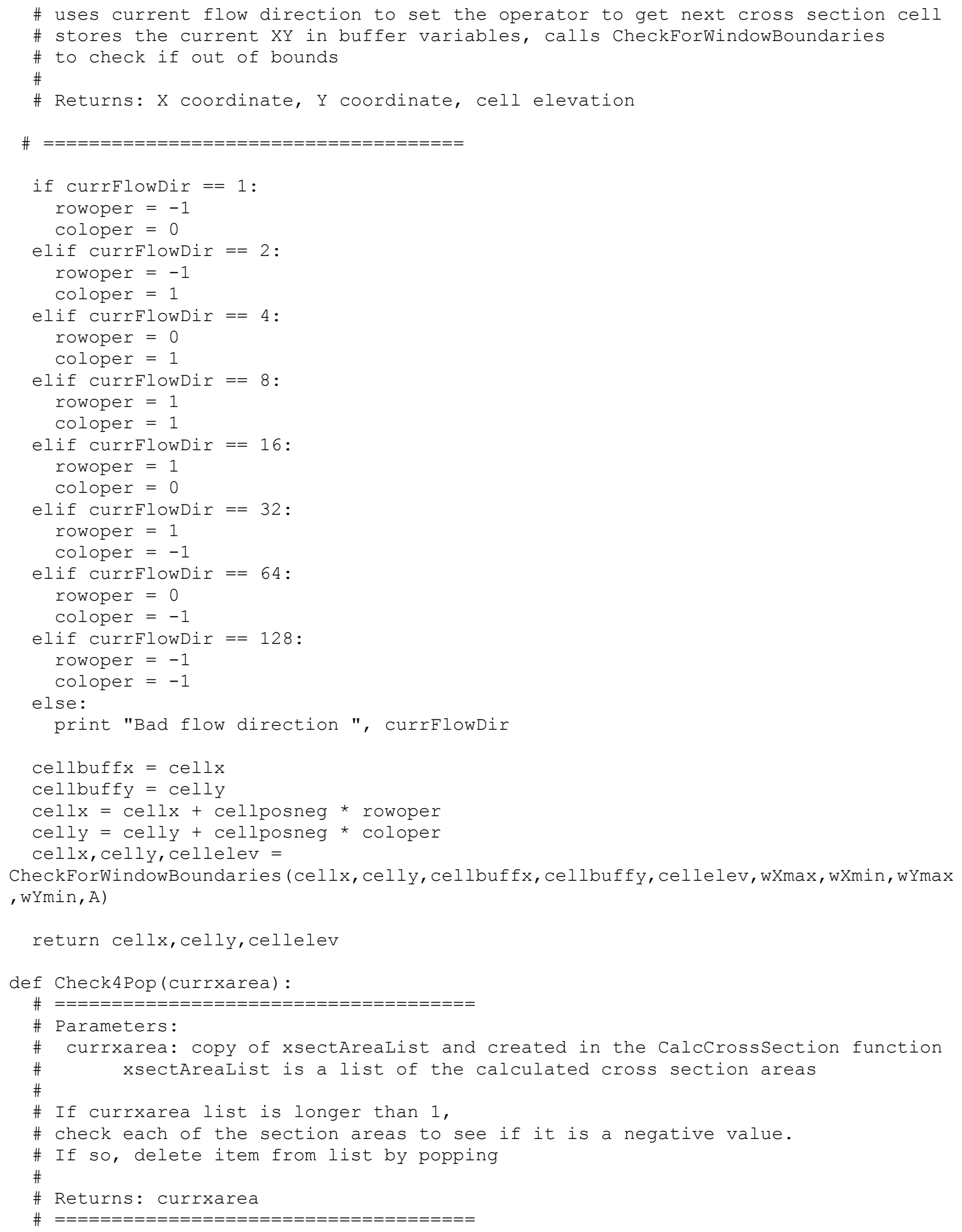




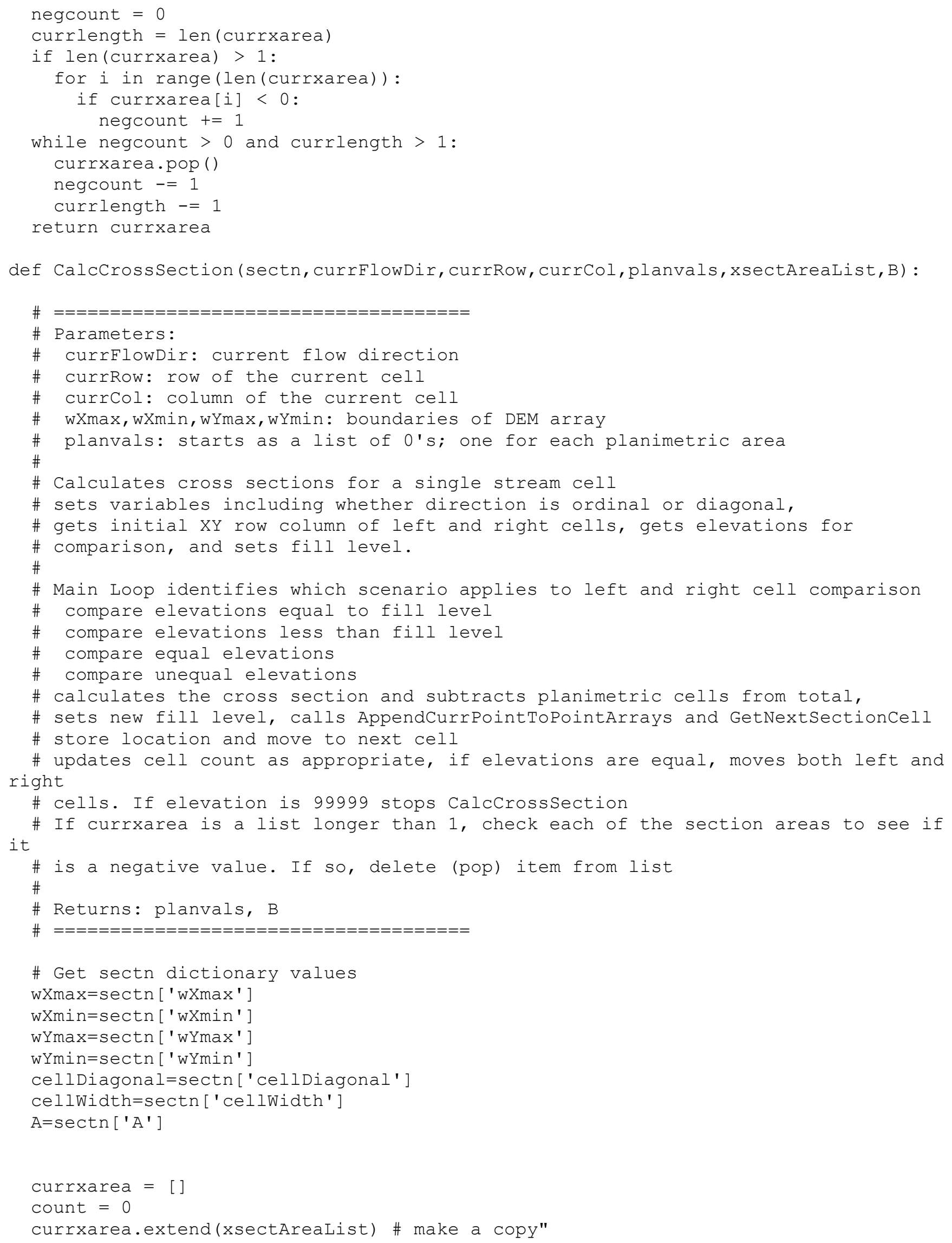




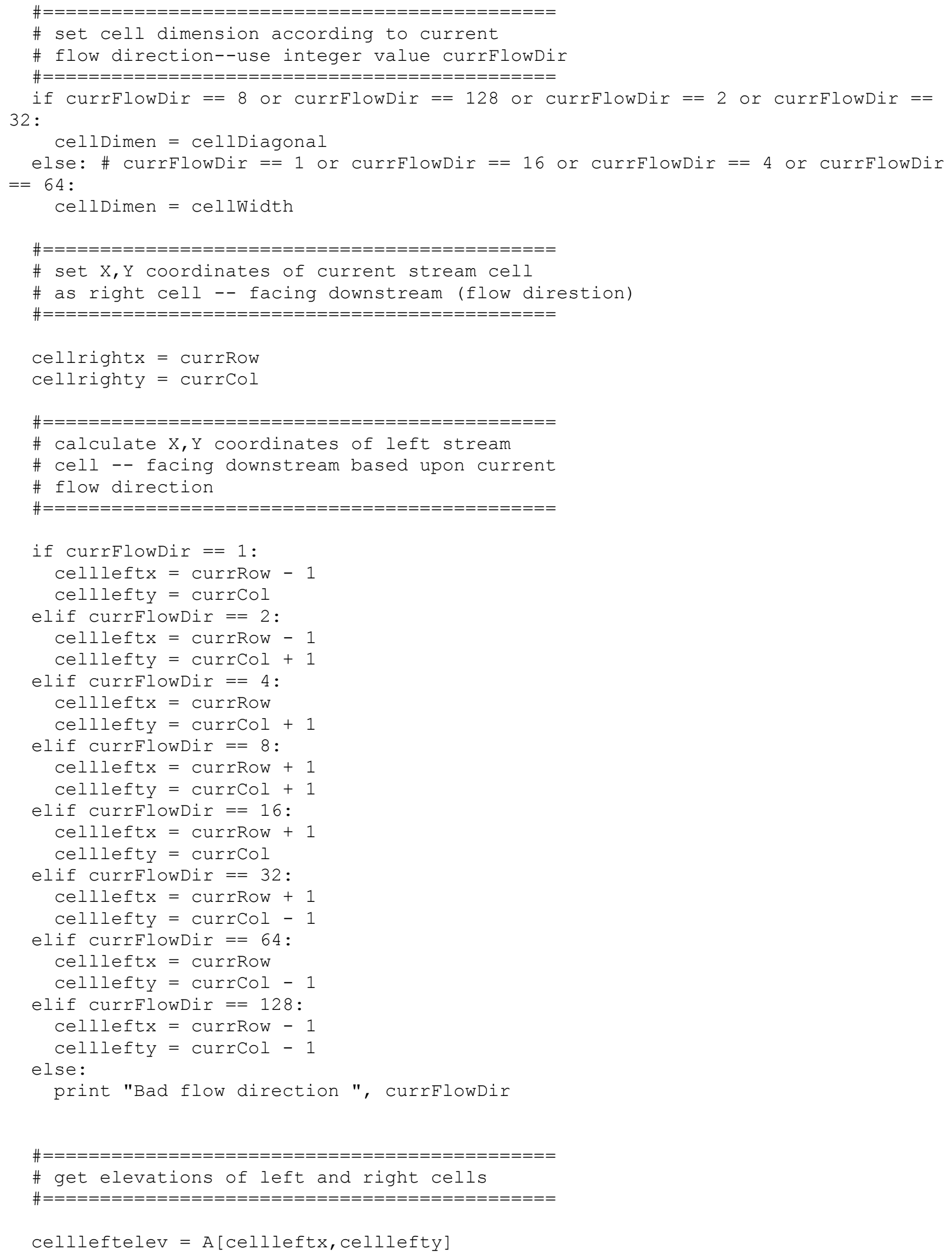




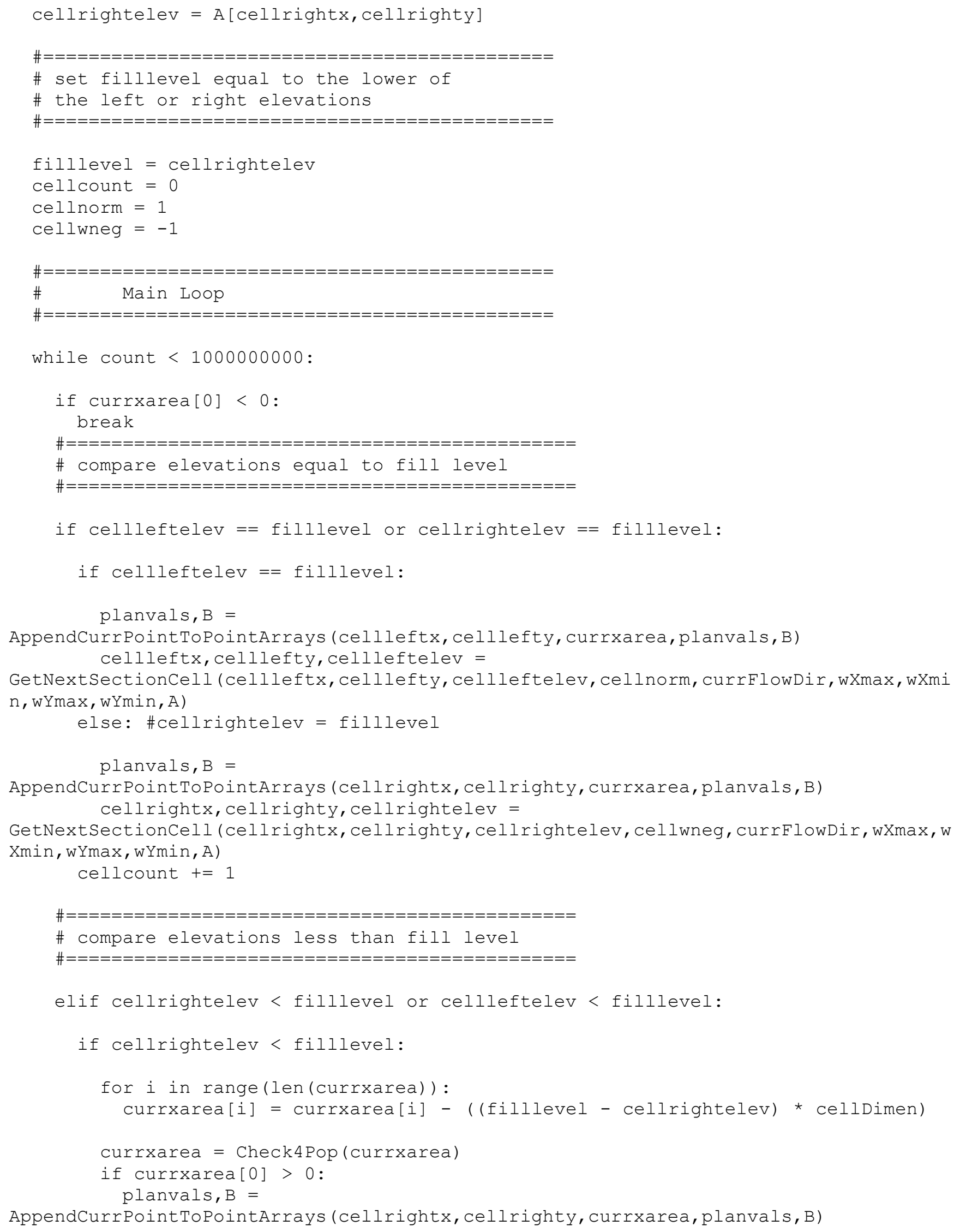


cellrightx, cellrighty, cellrightelev =

GetNextSectioncell (cellrightx, cellrighty, cellrightelev, cellwneg, currFlowDir,wXmax, w Xmin, wYmax, wYmin, A)

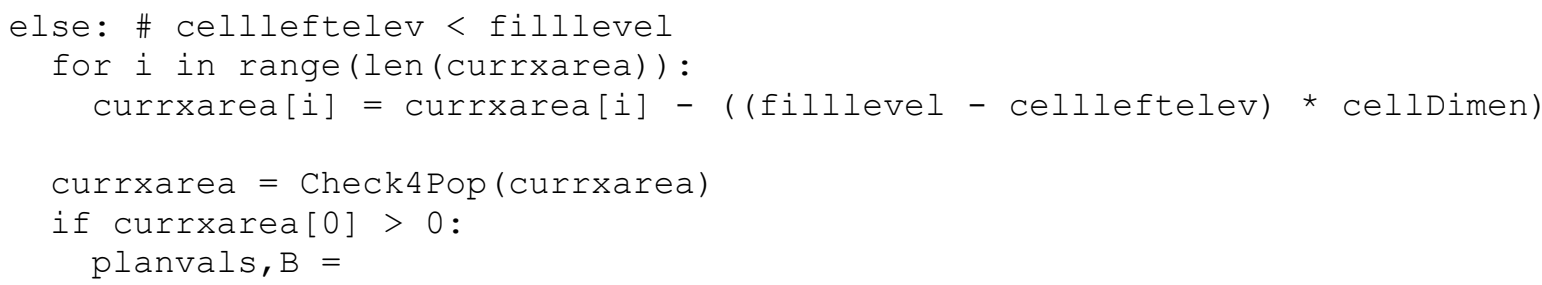




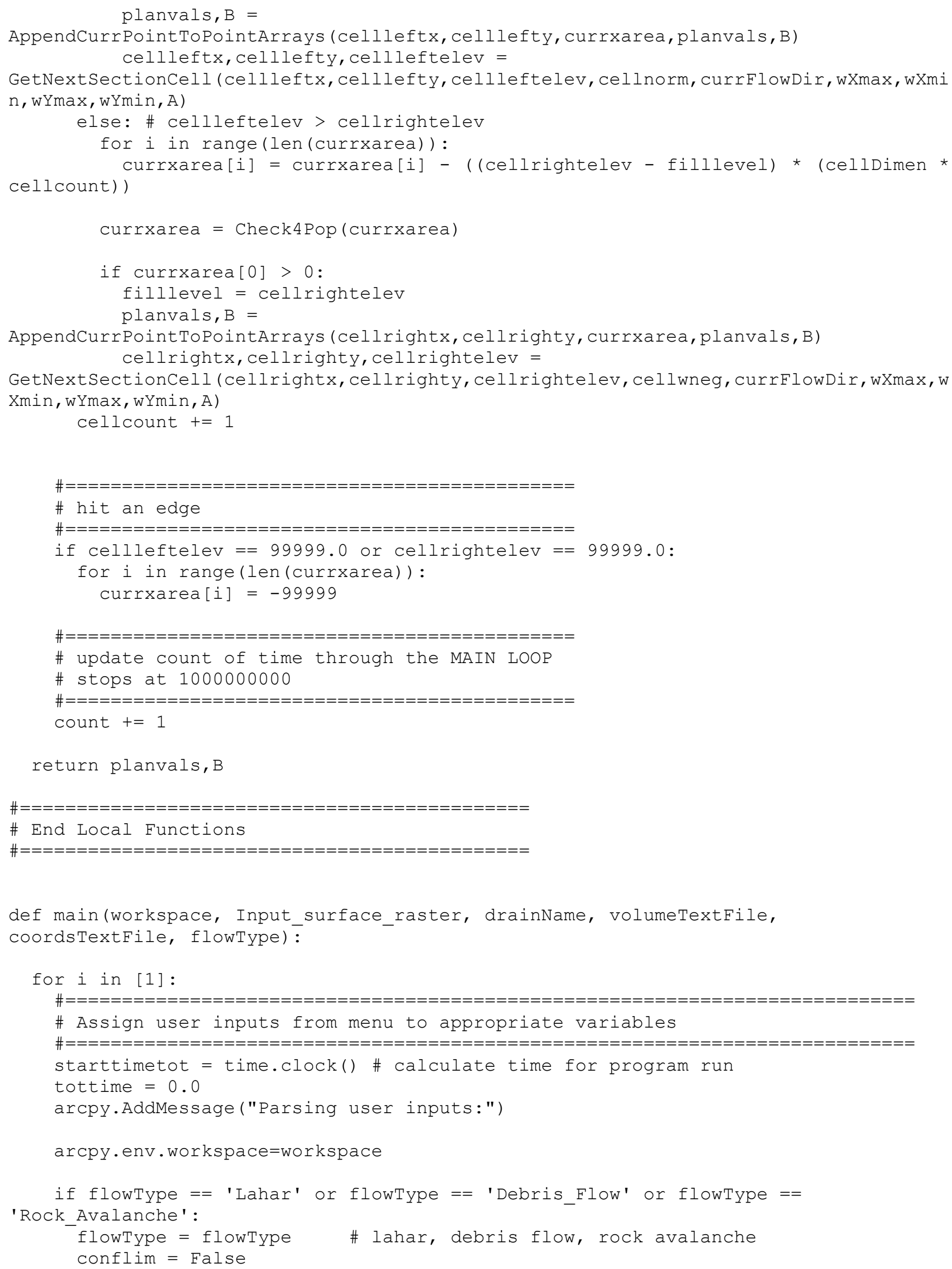




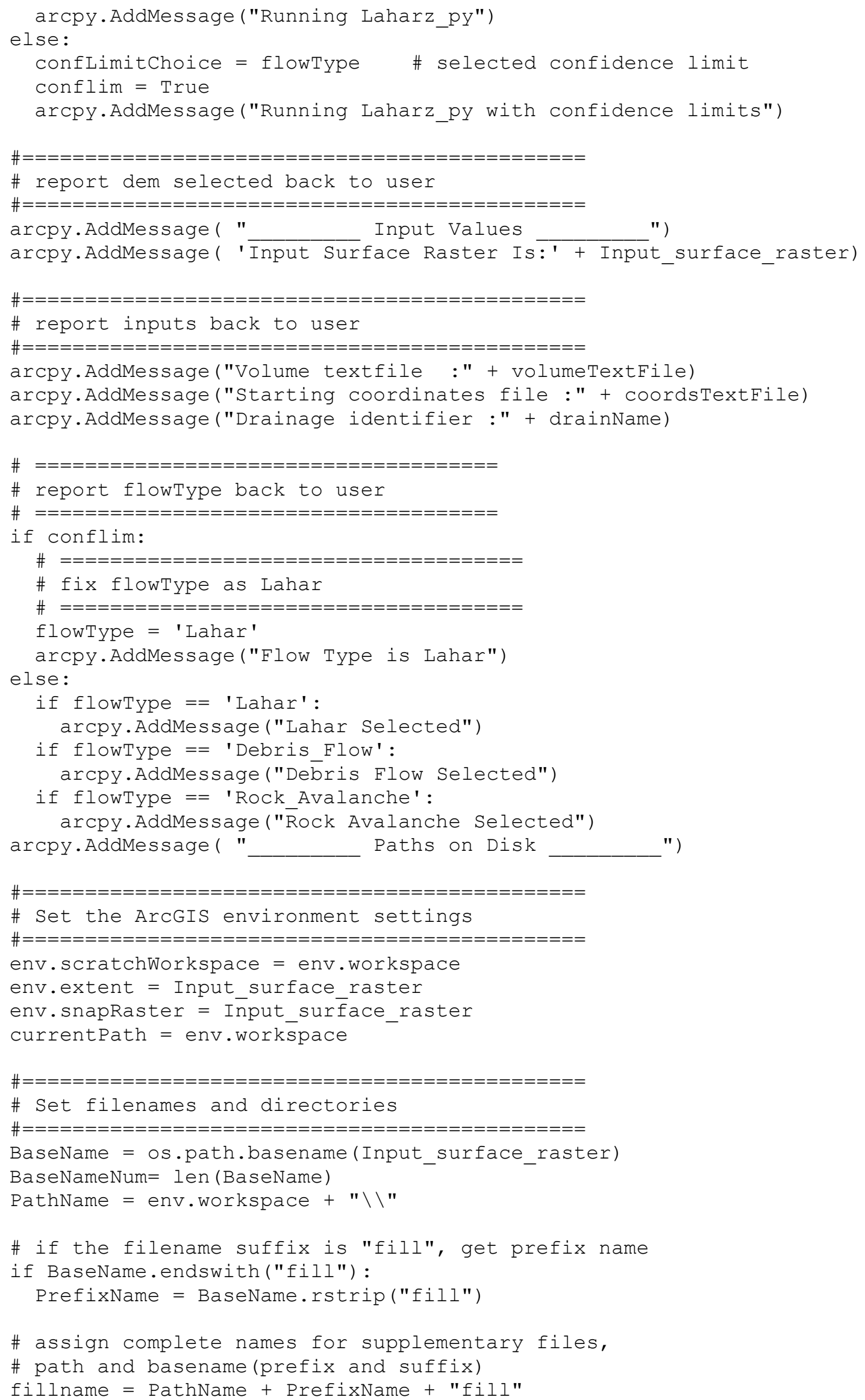




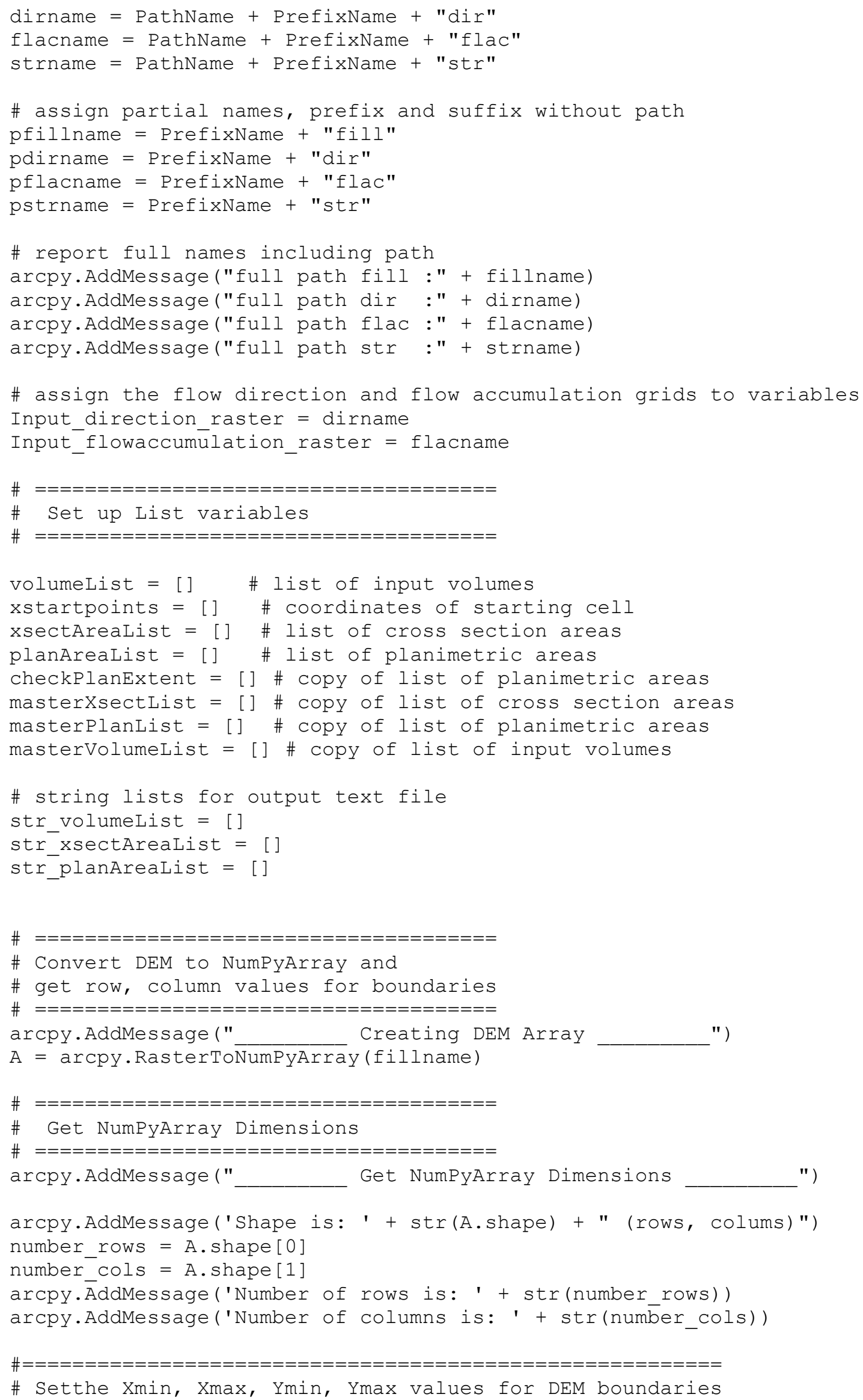




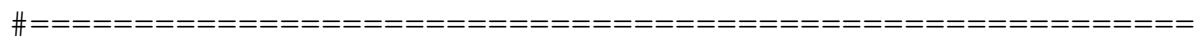

arcpy. AddMessage (" Set Window Boundaries

")

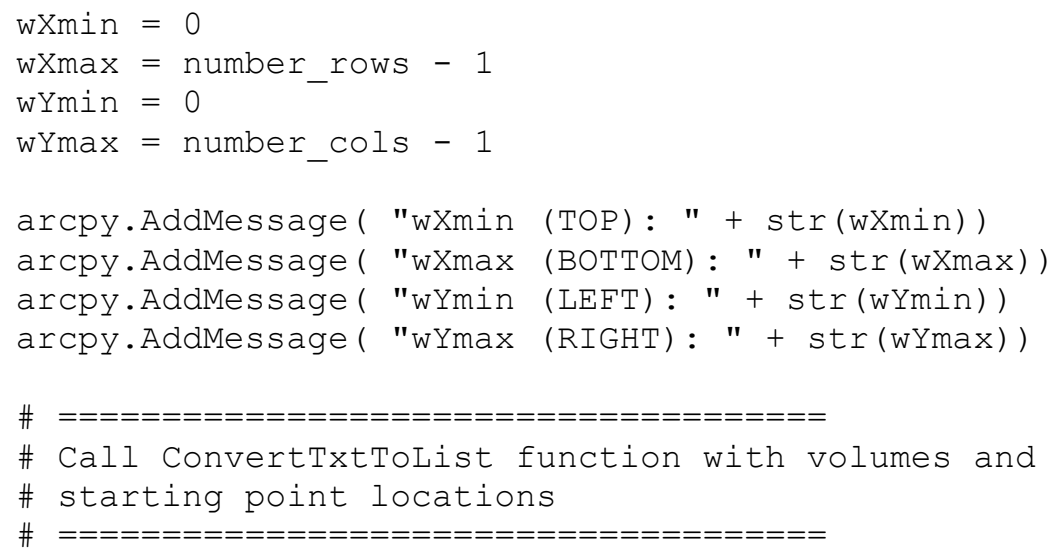


PlanArea1, PlanArea3 = StdErrModMean('B', PathName, oneVolume, confLimitChoice)

xsectAreaList. append (round (XSArea1))

xsectAreaList.append (round (XSArea3))

planAreaList. append (round (PlanArea1))

planAreaList. append (round (PlanArea3))

xsectAreaList.sort () \# sort

planAreaList.sort() \# sort

arcpy. AddMessage("Cross Section Area List is: " + str(xsectAreaList))

arcpy. AddMessage("Planimetric Area List is: " + str(planAreaList))

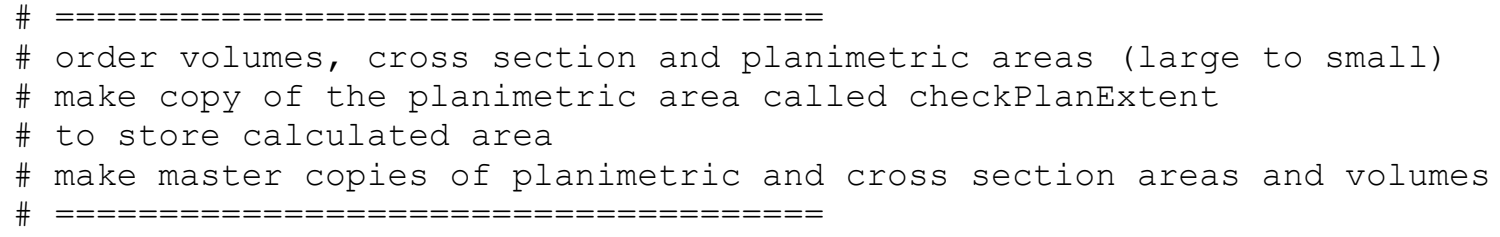


xonePoint = arcpy.Point (currx, curry)

startCoordsList.append(xonePoint) \# append current point to a list

arcpy. AddMessage (" Creating startpts_g ")

if arcpy.Exists (currentPath $+" \backslash \backslash "+$ "startpts_g"):

arcpy.Delete_management (currentPath + "\\" + "startpts_g") \# delete existing startpts $g$

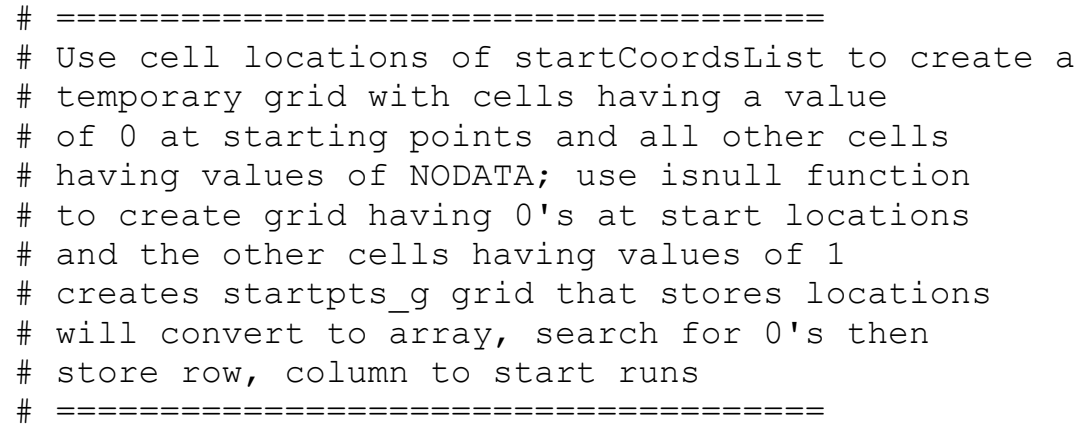




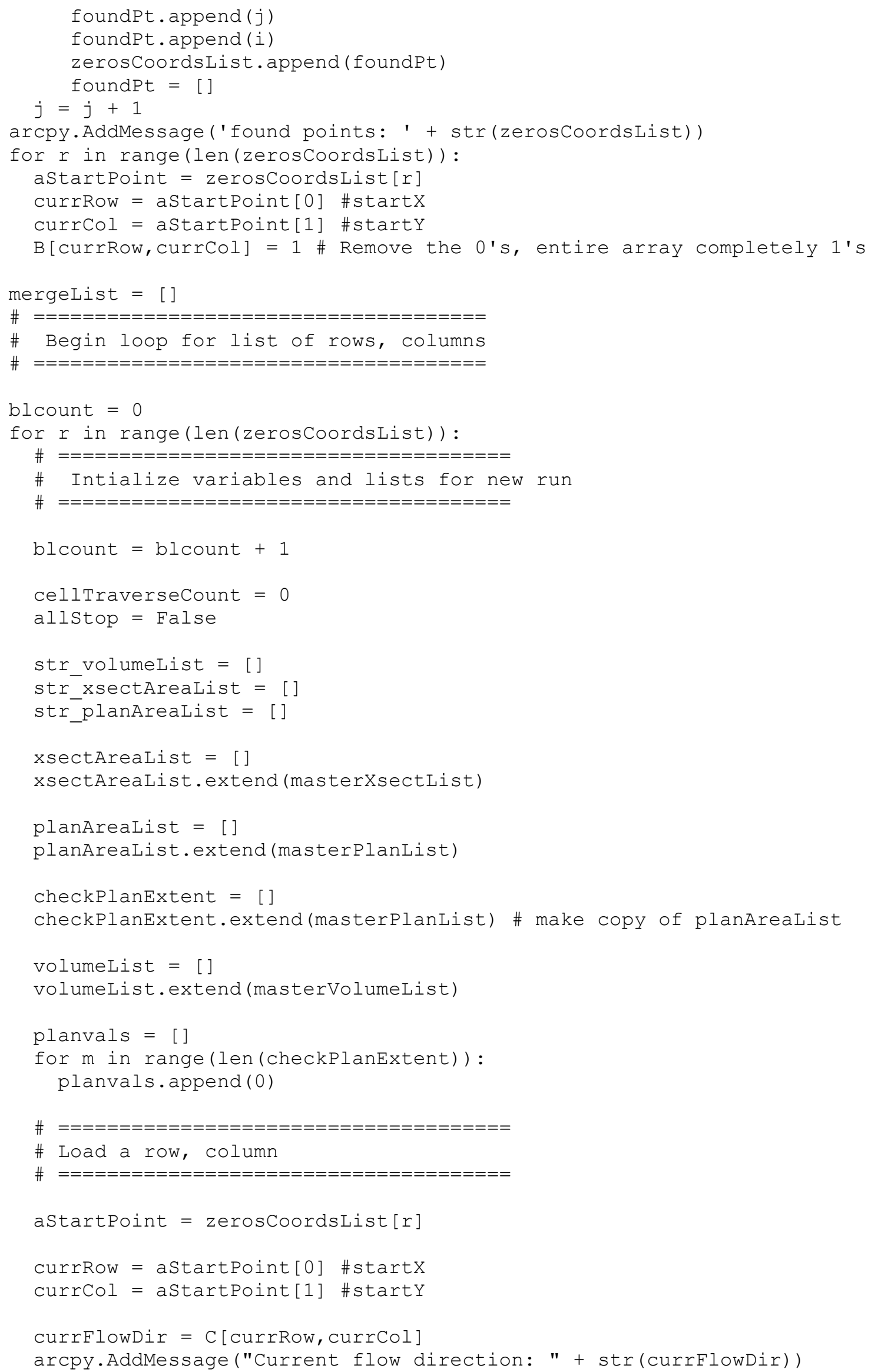




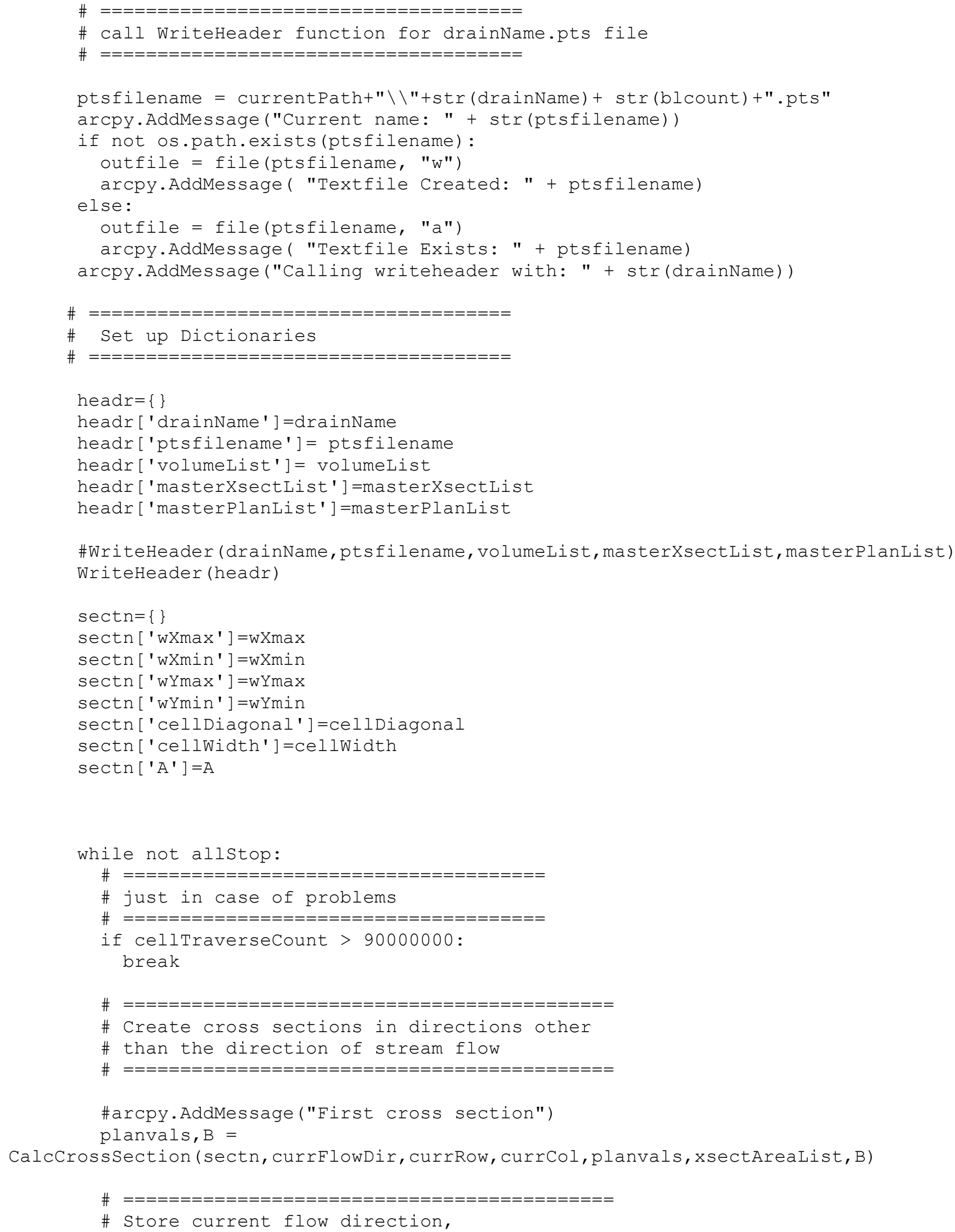




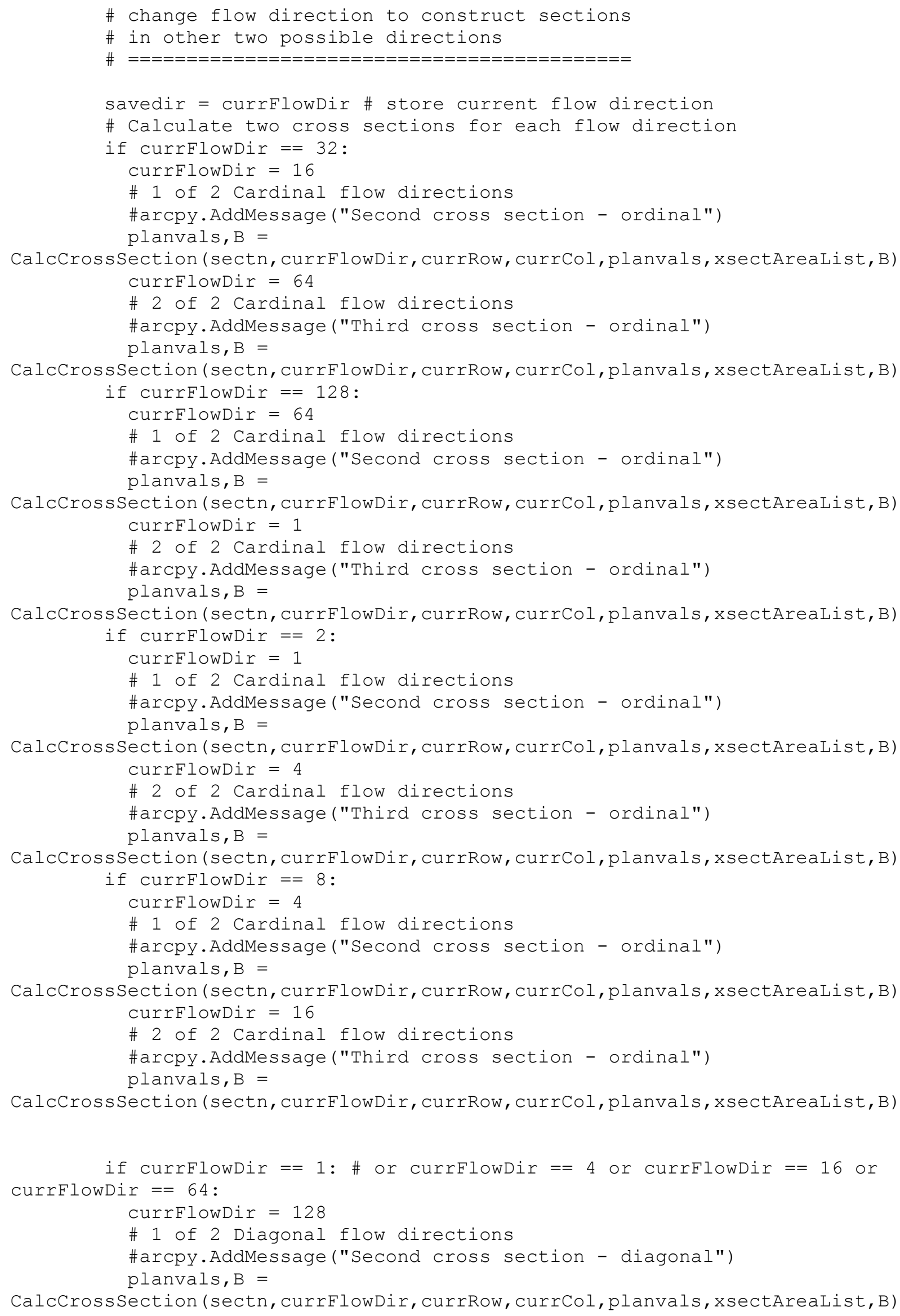




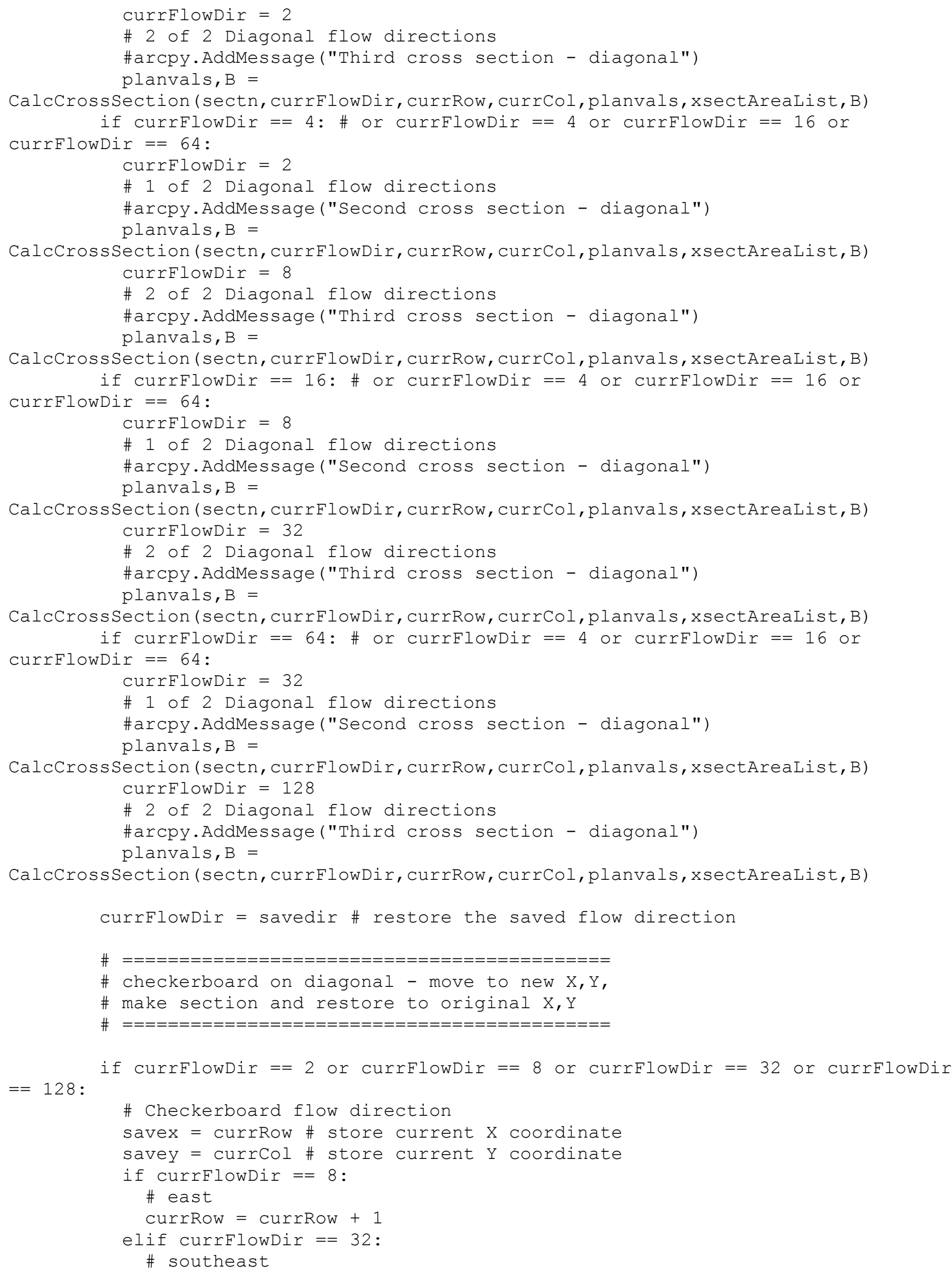




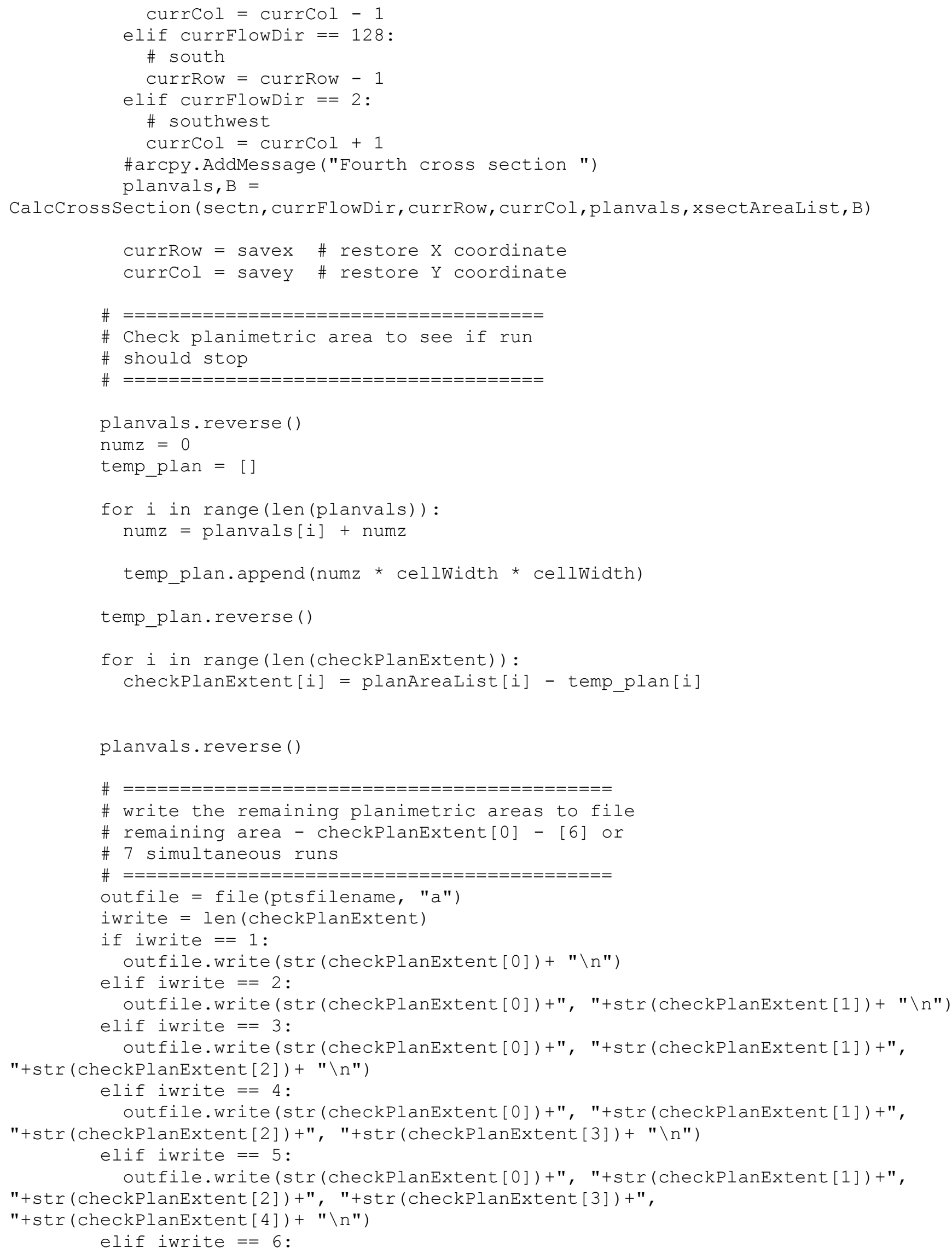




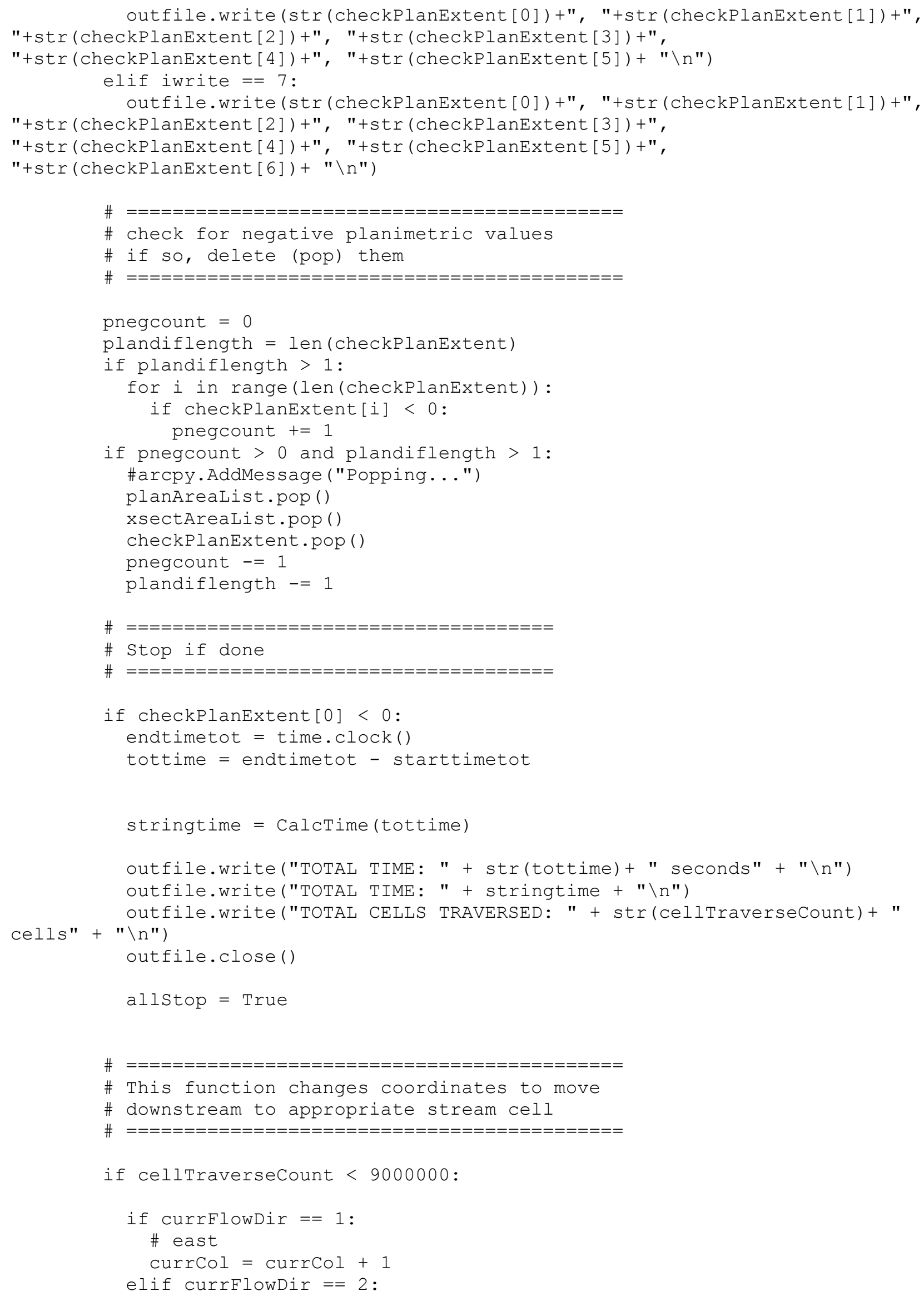




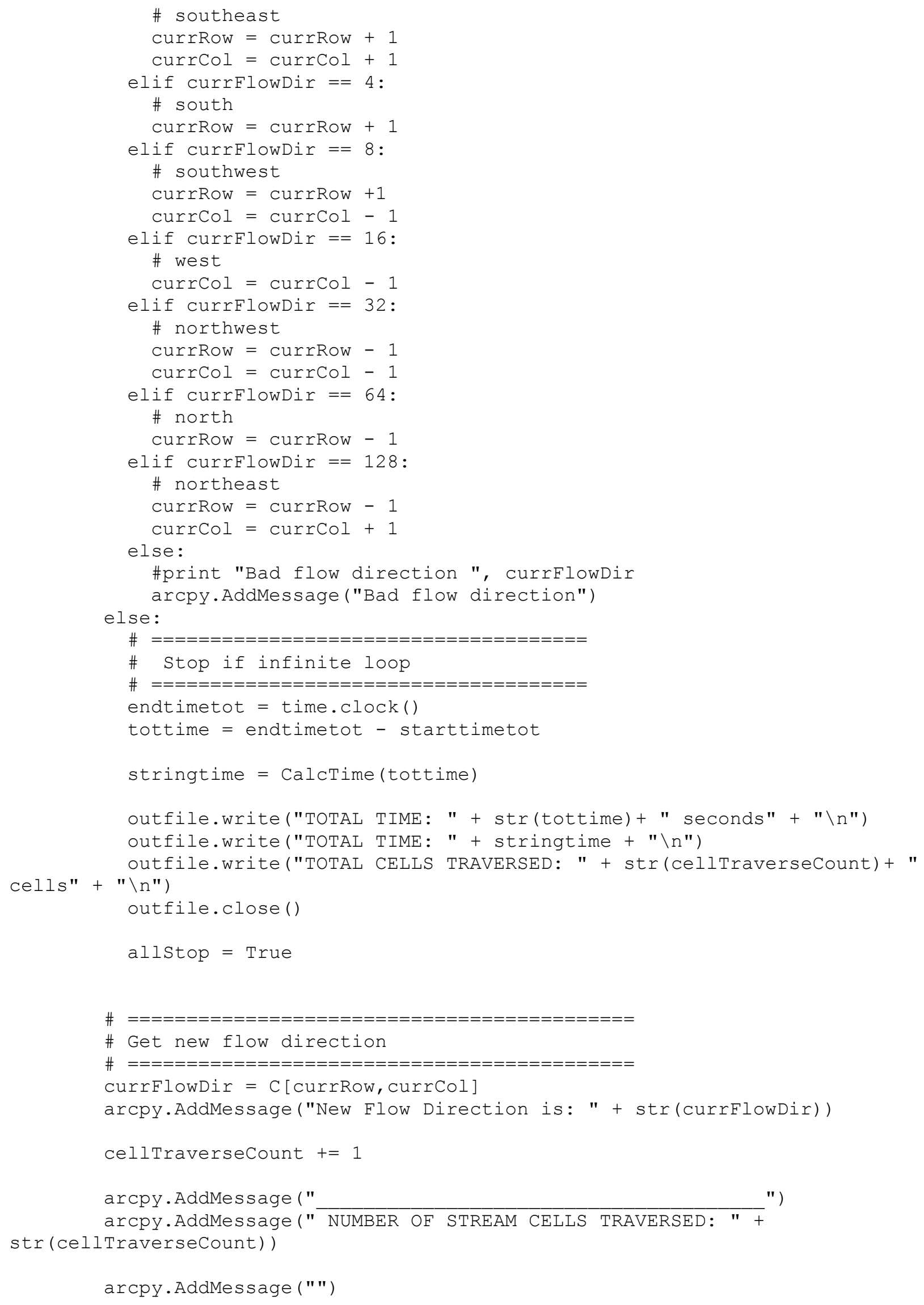




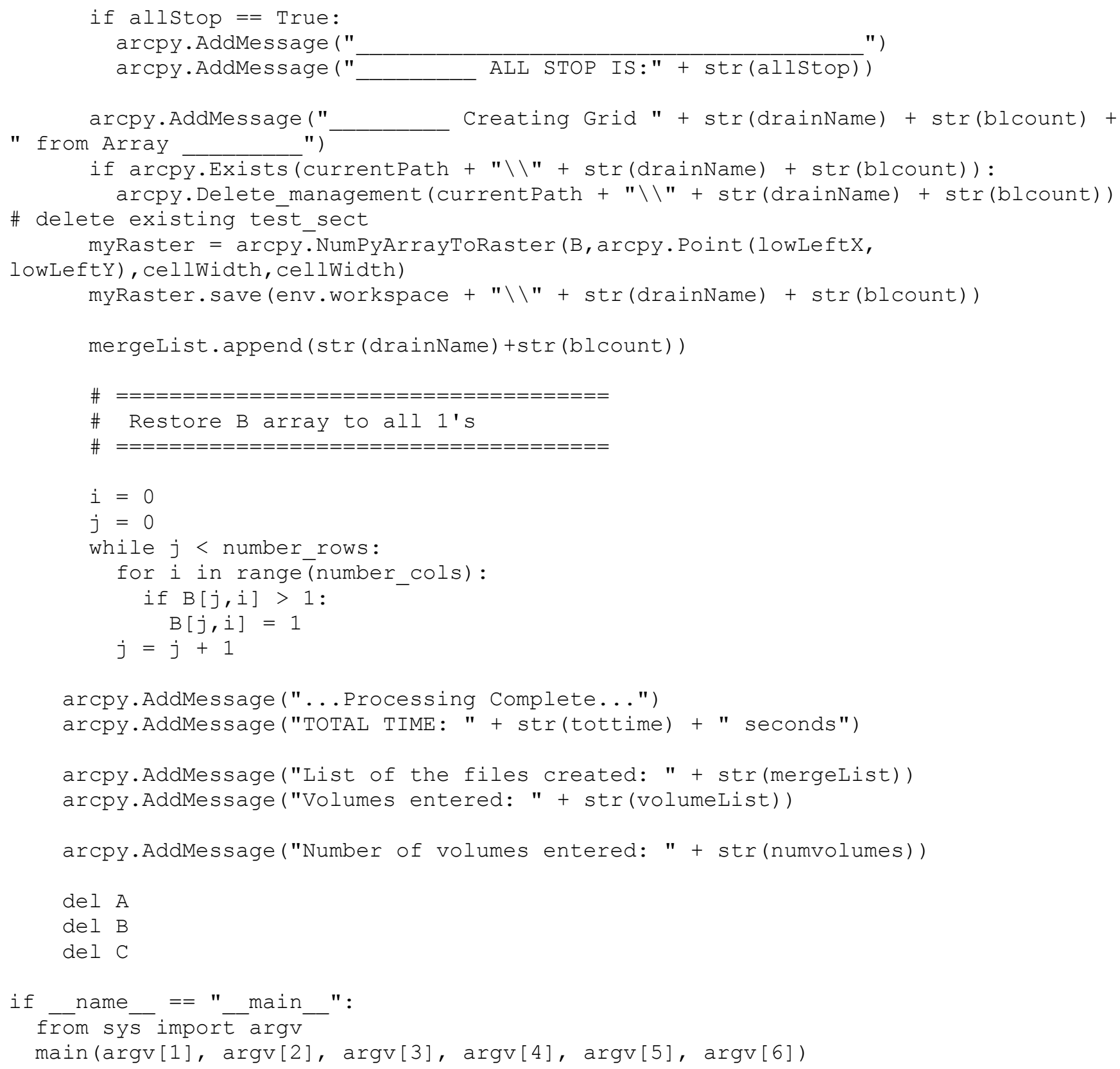

\section{merge_runs.py}

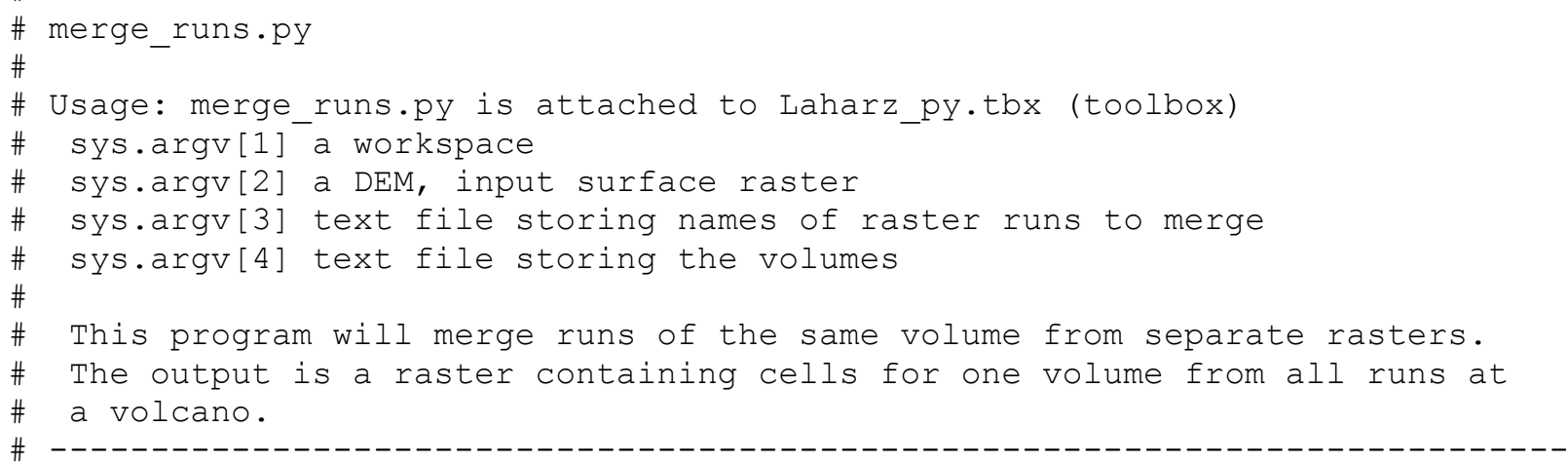




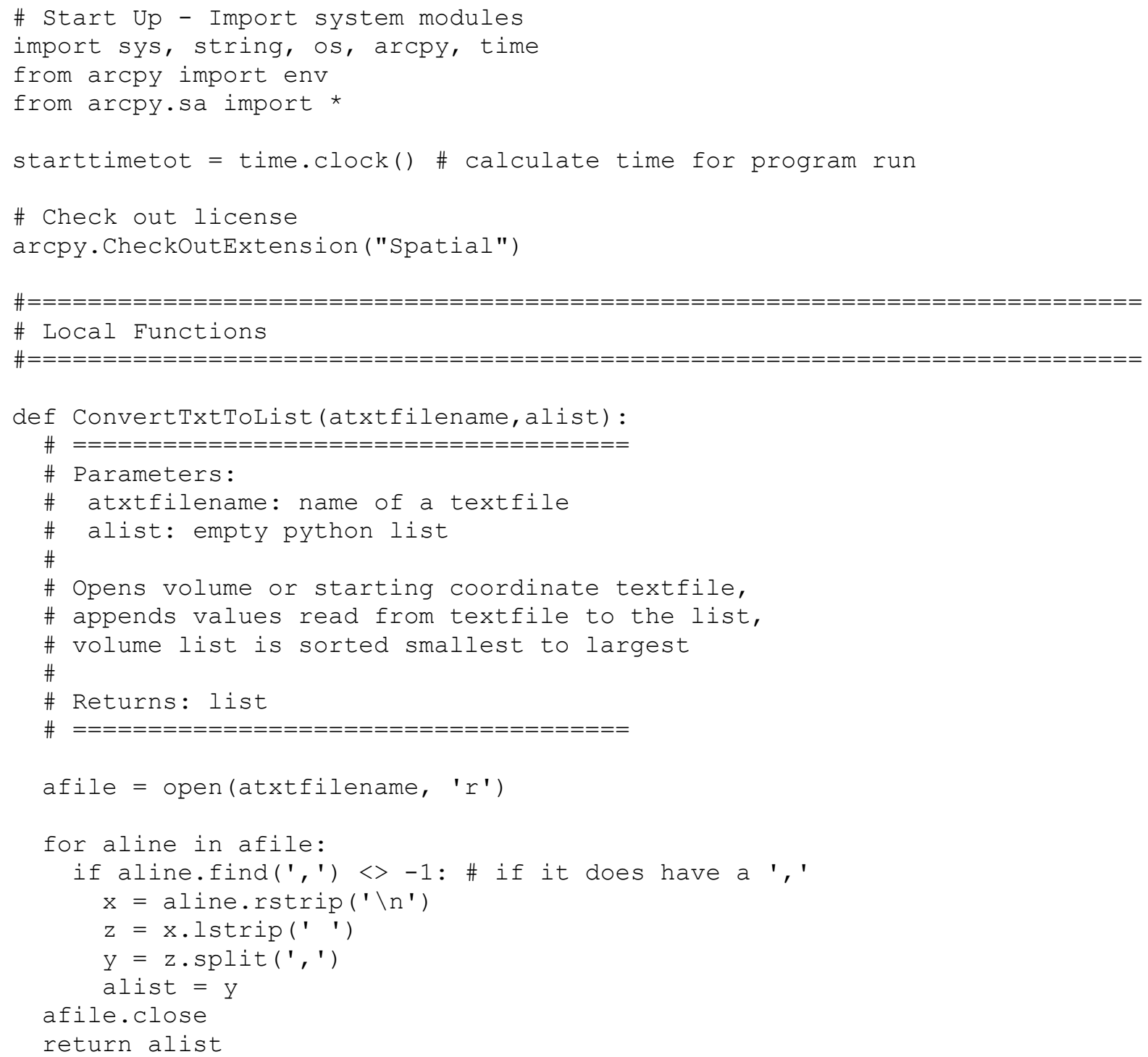




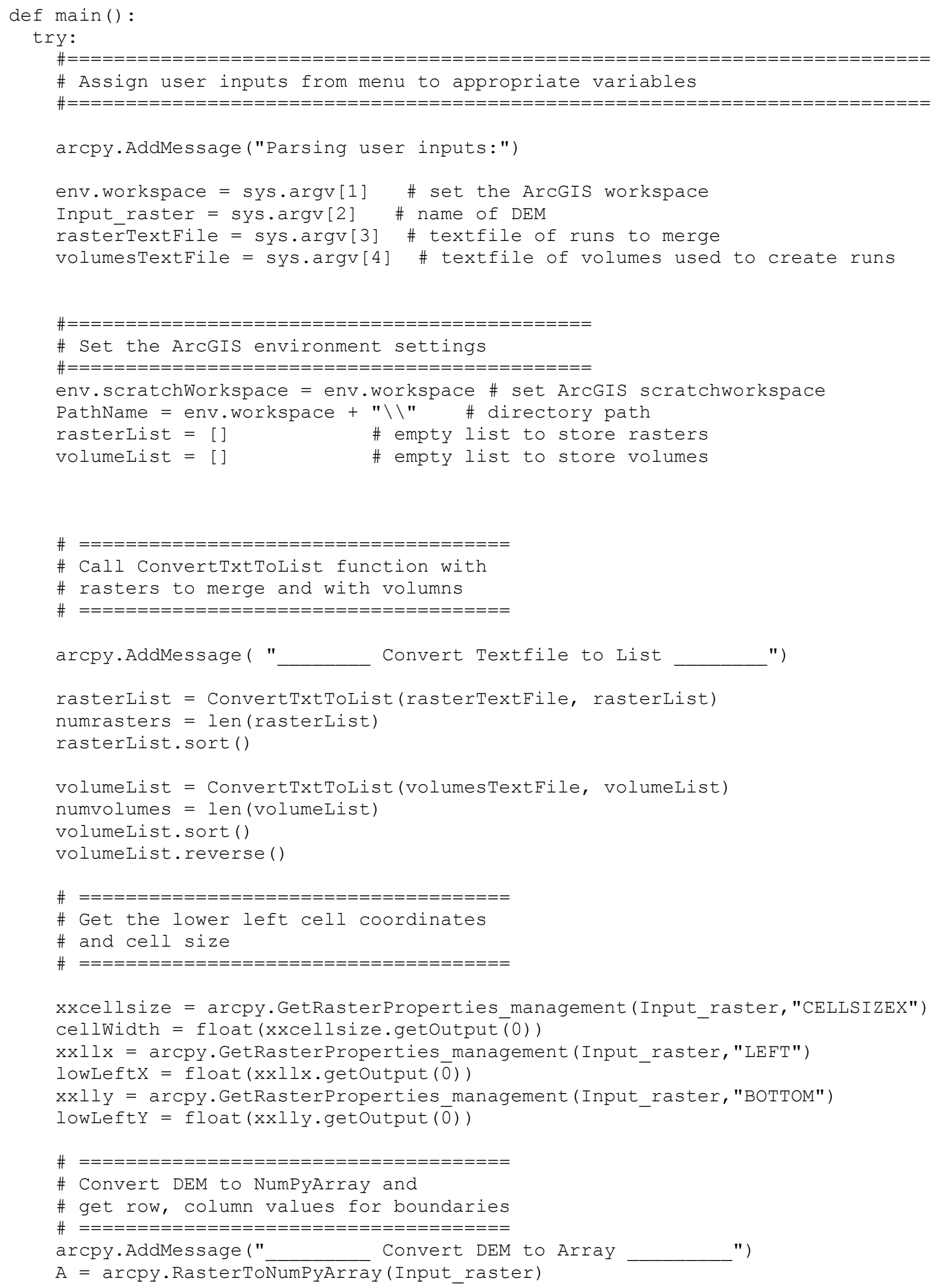




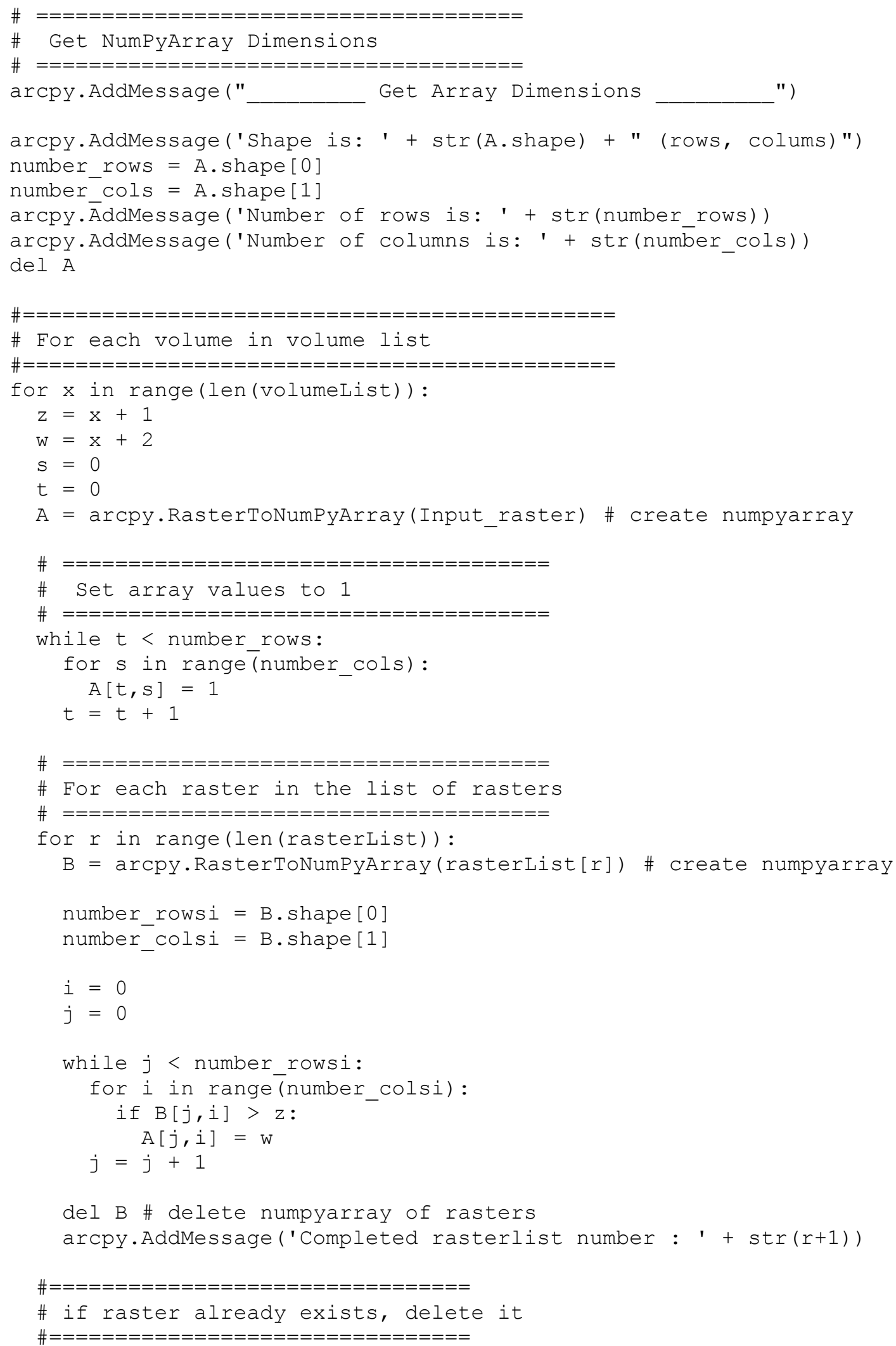




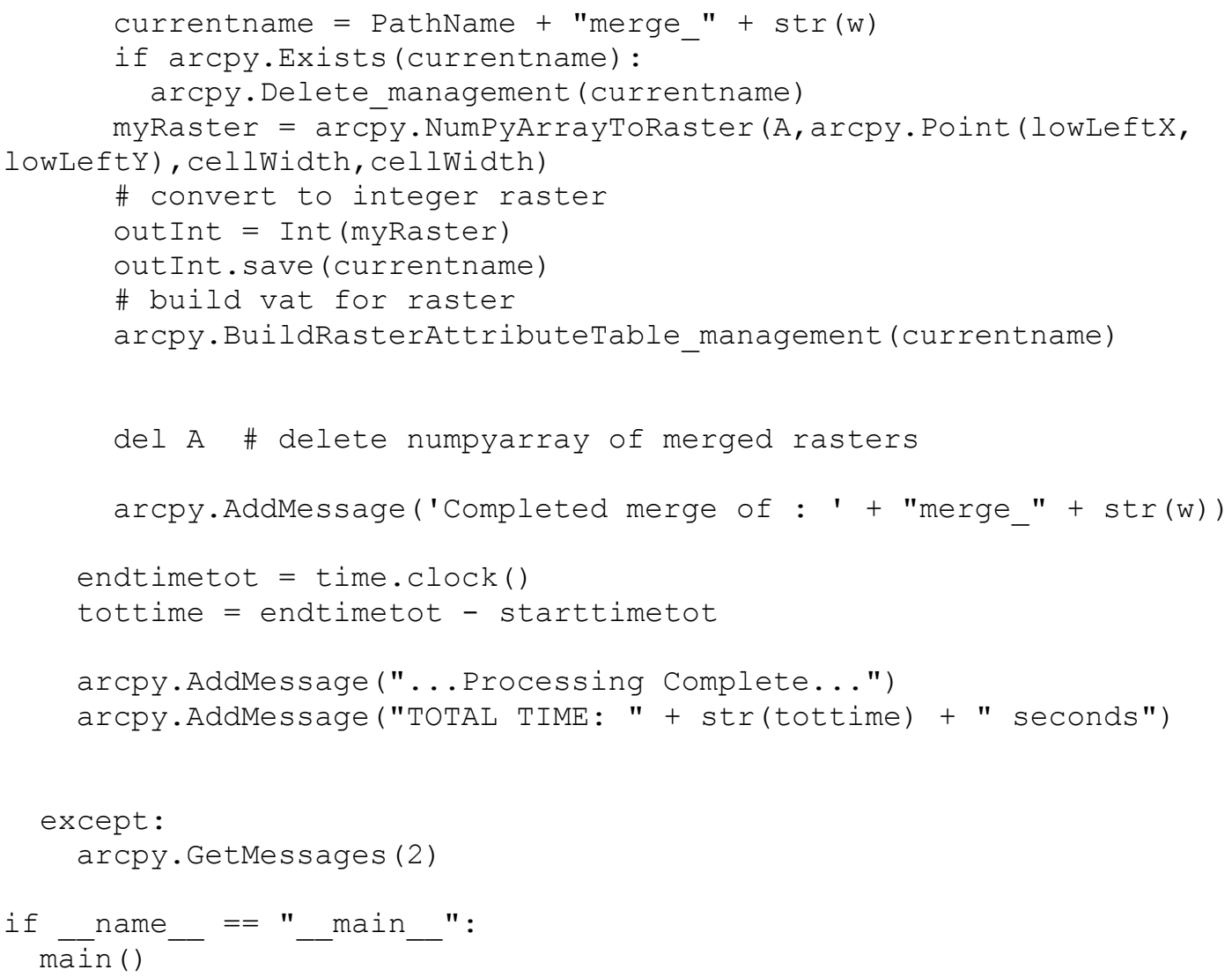




\section{raster_to_shapefile.py}

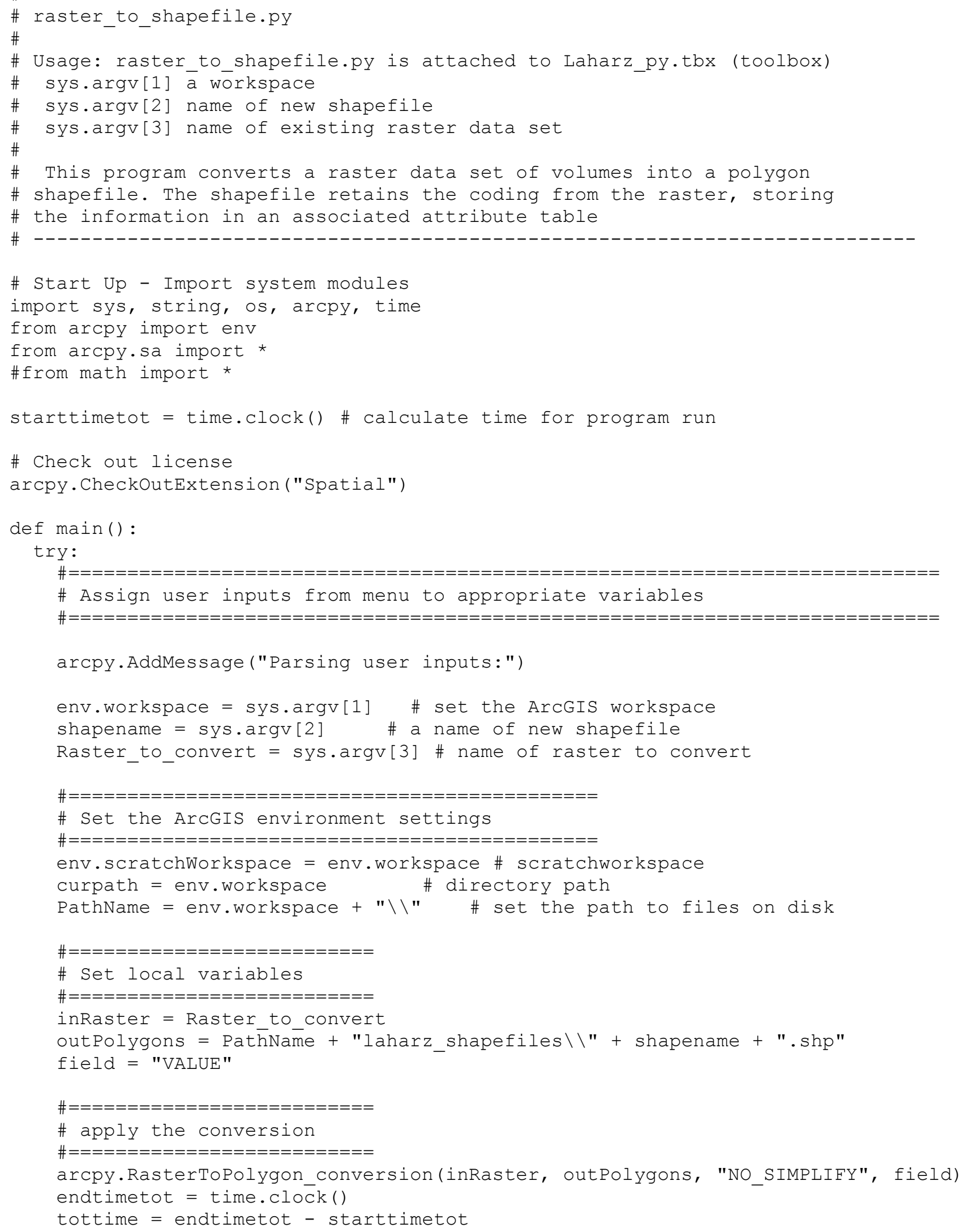




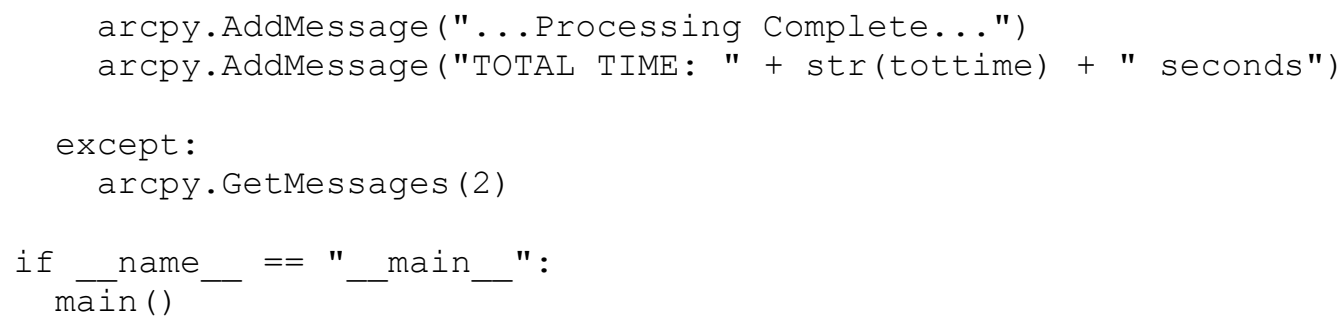

